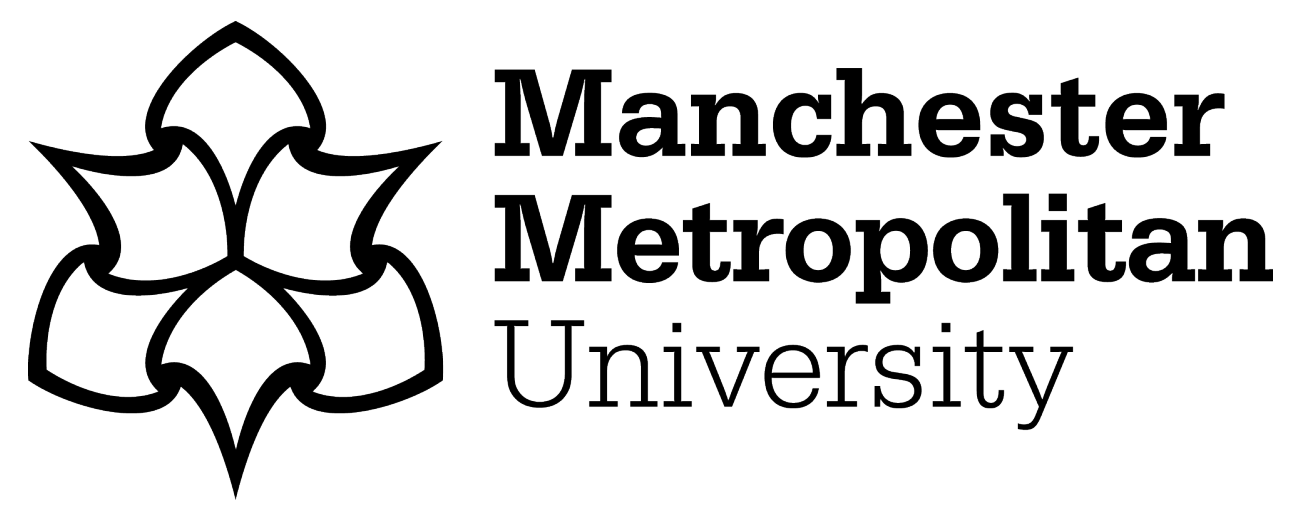

Robertson, TBR and Mewis, Ryan (2018) Perspective on the Hyperpolarisation Technique Signal Amplification by Reversible Exchange (SABRE) in NMR Spectroscopy and MR Imaging. Annual Reports on NMR Spectroscopy, 93. pp. 145-212. ISSN 0066-4103

Downloaded from: https: //e-space.mmu.ac.uk/619403/

Version: Accepted Version

Publisher: Elsevier

DOI: https://doi.org/10.1016/bs.arnmr.2017.08.001

Usage rights: Creative Commons: Attribution-Noncommercial-No Derivative Works 4.0

Please cite the published version 


\section{Perspective on the hyperpolarisation technique Signal Amplification By Reversible Exchange (SABRE) in NMR spectroscopy and MR imaging}

Thomas B. R. Robertson, Ryan E. Mewis*

School of Science and the Environment, Division of Chemistry and Environmental Science, Manchester Metropolitan University, John Dalton Building, Chester St., Manchester, M1 5GD, UK

ORCIDs : Thomas B. R. Robertson 0000-0001-9394-6185, Ryan E. Mewis 0000-0002-3756-6505

\section{Abstract}

Signal Amplification By Reversible Exchange (SABRE) is a parahydrogen based technique that utilises a metal complex, normally centred on iridium, to propagate polarisation from parahydrogen derived hydride ligands to spin- $1 / 2$ nuclei located in a bound substrate. To date, substrates possessing ${ }^{1} \mathrm{H},{ }^{13} \mathrm{C}$, ${ }^{15} \mathrm{~N},{ }^{19} \mathrm{~F},{ }^{31} \mathrm{P},{ }^{29} \mathrm{Si}$ and ${ }^{119} \mathrm{Sn}$ nuclei have been polarised by this technique. The exact positioning of these nuclei has a direct bearing on the enhancement observed and so substrates must be chosen or synthesised with care in order to maximise polarisation transfer, and hence the resulting enhancement. The chemical composition of the metal complex must be similarly appraised, as the exchange rate of substrates and parahydrogen are implicated heavily in efficient polarisation transfer. The nature of the polarisation transfer, whether homogenous or heterogeneous, is another important facet to consider here, as is conducting SABRE in water based systems. This review discusses the physical and theoretical aspects of the SABRE experiment, as well as the applications of the SABRE technique, namely the detection of analytes at concentrations far below what would be possible with conventional NMR techniques and the collection of hyperpolarised magnetic resonance images. Advances relating to utilising singlet states for SABRE, pulse sequence design and the nature of the polarisation transfer mechanism are also discussed and the implications for future SABRE-based discoveries highlighted.

Keywords : Hyperpolarisation, SABRE, parahydrogen, NMR, MRI

\section{Introduction}

Nuclear Magnetic Resonance (NMR) is an invaluable tool for ascertaining the chemical structures of materials and for gaining insight in to rates of reaction, for example. Similarly, Magnetic Resonance Imaging (MRI) is used routinely for the collection of anatomical images of the human body, which can be used to improve diagnosis and treatment strategies. However, both techniques suffer from an inherent sensitivity problem. Thermal energy effects, which are governed by $k_{B} T$ (where $k_{B}$ is the Boltzmann constant), are sufficiently large compared to the energy difference that exists between the two possible energy states that arise from the Zeeman splitting. Boltzmann statistics directly affect the population distribution of the states, and as such, broadly equally-populated states result. This population distribution is termed as polarisation $(\mathrm{P})$ and can be calculated according to Equation 1. For example, at $298 \mathrm{~K},{ }^{1} \mathrm{H}$ nuclei exposed to a $9.4 \mathrm{~T}$ field are polarised to $3.2 \times 10^{-5}(0.0032 \%)$ or a population distribution that differs by roughly one in every 31,000 nuclei.

$$
P=\frac{\gamma h B_{0}}{2 k_{B} T}
$$

Equation 1. Expression for calculating thermal polarisation. $v$ is the gyromagnetic ratio, $h$ is Planck's constant, $B_{0}$ is the magnetic field to which nuclei are exposed to, $k_{B}$ is the Boltzmann constant and $T$ is the temperature. 
Due to the Boltzmann-like distribution of nuclear spins across energy levels, the signal intensity observed in the ${ }^{1} \mathrm{H}$ NMR spectrum and the ${ }^{1} \mathrm{H}$ MR image, for example, is only a fraction of its true potential. Furthermore, for nuclei such as ${ }^{13} \mathrm{C}$ that possesses a gyromagnetic ratio of one quarter of that of ${ }^{1} \mathrm{H}$, the polarisation is significantly lower (Table 1 ). The inherent insensitive nature of NMR and MRI led to the development, and employment, of hyperpolarisation methods.

Table 1. Polarisation values for ${ }^{1} \mathrm{H},{ }^{13} \mathrm{C},{ }^{19} \mathrm{~F}$ and ${ }^{31} \mathrm{P}$ nuclei at different magnetic fields and temperatures.

\begin{tabular}{|l|l|l|l|}
\hline Nucleus & $\begin{array}{l}\text { Polarisation at } \mathrm{B}_{0}=1.5 \\
\mathrm{~T} ; \mathrm{T}=310 \mathrm{~K}\end{array}$ & $\begin{array}{l}\text { Polarisation at } \mathrm{B}_{0}=1.4 \\
\mathrm{~T} ; \mathrm{T}=298 \mathrm{~K}\end{array}$ & $\begin{array}{l}\text { Polarisation at } \mathrm{B}_{0}=9.4 \\
\mathrm{~T} ; \mathrm{T}=298 \mathrm{~K}\end{array}$ \\
\hline${ }^{1} \mathrm{H}$ & $4.9 \times 10^{-6}$ & $4.8 \times 10^{-6}$ & $3.2 \times 10^{-5}$ \\
\hline${ }^{13} \mathrm{C}$ & $1.2 \times 10^{-6}$ & $1.2 \times 10^{-6}$ & $8.1 \times 10^{-6}$ \\
\hline${ }^{15} \mathrm{~N}$ & $5.0 \times 10^{-7}$ & $4.9 \times 10^{-7}$ & $3.3 \times 10^{-6}$ \\
\hline${ }^{19} \mathrm{~F}$ & $4.7 \times 10^{-6}$ & $4.5 \times 10^{-6}$ & $3.0 \times 10^{-5}$ \\
\hline${ }^{31} \mathrm{P}$ & $2.0 \times 10^{-6}$ & $1.9 \times 10^{-6}$ & $1.3 \times 10^{-5}$ \\
\hline
\end{tabular}

The simplest form of hyperpolarisation is brute force [1]. Brute force techniques centre on manipulating Equation 1, in particular the temperature and magnetic field strength, to improve polarisation. Increasing the magnetic field in which the measurement takes place and / or decreasing the temperature of the sample being analysed results in better polarisation. However, these are only small gains. For example, for ${ }^{1} \mathrm{H}$ nuclei at $4 \mathrm{~K}$ and $9.4 \mathrm{~T}$ the polarisation is $2.4 \times 10^{-3}$, which is two orders of magnitude larger than at $298 \mathrm{~T}$. Increasing the magnetic field strength to $20 \mathrm{~T}$ only increases polarisation by a further $c a .50 \%\left(P=5.11 \times 10^{-3}\right)$. Achieving both a stronger magnetic field and / or low temperature is costly and in some cases, very impractical (e.g. MR images of humans cannot be acquired at $4 \mathrm{~K}$ ). Despite this, successful studies have been conducted, such as the hyperpolarisation of ${ }^{13} \mathrm{C}$-labelled pyruvic acid, which was enhanced by 1600 -fold [2]. However, brute force techniques have been largely superseded by other hyperpolarisation techniques, namely DNP (Dynamic Nuclear Polarisation) [3-7], SEOP (Spin Exchange Optical Pumping) [8] and PHIP (Parahydrogen Induced Polarisation) [9-14]. SEOP and DNP fall out of the scope of this review and hence readers are directed to the references indicated for information relating to these techniques.

PHIP utilises parahydrogen, a nuclear singlet, as the source of polarisation. At room temperature, $\mathrm{H}_{2}$ gas consists of $25 \%$ parahydrogen and $75 \%$ orthohydrogen. The interconversion between the two forms is spin forbidden and as such, a catalyst must be used to relax the spin selection rules. $\mathrm{Fe}_{2} \mathrm{O}_{3}$ [15], charcoal [10] and silica/ $\mathrm{FeCl}_{3}$ [11] fulfil this role very well and have been utilised extensively in the literature. In the absence of catalyst the conversion process can take years to occur. $\mathrm{The}_{2}$ gas also needs to be cooled so that parahydrogen is produced in larger amounts relative to orthohydrogen. At $77 \mathrm{~K}$, the ratio is $50: 50$ orthohydrogen to parahydrogen whereas at $20.3 \mathrm{~K}$ (boiling point of $\mathrm{H}_{2}$ ), 99.859\% parahydrogen is produced [12]. The requirement to cool the $\mathrm{H}_{2}$ gas becomes apparent when the wavefunction of $\mathrm{H}_{2}$ is considered. For the inversion of the two protons (fermions), only the rotational and nuclear spin components of the wavefunction change. The wavefunction has to be antisymmetric with respect to inversion. Thus, parahydrogen is associated with symmetric rotational values (even values of $J$ ) whereas orthohydrogen has asymmetric rotational values (odd values of $J$ ). For the former $S(S-1) / 2$ nuclear spin states exist whereas the latter has $S(S+1) / 2$ nuclear spin states (where $S=2 s+1(s=1 / 2)$ ). This equates to one and three states respectively, and therefore, parahydrogen exists in a nuclear singlet state whereas orthohydrogen exists in a nuclear triplet state. In the presence of a catalyst that relaxes the spin selection rules, improved conversion of orthohydrogen to parahydrogen therefore results at lower temperatures as the $J=0$ becomes more populated and is $1.4 \mathrm{~kJ} \mathrm{~mol}^{-1}$ lower in energy than the $J=1$ state. The 
production of parahydrogen has been automated in order to meet the specific requirements of some groups [15-17].

Bowers and Weitekamp first postulated the use of parahydrogen to obtain very large nuclear-spin polarisations in 1986 [18]. They predicted that following chemical reaction, and subsequent radiofrequency (RF) irradiation, the scalar parahydrogen state would be converted into polarisation of order unity on the nuclear spins of the hydrogenation products formed. It is worth noting that parahydrogen has a total spin of zero and is not visible by NMR and thus its symmetry must be broken in order to observe the polarised state. Furthermore, they stated that the phenomena should have "wide utility in the study of chemical reactions of molecules by hydrogen addition or subsequent reactions". The following year they experimentally proved it by hydrogenating acrylonitrile to propionitrile using Wilkinson's catalyst ([RhCl( $\left.\left.\left.\mathrm{PPh}_{3}\right)_{3}\right]\right)$ using parahydrogen within the magnetic field used for measurement [19]. The ${ }^{1} \mathrm{H}$ NMR spectrum showed large anti-phase multiplets for the parahydrogenated product following the application of a $\pi / 4$ pulse. The title of the paper "Parahydrogen and Synthesis Allow Dramatically Enhanced Nuclear Alignment", which was abbreviated to PASADENA, became synonymous with PHIP conducted within the magnetic field. Around the time of this publication, a similar observation had been made by the group of Eisenberg but had been mistakenly interpreted as spin sorting of a radical pair intermediate (otherwise known as chemically induced dynamic nuclear polarisation (CIDNP)) [20]. The storage of the sample in liquid nitrogen prior to reaction at room temperature had most likely created a sufficient concentration of parahydrogen to detect polarised signals [9]. In a further extension, the parahydrogenation was conducted at low-field and then the sample rapidly transported (adiabatically) to the measurement field for detection of the hyperpolarised signal. This approach is, therefore, different to PASADENA and thus the acronym ALTADENA (Adiabatic Longitudinal Transport After Dissociation Engenders Nuclear Alignment) was coined to differentiate that the polarised material was produced at low-field rather than at high-field [21]. The parahydrogenation of styrene using Wilkinson's Catalyst was the first substrate to be polarised by ALTADENA. $A \pi / 2$ pulse is required to optimally read-out the magnetisation created, and the signals present as in-phase signals, although they can be emissive or absorptive. The acronym PHIP [9] is used to broadly describe ALTADENA and PASADENA type reactions.

For the purposes of this work, SABRE (Signal Amplification By Reversible Exchange), will be the focus. Developments and applications of the technique have been previously reviewed [22]. Unlike other PHIP techniques, polarisation is transferred without chemical modification of the analyte. First reported in 2009, SABRE relies upon transferring polarisation from parahydrogen derived hydrides to the spin- $-1 / 2$ nuclei of ligated ligands through the J-coupling network at low magnetic field [23]. A metal catalyst is used to bring the two entities in to contact with one another. Both the ligand and hydrides can dissociate from the catalyst allowing other molecules to bind, and as such, the process can be repeated many times. Figure 1 exemplifies the process. Practically, this involves dissolving the catalyst and substrate in solvent and then either bubbling parahydrogen through the solution, or using a Young's capped NMR tube with an atmosphere of parahydrogen and physically shaking it. This leads to a build-up of polarisation within analyte molecules not ligated to the metal complex, which can be read-out by the application of RF pulses within the measurement field, following rapid transfer from low- to high-magnetic field. The precise nature of the polarisation transfer process is dependent on both scalar coupling and chemical shift effects [24]. Thus, polarisation is both magnetic field- and time-dependent, the latter reflecting the transient nature of the complex to which parahydrogen derived hydrides and substrate ligands are bound. Theoretical modelling has shown that the substrate ${ }^{1} \mathrm{H}$ nuclear spins, following polarisation transfer, evolve in to states, that when interrogated by RF pulses, produce in-phase signals originating from longitudinal 
magnetisation and antiphase signals originating from either longitudinal two-spin order or residual zero quantum terms. Under conditions where the chemical shift evolution is suppressed by locating the sample in a zero-field or through the substrate possessing isochronous spins, polarisation is predominantly transferred through spins and thus leads to the generation of a singlet state. This has been exemplified for a number of systems and is discussed further in the section entitled "Generation and utilisation of long-lived states by SABRE".

A

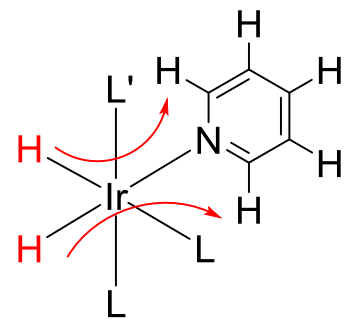

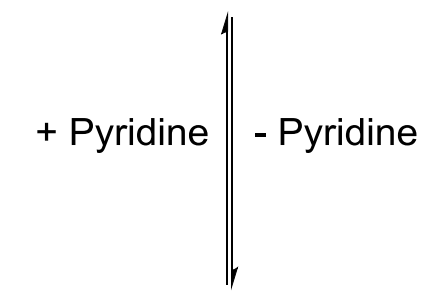

D<smiles>[3H][V]([3H])([3H])[3H]</smiles>

B

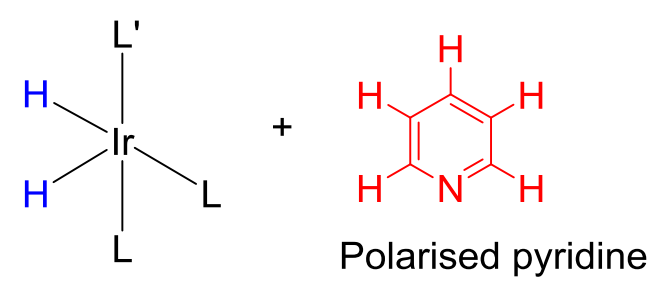<smiles>CC(C)C</smiles>

C<smiles>[1H][IH]([1H])([3H])C</smiles>

Figure 1. Mechanism for the transfer of polarisation to pyridine (L). L' represents a ligand not involved in the transfer mechanism e.g. a carbene or phosphine ligand. A) Transfer of polarisation through the J-coupling from parahydrogen derived hydride ligands to spin- $1 / 2$ nuclei of pyridine. B) Hyperpolarised pyridine dissociates leaving a vacant site. C). Parahydrogen occupies the vacant site. D) Hydrogen exchange resulting in parahydrogen derived hydrides reforming and loss of orthohydrogen.

\section{Early observations of the SABRE effect}

SABRE was first exemplified using cationic iridium complexes of the type $\left[\operatorname{Ir}(\mathrm{COD})\left(\mathrm{PR}_{3}\right)_{2}\right] \mathrm{BF}_{4}$, where $\mathrm{R}$ $=\mathrm{Ph}, p$-tolyl or $p-\mathrm{C}_{6} \mathrm{H}_{4}$-OMe) [25]. These complexes are essentially pre-catalysts as they not capable of polarisation transfer. In the presence of pyridine and parahydrogen these complexes were shown to form trans,cis,cis-[ $\left[\operatorname{lr}\left(\mathrm{PR}_{3}\right)_{2}(\mathrm{py})_{2}(\mathrm{H})_{2}\right]^{+}$(py = pyridine) and small amounts of fac,cis-[Ir $\left.\left(\mathrm{PR}_{3}\right)(\mathrm{py})_{3}(\mathrm{H})_{2}\right]^{+}$; these are the active polarisation transfer catalysts. These complexes are readily observable in the ${ }^{1} \mathrm{H}$ NMR due to the differences in the chemical shift of their hydride ligands. For example, when $\mathrm{R}=\mathrm{Ph}$, the hydride of trans, cis, cis-[Ir $\left.\left(\mathrm{PPh}_{3}\right)_{2}(\mathrm{py})_{2}(\mathrm{H})_{2}\right]^{+}$occurs at $\delta-21.64$ whereas the hydride of fac,cis$\left[\operatorname{Ir}\left(\mathrm{PPh}_{3}\right)(\mathrm{py})_{3}(\mathrm{H})_{2}\right]^{+}$is observed at $\delta-21.8$. When ${ }^{15} \mathrm{~N}$-labelled pyridine and a parahydrogen atmosphere were employed, both hydride signals are polarised in the ${ }^{1} \mathrm{H}$ NMR spectrum. Interestingly, the hydride signal of $f a c, c i s-\left[\operatorname{Ir}\left(\mathrm{PPh}_{3}\right)(\mathrm{py})_{3}(\mathrm{H})_{2}\right]^{+}$is much larger than the corresponding signal of trans,cis,cis-[Ir $\left.\left(\mathrm{PPh}_{3}\right)_{2}(\mathrm{py})_{2}(\mathrm{H})_{2}\right]^{+}$despite the latter being in substantially larger concentration (in the presence of a 9-fold excess of pyridine, relative hydride resonance intensities are $0.04: 1$ respectively). The propensity of these complexes to exchange $\mathrm{H}_{2}$ in trans, cis, $c i s-\left[\operatorname{Ir}\left(\mathrm{PPh}_{3}\right)_{2}(\mathrm{py})_{2}(\mathrm{H})_{2}\right]^{+}$ was probed using normalized hydride signal intensity ratios as a guide. These data revealed that the 
exchange process increases in the order $\mathrm{P}\left(p-\mathrm{C}_{6} \mathrm{H}_{4}-\mathrm{OMe}\right)_{3}>\mathrm{P}(p \text {-tolyl })_{3}>\mathrm{PPh}_{3}$. This trend mirrors the increase in the electron donating ability of the phosphine. Conversely, the trend observed for the $\mathrm{H}_{2}$ exchange in $f a c, c i s-\left[\operatorname{Ir}\left(\mathrm{PPh}_{3}\right)(\mathrm{py})_{3}(\mathrm{H})_{2}\right]^{+}$is the opposite and thus the extent of enhancement follows the reduction of electron donating power of the phosphine. It was noted, however, that EXSY (Exchange Spectroscopy) measurements revealed little or no exchange of hydride into free hydrogen at $335 \mathrm{~K}$ in these complexes, which is suggestive that reductive elimination of $\mathrm{H}_{2}$ under these conditions is not facile. Pyridine exchange rates for trans,cis, cis- $\left[\operatorname{Ir}\left(\mathrm{PR}_{3}\right)_{2}(\mathrm{py})_{2}(\mathrm{H})_{2}\right]^{+}$were determined and values of $0.4 \mathrm{~s}^{-1}, 0.82 \mathrm{~s}^{-1}$ and $0.90 \mathrm{~s}^{-1}$ were obtained at $335 \mathrm{~K}$ for when $\mathrm{R}=\mathrm{Ph}, p$-tolyl or $p-\mathrm{C}_{6} \mathrm{H}_{4^{-}}$ OMe respectively. Obtaining pyridine exchange rates at $335 \mathrm{~K}$ for $f a c, c i s-\left[\operatorname{Ir}\left(\mathrm{PR}_{3}\right)(\mathrm{py})_{3}(\mathrm{H})_{2}\right]^{+}$proved more difficult due to decomposition ( $\left.\mathrm{R}=p-\mathrm{C}_{6} \mathrm{H}_{4}-\mathrm{OMe}\right)$, or interconversion of the axial and equatorial pyridine ligands $(\mathrm{R}=\mathrm{Ph})$. However, a rate of $2.0 \mathrm{~s}^{-1}$ was obtained for when $\mathrm{R}=p$-tolyl; this is ca. 2.4 times quicker than the analogous bis-phosphine complex. Pyridine exchange rates for all three complexes were obtained at $308 \mathrm{~K}$ and were similar $\left(c a .0 .07 \mathrm{~s}^{-1}\right)$ and larger than those of trans,cis, cis-[Ir $\left.\left(\mathrm{PR}_{3}\right)_{2}(\mathrm{py})_{2}(\mathrm{H})_{2}\right]^{+}$complexes. Enthalpy data also suggested that $\mathrm{Ir}-\mathrm{N}$ bond is strengthened in trans, cis, cis-[Ir $\left.\left(\mathrm{PR}_{3}\right)_{2}(\mathrm{py})_{2}(\mathrm{H})_{2}\right]^{+}$complexes relative to $\left[\operatorname{Ir}\left(\mathrm{PR}_{3}\right)(\mathrm{py})_{3}(\mathrm{H})_{2}\right]^{+}$complexes. Resultantly, the $\left[\operatorname{Ir}\left(\mathrm{PR}_{3}\right)(\mathrm{py})_{3}(\mathrm{H})_{2}\right]^{+}$complexes represent the better class of complex to use for polarisation transfer in SABRE.<smiles>c1ccc(P(c2ccccc2)c2ccccc2)cc1</smiles>

$\mathrm{PPh}_{3}$<smiles>Cc1ccc(P(c2ccc(C)cc2)c2ccc(C)cc2)cc1</smiles>

$\mathrm{P}(p \text {-tolyl })_{3}$<smiles>COc1ccc(P(c2ccc(OC)cc2)c2ccc(OC)cc2)cc1</smiles>

$\mathrm{P}\left(p-\mathrm{C}_{6} \mathrm{H}_{4}-\mathrm{OMe}\right)_{3}$<smiles>CC(C)P(C(C)C)C(C)C</smiles>

$\mathrm{P}^{\mathrm{i}} \mathrm{Pr}_{3}$

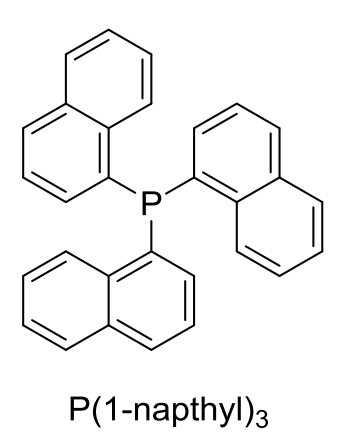

$\mathrm{P}(\text { 1-napthyl })_{3}$<smiles>C1CCC(P(C2CCCCC2)C2CCCCC2)CC1</smiles>

$\mathrm{PCy}_{3}$<smiles>c1ccc(P(C2CCCCC2)C2CCCCC2)cc1</smiles>

$\mathrm{PPhCy}_{2}$
$\mathrm{PEt}_{3}$<smiles>c1ccc(P(c2ccccc2)C2CCCCC2)cc1</smiles>

$\mathrm{PPh}_{2} \mathrm{Cy}$<smiles>CCP(CC)CC</smiles><smiles>CCCCP(CCCC)CCCC</smiles>

$\mathrm{P}^{\mathrm{n}} \mathrm{Bu}_{3}$

Figure 2. Phosphine ligands used in the construction of SABRE pre-catalysts.

The knowledge gleaned on the identity of the phosphine ligand led to a further study to investigate the use of $\left[\operatorname{Ir}(\mathrm{COD})\left(\mathrm{PCy}_{3}\right)\left(\mathrm{py}_{1}\right) \mathrm{BF}_{4}, \mathrm{Crabtree}^{\prime}\right.$ catalyst, to polarise pyridine in the presence of parahydrogen [26]. The active form of the catalyst, based on NMR studies and X-ray crystallographic data, proved to be $f a c, c i s-\left[\operatorname{Ir}\left(\mathrm{PCy}_{3}\right)(\mathrm{py})_{3}(\mathrm{H})_{2}\right] \mathrm{BF}_{4}$. The ${ }^{1} \mathrm{H}$ NMR signals of free pyridine were shown to 
be enhanced when a sample containing an excess of pyridine relative to the form of the catalyst was polarised in earth's magnetic field. The ortho-, para- and meta- ${ }^{1} \mathrm{H}$ sites of pyridine were enhanced $-144-,-47-$ and 220 -fold respectively at $298 \mathrm{~K}$. The enhancement is a measure of the increase in integral size in the hyperpolarised spectrum relative to the same integral in the non-hyperpolarised spectrum. Subsequent investigations revealed that polarisation transfer did not occur in the magnetic field used for measurement $(9.4 \mathrm{~T}$ ) or that the signals of pyridine were being enhanced through chemical incorporation of parahydrogen, perhaps through a $\mathrm{C}-\mathrm{H}$ bond activation route. Polarisation transfer to ${ }^{13} \mathrm{C}$ and ${ }^{15} \mathrm{~N}$ was also demonstrated. For example, the polarised ${ }^{15} \mathrm{~N}$ NMR spectrum displays a 128 -fold increase in signal strength for pyridine relative to the thermal spectrum. Furthermore both free and bound (trans to hydride) pyridine ${ }^{15} \mathrm{~N}$ signals are evident $\left({ }^{15} \mathrm{~N}\right.$ labelled pyridine was used in this study). Probing the identity of the phosphine yielded more results relating to the polarisation transfer process. It was observed that the more electron rich and most sterically demanding phosphines yielded larger relative enhancements. Thus, of the phosphines investigated $\left(\mathrm{PCy}_{3}, \mathrm{PPhCy}_{2}, \mathrm{PPh}_{2} \mathrm{Cy}, \mathrm{PEt}_{3}, \mathrm{P}^{\mathrm{i}} \mathrm{Pr}_{3}, \mathrm{P}^{\mathrm{n}} \mathrm{Bu}_{3}, \mathrm{P}^{\mathrm{t}} \mathrm{Bu}_{3}\right.$ and $\left.\mathrm{P}(1 \text {-napthyl })_{3}\right)$, it was $\mathrm{PPhCy}_{2}$, the most electron rich and sterically demanding phosphine, that yielded the most successful transfer of polarisation to pyridine.

These early studies demonstrated that sterically bulky electron-donating phosphines delivered the highest levels of transferred hyperpolarisation. Thus, exchanging phosphines for $\mathrm{N}$-heterocyclic carbenes (NHCs) might be expected to deliver even better results. Thus, the complex [Ir(IMes) $(\mathrm{COD}) \mathrm{Cl}]$ (IMes = 1,3-bis(2,4,6-trimethylphenyl)imidazole-2-ylidene, COD = cyclooctadiene) was synthesised and tested for SABRE activity [27]. In the presence of parahydrogen and pyridine, the complex $\left[\operatorname{Ir}(\mathrm{IMes})(\mathrm{py})_{3}(\mathrm{H})_{2}\right]^{+}$is formed (Figure 3). The crystal structure of $\left[\operatorname{Ir}(\mathrm{IMes})(\mathrm{py})_{3}(\mathrm{H})_{2}\right]\left[\mathrm{PF}_{6}\right]$ revealed that the equatorial and axial Ir- $\mathrm{N}$ bond lengths differed by less than $0.01 \AA$ relative to $\left[\operatorname{Ir}(\mathrm{H})_{2}\left(\mathrm{PCy}_{3}\right)(\mathrm{py})_{3}\right]\left[\mathrm{BF}_{4}\right]$. However, the former was able to enhance the ${ }^{1} \mathrm{H}$ NMR signal deriving from the meta-protons of pyridine by 266 -fold after polarisation transfer in earth's magnetic field, whereas the latter resulted in only an 18 -fold increase. Thus, the inclusion of a NHC ligand instead of a phosphine ligand substantially improved the polarisation transfer.
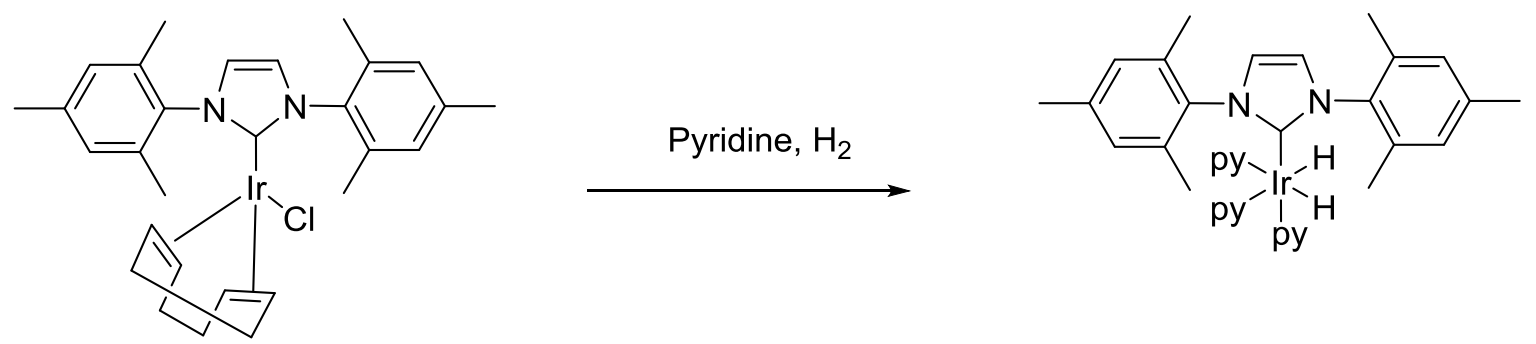

Figure 3. Reaction scheme showing the formation of $\left[\operatorname{Ir}(\mathrm{IMes})(\mathrm{py})_{3}(\mathrm{H})_{2}\right]^{+}$from $[\operatorname{Ir}(\mathrm{IMes})(\mathrm{COD}) \mathrm{Cl}$ in the presence of pyridine (py) and $\mathrm{H}_{2}$.

As SABRE involves the exchange of substrate and parahydrogen derived ligands at a metal centre, exchange rates can be measured to give insight into the process. Furthermore, when measured at different temperatures, Eyring plots can be constructed to provide information on the energetics of the system. Exchange rates have been measured using EXSY for $\left[\operatorname{Ir}(\mathrm{IMes})(\mathrm{py})_{3}(\mathrm{H})_{2}\right]^{+}$and they revealed that at $300 \mathrm{~K}$ the dissociation rates of pyridine and hydride are $11.7 \mathrm{~s}^{-1}$ and $9 \mathrm{~s}^{-1}$ respectively [27]. For $\left[\operatorname{Ir}(\mathrm{H})_{2}\left(\mathrm{PCy}_{3}\right)(\mathrm{py})_{3}\right]\left[\mathrm{BF}_{4}\right]$, the analogous pyridine exchange rate is only $1.9 \mathrm{~s}^{-1}$ [25]. These data again highlight that the incorporation of IMes instead of $\mathrm{PC}_{3}$ results in the better catalyst. Increasing the pyridine concentration led to a decrease in the observed hydride dissociation rate, which is suggestive that hydride loss occurs after pyridine dissociation. 


\section{Optimisation of the SABRE catalyst}

Following these early observations, it was clear that the composition of the catalyst was fundamental in terms of the polarisation transfer efficiency. Thus, in an effort to gain insight into optimising the identity of the $\mathrm{NHC}$ of the pre-catalyst, $[\operatorname{Ir}(\mathrm{NHC})(\mathrm{COD}) \mathrm{Cl}]$, a series of complexes were synthesised [28]. A total of nine complexes were synthesised, of which one was [ $\operatorname{Ir}(\mathrm{IMes})(\mathrm{COD}) \mathrm{Cl}]$. One complex, $[\operatorname{Ir}(\operatorname{IAd})(\mathrm{COD}) \mathrm{Cl}]$, could not be screened due to poor solubility in $d_{4}$-methanol, but the remainder were used to polarise pyridine via SABRE. Plots of signal enhancement against either the modified Tolman parameter, buried volume or exchange rate of pyridine all indicated that no trend was apparent. In all of these plots, $[\operatorname{Ir}(\mathrm{IMes})(\mathrm{COD}) \mathrm{Cl}]$ was the outlier and notably use of this complex produced the best ${ }^{1} \mathrm{H}$ NMR signal enhancement of pyridine out of the complexes studied. However, it was shown that increasing the buried volume led to an increase in exchange rate, which is consistent with a dissociative mechanism.<smiles>Cc1cc(C)c(N2C=CN(c3c(C)cc(C)cc3C)C2C)c(C)c1</smiles>

IMes

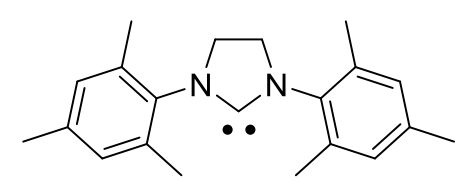

SIMes

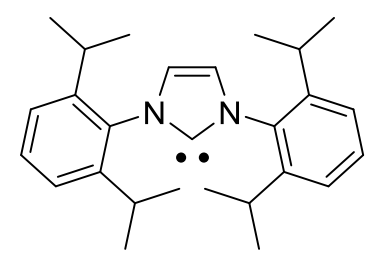

$\operatorname{IPr}$<smiles>CCN1CCN(c2c(C(C)C)cccc2C(C)C)C1c1cccc(C(C)C)c1C(C)C</smiles>

SIPr<smiles>CC(C)N1CCN(C(C)C)C1C</smiles>

$\operatorname{SImNPr}{ }_{2}^{\mathrm{i}}$<smiles>C[C@]1(C2CCCCC2)C=CN1C1CCCCC1</smiles>

ICy<smiles>CC(C)N1CCN(C(C)C)C1C</smiles>

$\mathrm{IMe}$<smiles>CC(C)N1C=CN(C(C)C)C1C</smiles>

$\operatorname{ImNPr}_{2}{ }^{i}$<smiles>CC1=C(C)N(C(C)C)C(C)N1C(C)C</smiles>

$\mathrm{I}^{\mathrm{t}} \mathrm{Bu}$

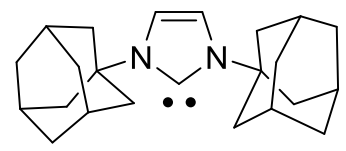

IAd

Figure 4. Chemical structures of carbenes evaluated for the production of SABRE catalysts.

A further work on the identity of the carbene in the SABRE process has been published [29]. The precatalyst $[\mathrm{Ir}(\mathrm{NHC})(\mathrm{COD}) \mathrm{Cl}]$ was again investigated; the NHCs used were IMes, SIMes, IPr, SIPr, ICy, IMe and $\mathrm{ImMe}_{2} \mathrm{NPr}_{2}{ }_{2}$. A number of observations were made using pyridine as the test substrate, which gave complexes of the type $\left[\operatorname{Ir}(\mathrm{NHC})(\mathrm{py})_{3}(\mathrm{H})_{2}\right]^{+}$in the presence of hydrogen. Firstly, ligand exchange studies revealed that the loss of pyridine from $\left[\operatorname{Ir}(\mathrm{NHC})(\mathrm{H})_{2}(\mathrm{py})_{3}\right]^{+}$was dissociative and controlled by the steric and electronic parameters of the NHC. When the NHC was bulky, this caused the Ir-py interaction to weaken, therefore promoting pyridine dissociation. Based on entropy values, the trend was found to be SiPr $>I P r>S I M e s>I M e s>I m M e_{2} N r_{2}{ }_{2}>I C y>I M e$. Due to this dissociative process, $\left[\operatorname{Ir}(\mathrm{NHC})(\mathrm{H})_{2}(\mathrm{py})_{2} \text { (methanol) }\right]^{+}$was detected, which had been postulated by prior DFT (Density Functional Theory) studies [27]. While it is SABRE active, the concentration of this species is low and therefore has a minimal role in polarising pyridine. The rate of $\mathrm{H}_{2}$ loss was also examined and this time the trend was shown to be SiPr $>$ SIMes $>I P r>I M e s>I m M e_{2} N \operatorname{Pr}_{2}^{i}>I C y>I M e$. Finally, the different carbene containing catalysts were ranked in terms of delivering the biggest enhancement of pyridine at $300 \mathrm{~K}$. The trend for this is $\mathrm{SiPr}<\mathrm{ICy}<\mathrm{IMe}<\mathrm{ImMe}_{2} \mathrm{NPr}_{2}<\mathrm{IPr}<\mathrm{SIMes}<$ IMes. It is noteworthy that IMes, which produces the largest enhancement of $c a .6000$-fold for 
pyridine (when a ratio of $1: 4$ [ $\operatorname{Ir}(\mathrm{IMes})(\mathrm{COD}) \mathrm{Cl}]$ : py was employed), resides in the middle of the trends examined and thus suggests that an optimum value for the dissociation rate of pyridine and $\mathrm{H}_{2}$ exists. The SABRE catalyst can, therefore, be further optimised and by doing so, deliver far greater signal enhancements.

The $\pi$-accepting ability parameter (PAAP) appears to be one of the better parameters to analyse the electronic properties of $\mathrm{NHC}$ ligands [30]. The chemical shift of ${ }^{77} \mathrm{Se}$ in selonourea complexes of various NHCs (SImNPr, ImNPr, ICy, SIMes, IMes, SIPr, IPr and IPent) was plotted against exchange rate of pyridine (Figure 5). This revealed a strong correlation between the two parameters. However, there were anomalies. Firstly, ${ }^{\mathrm{t}} \mathrm{Bu}$ was not utilised in the comparison as its extremely high ${ }^{77} \mathrm{Se}$ chemical shift $(\delta 183)$ has been already considered to be anomalous [31]. Furthermore, SImNPr did not fit along the correlation curve; despite having an exchange that is three times larger than its unsaturated analogue, ImNPr. The low absolute exchange rate of SImNPr was attributed to the aliphatic nature of the isopropyl group and that is has a relatively small buried volume (26.4\%). The effect of steric bulk was exemplified further by comparing IPr to IPent. The resulting selonourea complexes have comparative chemical shift values for ${ }^{77} \mathrm{Se}$ ( $\delta 90$ for IPr and $\delta 101$ for IPent). The buried volume of IPent is, however, approximately 5\% larger than IPr. Based on the general trend (derived from second order polynomial expression, see Figure 5), an exchange rate for pyridine for IPent was calculated to be $41.6 \mathrm{~s}^{-1}$. As the bound pyridine signal was only observable at temperatures below $263 \mathrm{~K}$, a much higher exchange rate was expected. Experimentally, the pyridine exchange rate for IPent was not determined. Thus, although the PAAP is useful in terms of ascertaining whether an NHC is applicable for SABRE, the steric bulk and other parameters should be considered also. It is important to note that IMes, the NHC that produces the best signal enhancement, is towards the bottom of the curve.

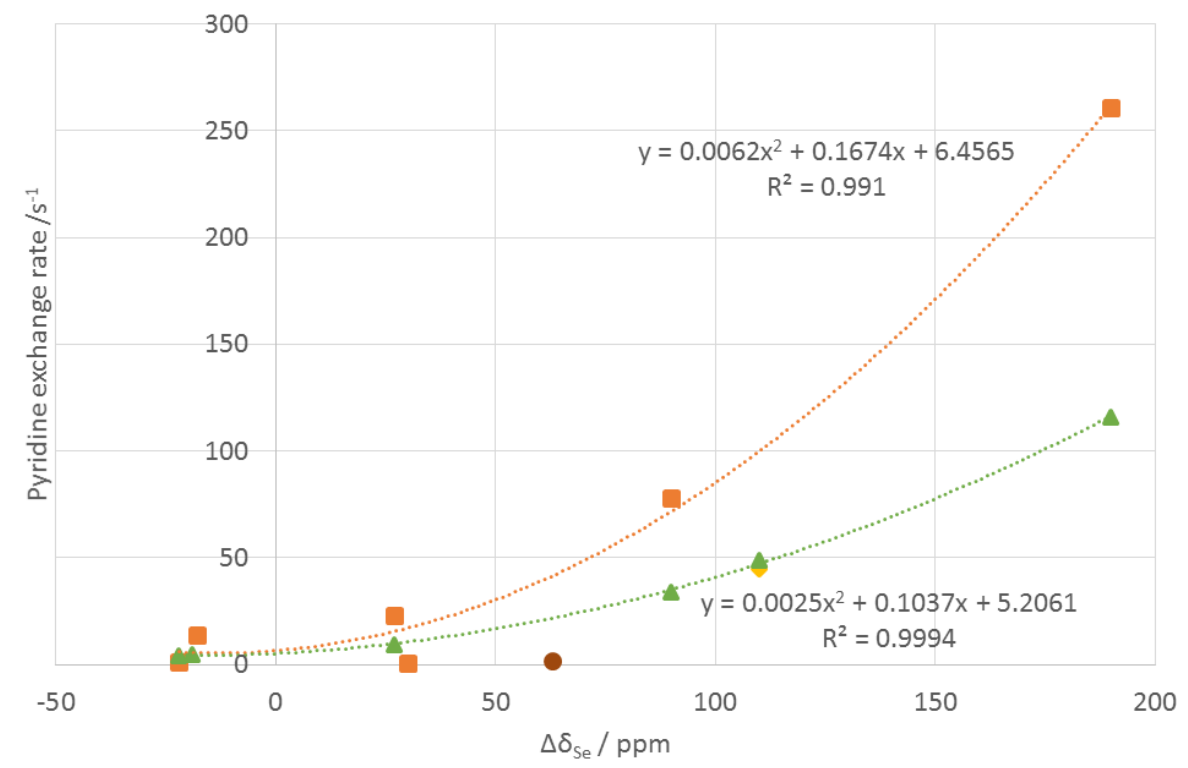

Figure 5. Plot of pyridine exchange rate against $\Delta \delta_{\text {se }}$ using data reported by Duckett and co-workers and Tessari and coworkers. Data reported by Duckett and co-workers at $300 \mathrm{~K}$. SIMes data point from Duckett and co-workers (outlier).

$\triangle$ Data reported by Tessari and co-workers at $298 \mathrm{~K}$. $\bullet \mathrm{SImNPri}_{2}$ data point from Tessari and co-workers (outlier)

Exchange data, in conjunction with DFT, have been used to rationalise the exchange processes occurring at the iridium centre of $\left[\operatorname{Ir}(\mathrm{IMes})(\mathrm{py})_{3}(\mathrm{H})_{2}\right]^{+}$and hence the mechanism of polarisation transfer. Optimisation of the $\left[\operatorname{Ir}(\mathrm{IMes})(\mathrm{py})_{3}(\mathrm{H})_{2}\right]^{+}$at the BP86/LANL2DZ level resulted in geometrical parameters very close to those determined from experimentally from X-ray crystallographic data 
[27]. Loss of pyridine trans to hydride or trans to IMes from $\left[\operatorname{Ir}(\mathrm{IMes})(\mathrm{py})_{3}(\mathrm{H})_{2}\right]^{+}$resulted in the same product after reorganization. Experimentally, EXSY data showed that only the pyridine trans to hydride dissociates on the NMR timescale. The computed gas-phase free-energy barrier for loss of pyridine trans to hydride is $48 \mathrm{~kJ} \mathrm{~mol}^{-1}$; this compares well with the experimentally determined value of $64 \pm 2 \mathrm{~kJ} \mathrm{~mol}^{-1}$. The positive $\Delta \mathrm{S}$ value of $97 \pm 9 \mathrm{~J} \mathrm{~K}^{-1} \mathrm{~mol}^{-1}$ for this process determined experimentally from the Eyring plot also indicated a dissociative mechanism. Three different routes of $\mathrm{H}_{2}$ exchange were investigated. Loss of dihydride from the intermediate, $\left[\operatorname{Ir}(\mathrm{IMes})(\mathrm{py})_{2}(\mathrm{H})_{2}\right] \mathrm{Cl}$, to give the 14-electron species $\left[\operatorname{Ir}(\mathrm{IMes})(\mathrm{py})_{2}\right] \mathrm{Cl}$, was shown to be thermodynamically unfavourable, as at least $117 \mathrm{~kJ} \mathrm{~mol}^{-1}$ of free energy is required. The second route involves solvent participation to yield an 18-electron intermediate, $\left[\operatorname{Ir}(\mathrm{IMes})(\mathrm{py})_{2}(\mathrm{H})_{2}(\mathrm{MeOH})\right] \mathrm{Cl}$. Whilst methanol binding requires only $13 \mathrm{~kJ} \mathrm{~mol}^{-1}$ of free energy, subsequent elimination of dihydride requires an additional $83 \mathrm{~kJ} \mathrm{~mol}^{-}$ ${ }^{1}$. Again, the experimental data did not support these findings. The third route, and most likely based on experimental evidence, involves the formation of $\left[\operatorname{Ir}(\operatorname{IMes})(\mathrm{py})_{3}(\mathrm{H})_{2}\left(\eta^{2}-\mathrm{H}_{2}\right)\right]^{+}$. This involves the incoming $\mathrm{H}_{2}$ ligand to bind in the faster relaxing dihydrogen form. The combined gas-phase freeenergy barrier to form this product from $\left[\operatorname{Ir}(\mathrm{IMes})(\mathrm{py})_{3}(\mathrm{H})_{2}\right]^{+}$is $44 \mathrm{~kJ} \mathrm{~mol}^{-1}$. However, this would require the lifetime of $\left[\operatorname{Ir}(\mathrm{IMes})(\mathrm{py})_{3}(\mathrm{H})_{2}\left(\mathrm{\eta}^{2}-\mathrm{H}_{2}\right)\right]^{+}$to be short enough to avoid the conversion of parahydrogen to orthohydrogen.

To gain further insight into the polarisation transfer process, and hence improve the catalytic system for future experiments, DFT was again used to provide a computational basis for the presence of various complexes produced when $[\mathrm{Ir}(\mathrm{IMes})(\mathrm{COD}) \mathrm{Cl}]$ was exposed to methyltriazole $(\mathrm{mtz})$, pyridine and $\mathrm{H}_{2}$ [32]. The complexes possibly formed by this process are shown in Figure 6 along with their relative energies. The relative energies could not be directly compared to previous work, although the optimized geometry of $\left[\operatorname{Ir}(\mathrm{IMes})(\mathrm{py})_{3}(\mathrm{H})_{2}\right]^{+}$does show similar features. $\left[\operatorname{Ir}(\mathrm{IMes})(\mathrm{py})_{2}(\mathrm{mtz})(\mathrm{H})_{2}\right]^{+}$ has the highest relative energy of the complexes investigated. This is consistent with NMR data, as this species is not observable using this technique. The relative abundances at different ratios of pyridine : $\mathrm{mtz}$ were computed using DFT and compared with NMR data. This revealed that $\left[\operatorname{lr}(\mathrm{IMes})(\mathrm{py})_{3}(\mathrm{H})_{2}\right]^{+}$was only observed at very low concentrations of $\mathrm{mtz}$ (below $1: 0.6$ pyridine : $\mathrm{mtz})$. DFT calculations indicated that the presence of two structural isomers of $\left[\operatorname{Ir}(\operatorname{IMes})(\mathrm{py})(\mathrm{mtz})_{2}(\mathrm{H})_{2}\right]^{+}$, in which both $\mathrm{mtz}$ ligands are trans to hydride or only one mtz ligand is trans to hydride and the other trans to IMes, were underestimated and overestimated respectively relative to NMR experimental data. Similarly, $\left[\operatorname{Ir}(\mathrm{IMes})(\mathrm{mtz})_{3}(\mathrm{H})_{2}\right]^{+}$was underestimated. The relative concentrations of $\left[\operatorname{Ir}(\mathrm{IMes})(\mathrm{py})_{2}(\mathrm{mtz})(\mathrm{H})_{2}\right]^{+}$(one pyridine trans to IMes, the other trans to hydride) and $\left[\operatorname{Ir}(\mathrm{IMes})(\mathrm{py})(\mathrm{mtz})_{2}(\mathrm{H})_{2}\right]^{+}$(one mtz trans to IMes, the other trans to hydride) were shown to be in good agreement, albeit the former more than the latter, with the experimentally determined ${ }^{1} \mathrm{H}$ NMR data. The coordination bonds in these complexes were subjected to energy decomposition analysis (EDA). The EDA performed for the ligand trans to NHC and both cis-ligands revealed that the trans ligand was hardly affected by the nature of the cis ligands, and vice versa. Furthermore, regardless of the type of ligand, trans ligands produced a more stabilizing interaction than cis ligands. This was rationalised to be due to more favourable electrostatic and orbital interaction energy terms in trans ligands compared to those of cis ligands. 


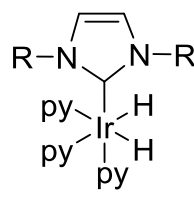

$-2.08$

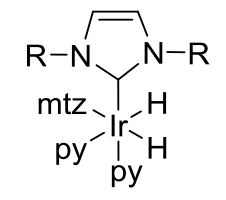

$-5.04$

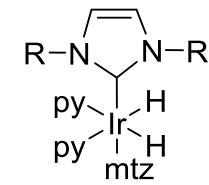

0.00

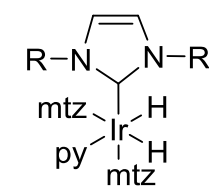

$-4.76$

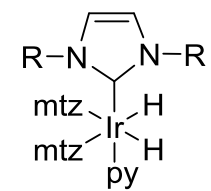

$-3.55$

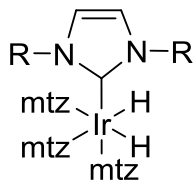

$-2.65$

Figure 6. Chemical structures ( $p y=$ pyridine, $\mathrm{mtz}=$ methyltriazole and $\mathrm{R}=1,3,6$-trimethylphenyl) and their relative energies (kcal mol-1) calculated by DFT [32].

A simple analytical model for SABRE has been presented that provides rationale for deciding which system parameters to optimise to achieve higher signal enhancements [33]. Parameters such as Jcouplings, relaxation rates and reaction rate constants were considered. An expression was derived for determining the enhancement provided by SABRE. The relaxation rates were highlighted as being the key parameter to be optimised and not the dissociation constants. Furthermore, an optimal value for the dissociation rate constant for the substrate was derived to be $4.5 \mathrm{~s}^{-1}$ (which equalled the angular frequency of a level anti-crossing (LAC)), $\omega_{\text {LAC }}$, which is lower than that of pyridine in $\left[\operatorname{Ir}(\mathrm{IMes})(\mathrm{py})_{3}(\mathrm{H})_{2}\right]^{+}\left(11.7 \mathrm{~s}^{-1}\right)$ [27]. A theoretical approach based on LACs had previously been described for pyridine polarised by Crabtree's catalyst which accounted for the SABRE effects and their magnetic-field dependence observed experimentally [34]. Thus, the expression could be used to predict the structure of future catalysts for SABRE. Recommendations for the design of an optimal chemical system were proposed and these were : i) the substrate-to-catalyst ratio should be as low as possible provided that $\left[\operatorname{Ir}(\mathrm{NHC})(\mathrm{H})_{2}(\mathrm{sub})_{3}\right]^{+}$remains the main catalyst in solution; ii) for low-field SABRE, the substrate dissociation rate constant should be of the same order as the spin mixing frequency, whereas for high-field sample, the dissociation rate should be as high as possible; iii) the catalytic species should have minimal effect on the relaxation rate; iv) the parahydrogen concentration in solution should be as high as possible.

\section{SABRE catalysts utilising rhodium and cobalt}

To date only one example of a rhodium based catalyst being used in conjunction with SABRE has been reported. This is despite numerous reports of its use in PHIP-based studies [11-13, 35].

Zhivonitko et al. have demonstrated that $\left[\operatorname{Ir}\left(\mathrm{PPh}_{3}\right)_{3}(\mathrm{H})_{2} \mathrm{Cl}\right]$ can be generated easily from $\left[\mathrm{Ir}_{2} \mathrm{Cl}_{2}(\mathrm{COD})_{2}\right]$ and $\mathrm{PPh}_{3}$ in the presence of parahydrogen to produce hyperpolarised ${ }^{31} \mathrm{P} \mathrm{NMR}$ spectra (see the ${ }^{31} \mathrm{P}$ Imaging Applications of SABRE section for more details) [36]. They further report that $\left[\operatorname{Ir}(\mathrm{COD})\left(\mathrm{PC} \mathrm{y}_{3}\right)(\mathrm{py})\right] \mathrm{PF}_{6}$ and $[\mathrm{Rh}(\mathrm{COD})(\mathrm{DPPB})] \mathrm{BF}_{4}(\mathrm{DPPB}=1,4-$ bis (diphenylphosphino)butane) also demonstrate polarisation transfer via SABRE to ${ }^{31} \mathrm{P}$. However, the authors note that the signals were hard to assign to a particular metal complex most likely due to the complex equilibria present and the low concentrations of polarised species. To date, this is the only report of rhodium complexes being used for SABRE and, therefore, represents a major area for future development.

Recent literature has also demonstrated the use of cobalt to facilitate polarisation transfer in SABRE. The majority of extant SABRE literature focuses on the use of a range of iridium centred polarisation transfer catalysts, however recent publications have demonstrated cobalt catalysts can also facilitate the SABRE effect. The first reported instance made use of $\left(\mathrm{Mes}^{\mathrm{CCC}}\right) \mathrm{Co}\left(\mathrm{N}_{2}\right)\left(\mathrm{PPh}_{3}\right)$, a trigonal dipyramidal complex supported by an electron rich monoanionic pincer ligand ${ }^{\mathrm{Mes}} \mathrm{CCC}$ (bis(mesitylbenzimidazol-2-ylidene)phenyl) [37]. This bis-carbene ligand is structurally similar to the commonly used electron donating NHC IMes, whose advantages over previously used phosphines has been discussed [27]. Mes CCC predominantly differs from IMes in terms of the buried volume, one of the key parameters for the optimisation of the SABRE process, which could restrict bulky substrates from making use of this system. Studies of ligand buried volume in SABRE catalysis have 
demonstrated that ligand steric properties can impact catalytic activity as well as determining an optimal buried volume which when exceeded results in a loss of signal enhancement [28]. However, the literature of SABRE ligand optimisation focuses almost exclusively on monodentate ligands as opposed to the tridentate system described by Tokmic et al. [37]. It should be noted, though, that in the proposed octahedral coordination geometry the presence of the tridentate $\mathrm{NHC}$ and two hydrides will likely restrict the exchange rate of the substrate on the catalyst thus reducing the buildup rate of hyperpolarised bolus.
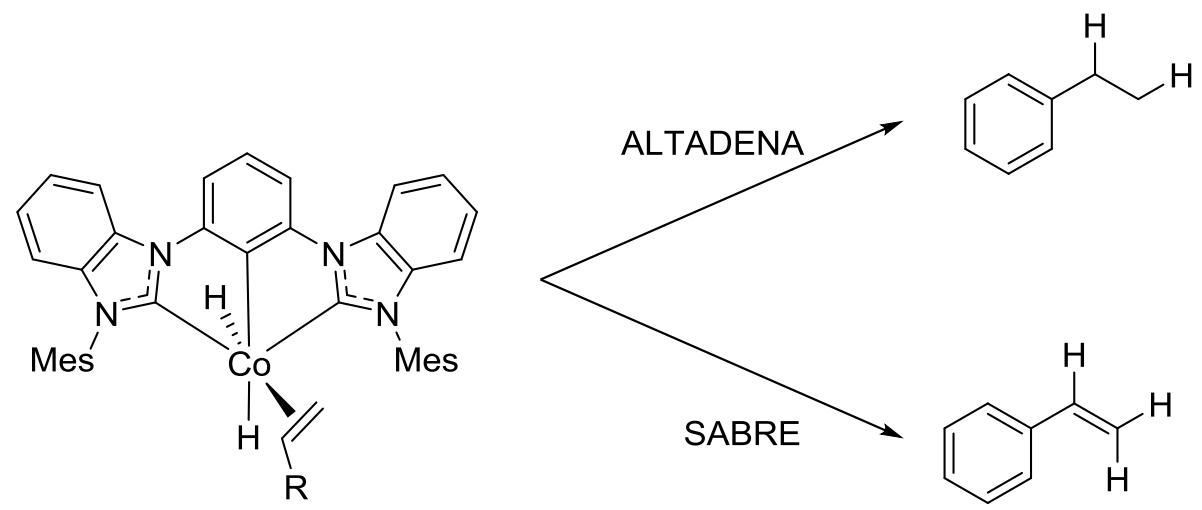

Figure 7. Styrene products identified when the indicated cobalt catalyst, in conjunction with parahydrogen, was utilised. $R$ $=\mathrm{Ph}$ and $\mathrm{Mes}=1,3,6$-trimethylphenyl

The cobalt catalytic system was intended to facilitate hydrogenation of olefins, which would be monitored making use of PHIP, however, SABRE was observed in a joint manner along with the expected hydrogenation under 4 atmospheres of $99.99 \%$ parahydrogen in a standard Young's NMR tube. OPSY (only parahydrogen spectroscopy) $[38,39]$ showed that this effect occurs for a range of substrates (including styrene, 4-vinylcyclohexene and both geometric isomers of 4-octene) [40] all demonstrating simultaneous PHIP and SABRE enhancements (see Figure 7 for an example). All the substrates used demonstrate only the terminal alkene underwent PHIP whereas SABRE was observed at all alkene sites (and in neighbouring proton environments in olefins) except for the ortho-protons in styrene. Furthermore, the reversible exchange of hydrogen without hydrogenation at the alkene sites was demonstrated through the spectroscopic observation of HD gas when the reaction was carried out under deuterium (4 atm).

\section{SABRE catalysts with bi- and tri-dentate ligands}

Iridium catalysts have been prepared with bi- and tri-dentate ligands, which resemble the cobalt catalysts shown in the previous section. A SABRE catalyst, which utilises a bidentate carbene ligand, has been synthesised by Ruddlesden et al. and the solvent capability of SABRE investigated [41]. In $d_{2}$-DCM, an enhancement of 141-fold was observed for the ortho-proton resonances. This increases to 346 -fold after a period of 24 days due to the slow formation of the active form of the catalyst. The complex shown in Figure 8 is the only inorganic product detected and no deuterium exchange with the solvent is evident. Similar observations were made in benzene and THF, with THF yielding a total enhancement of $c a$. 1300-fold after 24 days. When the solvent was changed to methanol or ethanol, different behaviour was observed. After 24 days of exposure, significant deuterium incorporation was observed for the ortho signal of pyridine. In the case of methanol, 50\% deuteration had occurred. The same process occurs for ethanol but is slower. Thus, when SABRE was conducted in methanol, the ortho signal is enhanced by 185 -fold, but after 24 days, the signal decreased to 29 fold. Although for ethanol, the analogous enhancements are 86 - and 282-fold respectively, these are still much smaller than those observed for the non-protic solvents. 
Table 2. ${ }^{1} \mathrm{H}$ NMR signal enhancements for the three ${ }^{1} \mathrm{H}$ sites of pyridine $(0.15 \mathrm{M})$ following polarisation transfer at $65 \mathrm{G}$ and using the $[\mathrm{Ir}(\mathrm{IMes})(\mathrm{COD}) \mathrm{Cl}]$ template $(15 \mathrm{~mol} \%)$ after 48 hours and 24 days

\begin{tabular}{|l|l|l|l|l|l|l|}
\hline & \multicolumn{5}{|c|}{${ }^{1}$ H NMR enhancement following SABRE for the indicated pyridine sites } \\
\hline & \multicolumn{3}{|c|}{$48 \mathrm{~h}$} & \multicolumn{3}{c|}{24 days } \\
\hline $\begin{array}{l}\text { Deuterated } \\
\text { solvent }\end{array}$ & ortho / fold & meta / fold & para / fold & ortho / fold & meta / fold & para / fold \\
\hline Benzene & 121 & 93 & 56 & 561 & 469 & 253 \\
\hline THF & 98 & 61 & 49 & 600 & 442 & 265 \\
\hline DCM & 141 & 105 & 65 & 346 & 212 & 159 \\
\hline Ethanol & 86 & 35 & 36 & 282 & 145 & 142 \\
\hline Methanol & 185 & 130 & 82 & 29 & 24 & 18 \\
\hline
\end{tabular}<smiles></smiles>

Figure 8. The inorganic product detected in $d_{2}$-DCM by Ruddlesden et al. that is responsible for polarisation transfer [41].

Modification of the catalyst structure as shown in Figure 8 was modified so that it did not possess a nitro group on the phenolate ring [42]. The Ir-O bond is retained in $d_{6}$-benzene and $d_{2}$-DCM in the presence of pyridine and hydrogen. However, in methanol, the Ir-O bond breaks and subsequently, the phenolate dissociates to form the zwitterionic complex. A single hydride at $\delta-22.18$ is observed for this complex. Pyridine, nicotinaldehyde and nicotine were all polarised in the three solvents described. Enhancements were consistently better in DCM and benzene with an enhancement of 1850-fold over the five proton sites of pyridine being obtained. In DCM and benzene, only one substrate ligand is ligated trans to hydride, whereas in methanol, there are two because the phenolate is no longer ligated to the metal centre. Thus, the available polarisation becomes shared over a greater number of spins and, therefore, the signal enhancement is smaller. Both this report and the one detailed in ref. [41] highlight the importance of solvent selection in terms of maximising the observable enhancement due to polarisation transfer.

A SABRE catalyst that utilises a tri-dentate ligand, a PNP pincer ligand, has also been synthesised and the polarisation transfer to pyridine investigated [43]. After polarisation transfer in a magnetic field of $65 \mathrm{G}$, the ortho-proton signal of pyridine was enhanced by 12 -fold. Warming the solution from $295 \mathrm{~K}$ to $310 \mathrm{~K}$ increases the signal intensity further (by 8\%). The pyridine exchange rates at 298 and $310 \mathrm{~K}$ are $18 \pm 4 \mathrm{~s}^{-1}$ and $66 \pm 18 \mathrm{~s}^{-1}$; the former is more suited to polarisation transfer at $0 \mathrm{G}$ whereas the latter to $65 \mathrm{G}$. In either case, the efficiency of the transfer is not as good as [ $\operatorname{Ir}(\mathrm{IMes})(\mathrm{COD}) \mathrm{Cl}][27$, 29], for example. Deuterating the PNP ligand, as shown in Figure 9, resulted in a 35\% increase in efficiency of polarisation transfer to pyridine at $65 \mathrm{G}$; the ortho-protons were enhanced 16 -fold respectively using the deuterated template. 

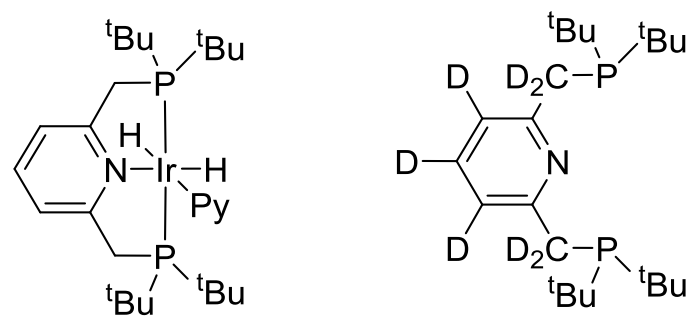

Figure 9. Chemical structures of the PNP pincer based catalyst and the deuterated pincer ligand synthesised by Holmes et al [43].

\section{Exploring the field dependency of SABRE}

The magnetic field in which polarisation is transferred is key to optimising the coherent spin mixing which is the dominant polarisation transfer mechanism. Maximising coherent spin mixing thus entails larger enhancements. The seemingly similar magnetic field dependence of SABRE has been examined using a range of substrates [44]. The substrates pyridine, pyrazole, 1-methylpyrazole, 3methylpyrazole, 3-phenylpyrazole, 3-(3-bromophenyl)pyrazole, indazole, 3,5-dimethylpyrazole and 3,5-diphenylpyrazole were all examined in this work and were polarised using the $\left[\operatorname{Ir}\left(\mathrm{PCy}_{3}\right)(\mathrm{COD})(\mathrm{py})\right]$ template. All of the substrates analysed, aside from 3,5-dimethylpyrazole, indazole and 3,5diphenylpyrazole, possessed similar magnetic field dependences in terms of maximal enhancements. Maxima were observed at $3-4 \mathrm{mT}$ and $12-14 \mathrm{mT}$ with a $180^{\circ}$ phase difference apparent. The magnetic field dependence of indazole was not determined as the signal enhancement was too low. 3,5-diphenylpyrazole was not enhanced under the conditions employed. As the pyridine ligand of the catalyst was also not polarised, this observation is suggestive of an inactive iridium complex being formed. The phenyl rings of 3-phenylpyrazole and 3-(3-bromophenyl)pyrazole both showed no signal enhancement whereas the pyrazole ring protons did so. 3,5-dimethylpyrazole possessed a different magnetic field dependence. It is noteworthy that only a ${ }^{5} J_{\mathrm{HH}}$ coupling exists between a parahydrogen derived hydride and its aromatic proton. This contrasts to the other substrates as they possess ${ }^{4} J_{\mathrm{HH}}$ couplings. The aromatic proton of 3,5-dimethylpyrazole was only enhanced following polarisation transfer at magnetic fields above $5 \mathrm{mT}$ whereas the methyl groups showed no enhancement over the field range $0-25 \mathrm{mT}$. This work also noted that the hydroxyl ${ }^{1} \mathrm{H}$ NMR signal of $\mathrm{CD}_{3} \mathrm{OH}$ was slightly polarised when pyrazole was investigated.

In a further study, Moreno et al. probed the field dependency of the enhancement observed for the hydroxyl ${ }^{1} \mathrm{H}$ NMR signal of $\mathrm{CD}_{3} \mathrm{OH}$ [45]. In the absence of $\mathrm{HCl}$, the hydroxyl signal showed negligible polarisation when pyridine was polarised in the presence of the pre-catalyst $[\mathrm{Ir}(\mathrm{IMes})(\mathrm{COD}) \mathrm{Cl}]$ and parahydrogen. However, the addition of aqueous $\mathrm{HCl}$ to a concentration of $5 \mathrm{mM}$, led to a 40 -fold enhancement at $25 \mathrm{mT}$, which mirrored the magnetic field in which optimal enhancement was observed for pyridine. Exchanging the substrate for pyrazole or pyridazine led to the same observation, albeit both enhancement values were smaller. The employment of imidazole instead of pyridine resulted in no enhancement of the hydroxyl ${ }^{1} \mathrm{H}$ NMR signal of $\mathrm{CD}_{3} \mathrm{OH}$. When $d_{5}$-pyridine was used instead of protio-pyridine, the enhancement of the solvent dropped by a factor of six, suggesting the polarisation transfer to the solvent occurs through chemical exchange or by direct coordination of the solvent to the catalyst to propagate polarisation. Cross-relaxation from the hydride protons to bound solvent molecules may also occur at high-field.

The reasons behind the observed field dependency similarity of SABRE have been explored theoretically and compared to experimental results [46]. At low fields, the dominant polarisation transfer mechanism for SABRE is coherent spin mixing, and this mixing is the most efficient in LAC regions. By comparing the use of Crabtree's catalyst and $[\operatorname{Ir}(\mathrm{IMes})(\mathrm{COD}) \mathrm{Cl}]$ to polarise pyridine, it was 
possible to explain the reason why two maxima are observed in the field dependence plot over the region $0-50 \mathrm{mT}$ for the former, whereas only one maxima was observed for the latter. Spin-spin interactions in Crabtree's catalyst involving the ${ }^{31} \mathrm{P}$ spins caused the LAC to split, thus doubling the number of maxima observed. These observations demonstrate the significant role of spin- $1 / 2$ heteronuclei in the formation of SABRE at low magnetic fields. The experimental and theoretical curves produced were in very good agreement and the model further suggested that only the orthoprotons of pyridine acquire polarisation directly from parahydrogen derived hydrides; the other protons acquire polarisation indirectly from the ortho-proton via their J-coupling.

The design, and employment of a fast field-cycling device has enabled the field dependency of the SABRE enhancement of 1,2,3-triazole to be measured and compared to theoretical values [47]. The pre-catalyst [Ir(IMes)(COD)Cl] was employed. The field cycling device enabled the transfer of the hyperpolarised solution from the polarisation transfer field to the measurement field in $0.5 \mathrm{~s}$, which is quicker than the conventional transfer method of inserting the sample manually (generally in the order of seconds). Resultantly, the field dependency of 1,2,3-triazole showed a single maxima at 6 $\mathrm{mT}$ with a corresponding enhancement value of 600 -fold. The experimental and theoretical data showed very good agreement, and again showed that a single LAC region existed over the field range explored $(0-15 \mathrm{mT})$. A single LAC was also observed for the hydride ligands of the polarisation catalyst, and the maxima was again observed at $6 \mathrm{mT}$, although unlike 1,2,3-triazole, this maxima was positive rather than negative.

\section{Automated delivery of SABRE hyperpolarised samples using a}

\section{Polarizer}

The nature of the polarisation transfer in SABRE, namely shaking the tube in a fringe field of a superconducting magnet, before transfer into the measurement field, has led some to groups to evaluate other strategies to transfer the hyperpolarised solution into the magnet. Duckett and coworkers have described how a reaction cell has been interfaced with an NMR spectrometer (equipped with a flow NMR probe that has a head flow volume of $200 \mu \mathrm{L}$ ) to measure both the sample hyperpolarisation level and the nuclear spin states [27]. The reaction cell is housed within a magnetic coil that is capable of generating a magnetic field up to $150 \mathrm{G}$ in the vertical direction only. The setup enables a predefined magnetic field to be established prior to bubbling parahydrogen through a solution for a set period of time (10 s was used at a pressure of $2 \mathrm{bar}$ ). Using this setup, ${ }^{1} \mathrm{H}$ NMR spectra were obtained for hyperpolarised pyridine over the range of 0 (magnetic coil turned off) - $150 \mathrm{G}$. The ortho- and para- peaks mirror one another in terms of the direction (all emission) and relative size of the signals produced. A maximum was observed at $65-70 \mathrm{G}$. The meta-signal, also had a maximum enhancement following polarisation transfer at $65-70 \mathrm{G}$, however, the signal direction flipped to being purely absorption at $15 \mathrm{G}$ from emission.

The reaction cell linked to a flow-probe (often referred to as the Polarizer) can be fully automated when interfaced with the NMR hardware correctly and the appropriate pulse sequences used [48]. This circumvents experimental error associated with initiating polarisation transfer by shaking the sample tube and also the transfer of the sample to the measurement field. This setup has been used to probe the magnetic states of nicotinamide, and to optimise the conditions under which polarisation can be transferred most effectively. Increasing the parahydrogen pressure from 0.5 to 5 bar (limit of the equipment) showed an increase in the signal intensity from ca. 150-fold to ca. 850fold for the four proton environments of nicotinamide. These measurements were conducted using a parahydrogen purge time (the time that parahydrogen is flowed through the reaction chamber) of $6 \mathrm{~s}$. In a separate experiment, increasing the parahydrogen purge time from 1 to $30 \mathrm{~s}$ showed a 
general increase with evidence for plateauing between 20 and $30 \mathrm{~s}$. The concentration of the polarisation transfer catalyst, [Ir(IMes)(COD)Cl], was found to affect the build-up of polarisation in nicotinamide and the resulting enhancement. This is because the catalyst not only facilitates polarisation transfer, but also accelerates $T_{1}$. Both of these factors are concentration dependent. Using the Polarizer, the production of higher order spin terms via SABRE was probed using OPSY [38, 39]. The hard pulses of the OPSY sequence were exchanged for selective pulses so that individual resonances could be excited. Thus, the longitudinal four-spin order term, the four longitudinal threespin order terms and the six longitudinal two-spin order terms were all detected and their relative signal enhancements reported. The relative amplitudes decrease with the increasing number of spins involved in the spin order term.

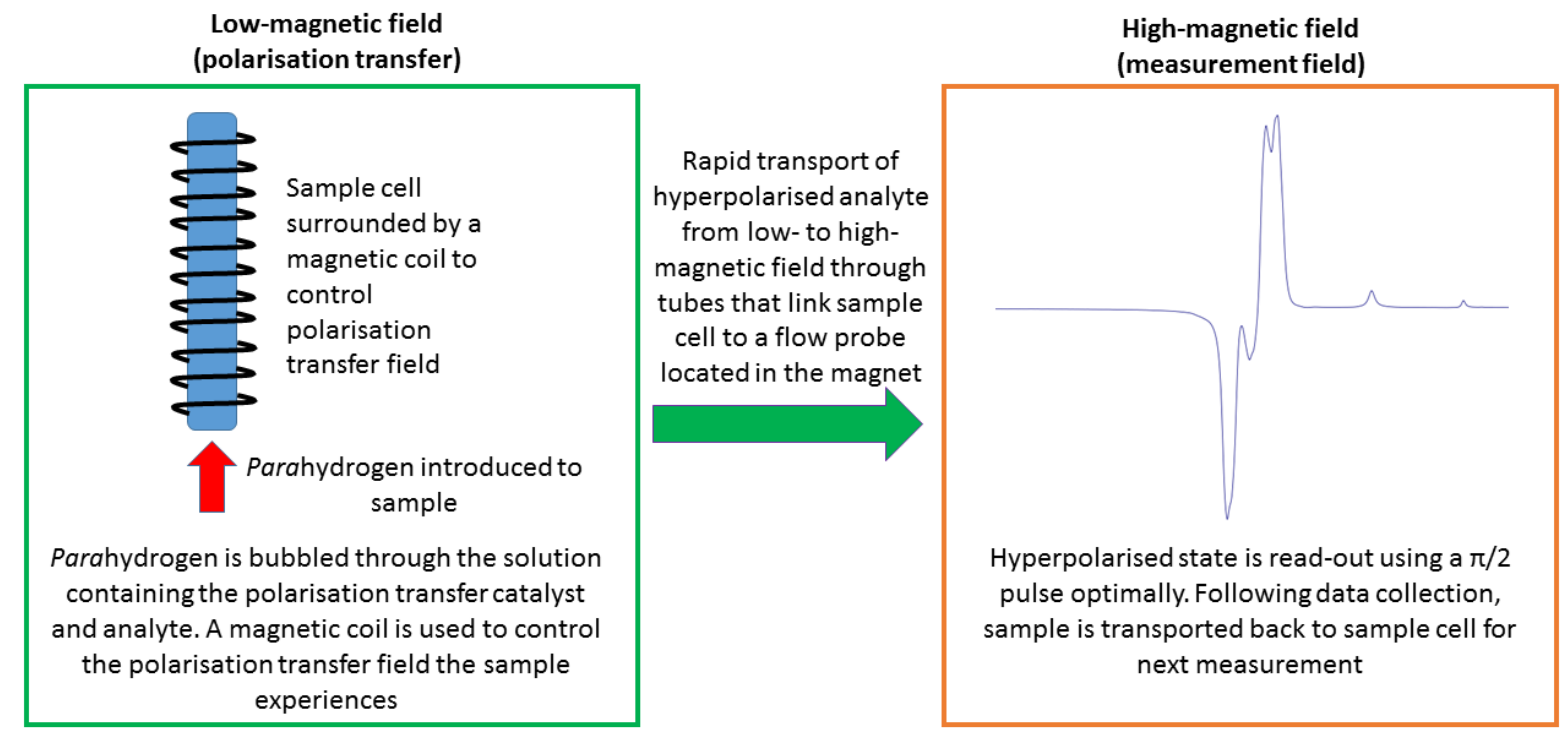

Figure 10. Overview of the Polarizer

\section{High-field SABRE}

Normally, polarisation transfer from parahydrogen derived hydrides to nuclei in a desired analyte is transferred at low magnetic field (typically less than $150 \mathrm{G}$ ). Polarisation within the field of the spectrometer (e.g. 9.4 T) was originally thought not to result in SABRE. However, Chekmenev and coworkers have shown that it is possible to generate SABRE-derived signals in a high-field instrumentation using the [Ir(IMes)(COD)Cl] template [49]. Compared to performing the polarisation transfer at low-field, only the ortho-signals of pyridine (4-fold enhancement) were significantly enhanced following 2 minutes of parahydrogen being bubbled through the solution. The rate of signal build-up, $T_{\mathrm{b}}$, was found to be $21 \pm 2 \mathrm{~s}$ which mirrors that of the $T_{1}(19 \pm 1 \mathrm{~s})$. Nuclear spin cross-relaxation was suggested as the mechanism for polarisation transfer. This was later confirmed by Pravdivstev et al. through a theoretical and experimental approach [50]. The analysis of $d_{5}$ pyridine also highlighted that $\mathrm{H} / \mathrm{D}$ exchange was occurring due to the formation of $d_{4}$-pyridine over a number of hours. $H / D$ exchange is unlikely to contribute significantly to the hyperpolarisation process.

High-field SABRE has been further investigated using RF saturation studies [51]. Application of a frequency-selective saturation RF pulse at the hyperpolarised hydride resonance frequency during 
polarisation transfer resulted in diminished signal intensities for the ortho-hydrogen peak and the hydride peak even when using a soft ( $\mathrm{B} \sim 7.5 \mathrm{~Hz}$ ) RF saturation. In addition, the use of a relatively strong RF saturation $\left(B \sim 2.4 \times 10^{2} \mathrm{~Hz}\right.$ ) resulted in significant reduction of the high-field SABRE enhancement. Similar effects were seen by applying the RF saturation pulse to the orthohydrogen signal, whereas shifting the RF saturation to the ortho ${ }^{1} \mathrm{H}$ NMR signal of pyridine resulted in suppression of the ortho free pyridine ${ }^{1} \mathrm{H}$ NMR signal and that of the exchangeable pyridine signal bound to the catalyst. These results reinforce the proposed nuclear dipolar cross-relaxation mechanism for polarisation transfer.

It has subsequently been demonstrated that high-field SABRE can be much improved by using a spinlock $[52,53]$. Following bubbling a sample containing $[\operatorname{Ir}(\mathrm{IMes})(\mathrm{COD}) \mathrm{Cl}]$ and pyridine with parahydrogen gas, a RF-field with amplitude $v$ and frequency $v_{\mathrm{rf}}$ was turned on for $\tau_{\mathrm{rf}}$ (which is smaller than the relaxation time of the protons in free pyridine and comparable to the relaxation time of the pyridine protons in the active complex). Enhancements of $c a .360$ were obtained for the single proton of 3,4,5,6- $d_{4}$-pyridine which are larger than those of high-field SABRE without RF excitation [49]. Pyridine, 3-methyl-1H-pyrazole, 4,4'-bipyridine and 2,2'-bipyridine were also polarised using this technique. The method exploits the mixing of spin states at Level Anti-Crossings (LACs) as identified from the doubly tilted frame (DTF) schematic representations; fulfilling the LAC conditions by utilising the appropriate RF-field results in the observation of polarisation transfer. The phase of the spectrum can be controlled by using the appropriate $v_{\text {rf }}$ to select the corresponding LAC.

High-field SABRE has been combined with a continuous hyperpolarisation approach to collect 2D ${ }^{1} \mathrm{H}$ NMR spectra of complex mixtures in the nanomolar range [54]. The pulse sequence used is detailed in Figure 11 and utilised a $1 \mathrm{~s}$ parahydrogen bubbling time. This approach specifically focused on the bound substrate and hydride signals generated and as such, did not require stringent conditions such as the employment of selective radiofrequency irradiation to collect the data. $\mathrm{A}^{1} \mathrm{H}-{ }^{1} \mathrm{H}$ COSY NMR spectrum was acquired in 23 minutes of a mixture of thirteen substrates at concentrations between $250 \mathrm{nM}$ and $2 \mu \mathrm{M}$. Cross peaks were generated between the substrate proton nuclei and those of the parahydrogen derived hydrides which are typically ${ }^{4} \mathrm{JHH}_{\mathrm{HH}}$ Compared to the corresponding $1 \mathrm{D}^{1} \mathrm{H}$ NMR spectrum of the aromatic region (which took 9.5 hours of measurement time to obtain a sufficient signal-to-noise ratio for analysis), all the hydride signals are resolved in the COSY spectrum and thus this approach circumvents extensive signal crowding. Linear plots of the 2D signal intensities were utilised in standard addition curves which enabled the concentrations of substrates, such as (-)-cotinine and methyl nicotinate, to be determined in good agreement with the nominal values. 

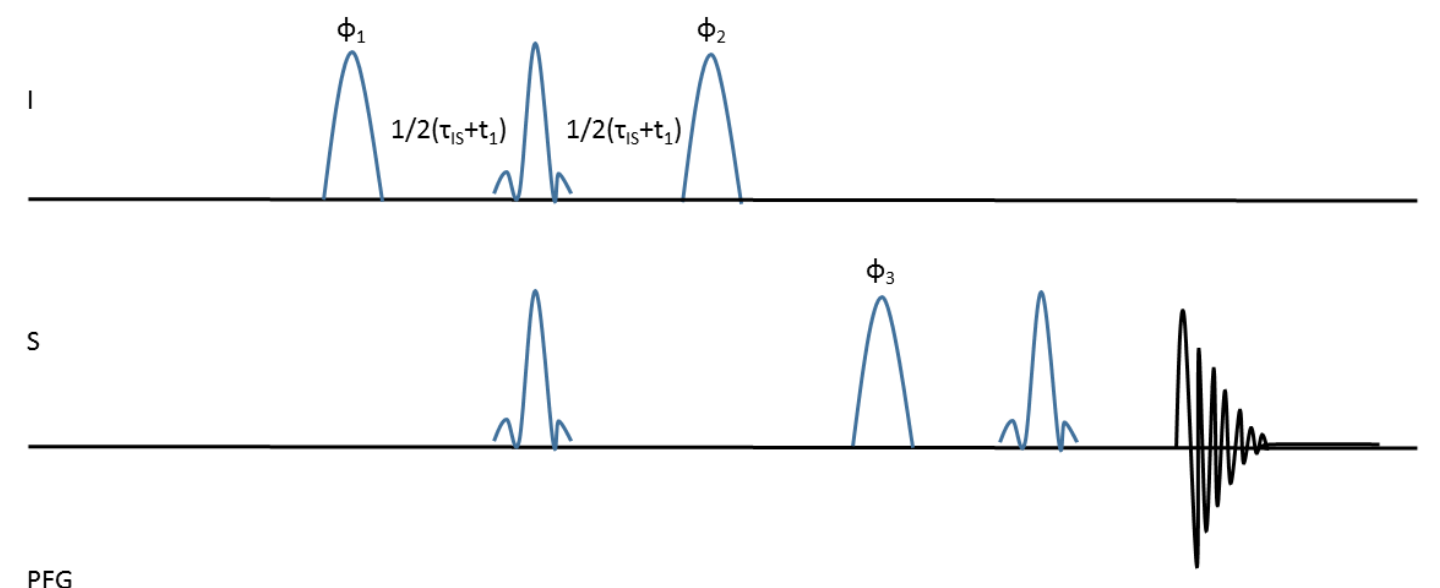

PFG

Figure 11. Pulse scheme for continuous hyperpolarisation at high-field developed by Tessari and co-workers [54]. The different $\phi$ values are for the phase cycling implemented. $\tau_{I S}$ is $1 / 2 J_{A X}$, where $J_{A X}=8 \mathrm{~Hz}$ (hydride-hydride coupling)

This approach has been extended to provide NMR-based chemosensing of natural extracts, namely those contained within ground coffee [55]. High-field parahydrogen enhanced 2D correlation spectra linked the hydride signals with substrates bound trans to them in the $\left[\operatorname{Ir}(\mathrm{IMes})(\mathrm{H})_{2}(\mathrm{sub})(\mathrm{mtz})_{2}\right]^{+}$complexes that formed (mtz used as a co-substrate). This again simplified spectra to overcome spectral crowding. The chemosensory response is effectively the generation of two hydride signals that results when a substrate species associates with the complex, which are unique to that complex. Furthermore, as the hydride signals are derived from parahydrogen, substantial signal-to-noise results. Using this approach, in conjunction with standard addition curves, substrates such as 3-hydroxypyridine, pyridine, pyrazine and 2-methylpyrazine were detected in the micromolar regime.

A further high-field study using 2D NMR has been reported that focuses on heteronuclear data collection [56]. A pulse sequence was developed, SABRE-HETCOR, that makes use of the SABREINEPT sequence [25]. Unlike PH-INEPT and PH-INEPT+, which transfer polarisation only to the bound substrate, SABRE-INEPT, enables efficient transfer to the free form of the substrate. This was exemplified for ${ }^{15} \mathrm{~N}$-pyridine and ${ }^{15} \mathrm{~N}_{2}$-imidazole. Using a theoretical description of the underlying spin dynamics and chemical kinetics of SABRE [57], the ${ }^{15} \mathrm{~N}$ polarisation of ${ }^{15} \mathrm{~N}$-pyridine formed via the SABRE-INEPT pulse sequence was probed. Experimentally, the ${ }^{15} \mathrm{~N}$ signal of free pyridine was enhanced by 200 fold and the lifetime of the hyperpolarisation calculated to be either $10 \mathrm{~s}$ for when [free-pyridine] : [equatorially bound pyridine] is $10: 1$ or $100 \mathrm{~s}$ for when [free-pyridine] : [equatorially bound pyridine] is $20: 1 . \mathrm{A}^{15} \mathrm{~N}-{ }^{1} \mathrm{H}$ 2D NMR spectrum obtained using SABRE-HETCOR revealed three cross-peaks for a solution of $2 \mathrm{mM}^{15} \mathrm{~N}$-pyridine in the presence of hydrogen and the pre-catalyst [Ir(IMes)(COD)Cl]; two for equatorially bound pyridine and one for free-pyridine. This spectrum was collected in 64 transients with 8 scans per transient. An advantage of the technique is not having to wait several $T_{1}$ periods prior to collecting the next scan; simply bubbling parahydrogen though the solution for a few seconds is sufficient to begin a new acquisition. 


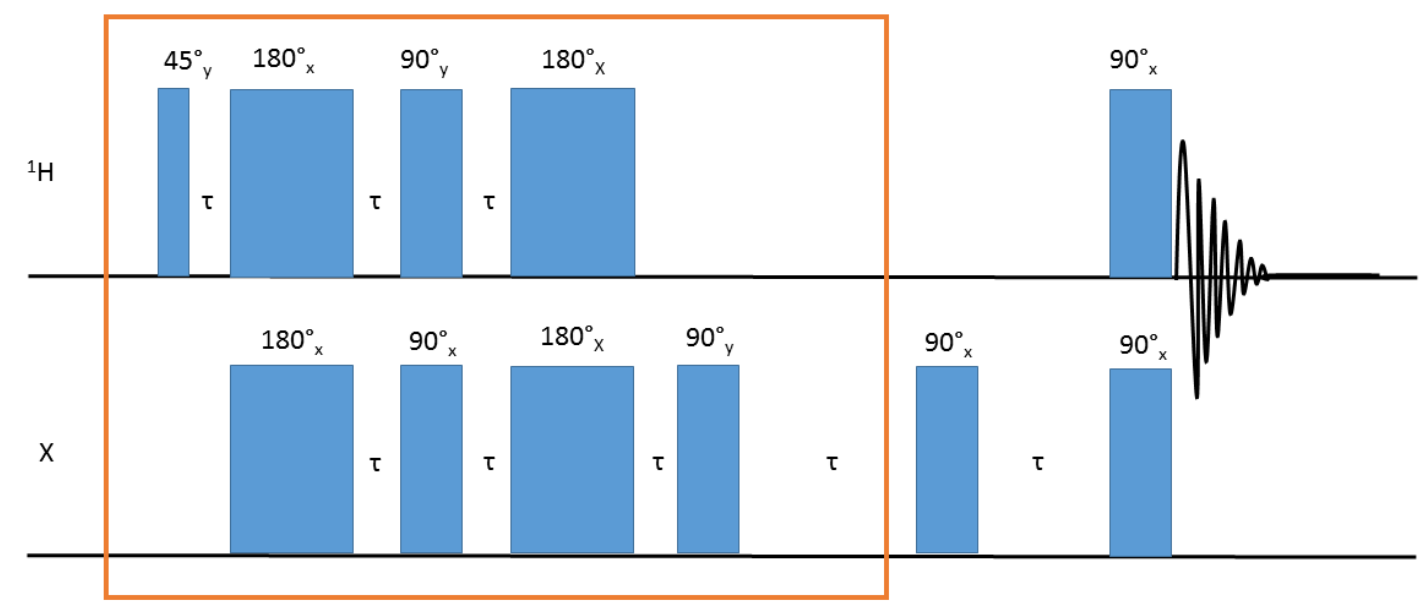

Figure 12. SABRE-HETCOR pulse sequence. The boxed component is the SABRE-INEPT sequence.

The $\left[\operatorname{Ir}(\mathrm{IMes})(\mathrm{H})_{2}(\mathrm{mtz})_{2}(\mathrm{py})\right]^{+}$system, along with $\left[\operatorname{Ir}(\mathrm{SIMes})(\mathrm{H})_{2}(\mathrm{mtz})_{2}(\mathrm{py})\right]^{+}$, have been the focus of a study in which EXSY data were collected in a short experimental time using a high-field hyperpolarisation-EXSY pulse sequence [58]. As the pulse sequence relies upon the hyperpolarisation of the hydrides, there is no requirement for excessively long recycle delays. Enhanced substrate proton magnetisation is obtained following a COSY-type coherence transfer from the hyperpolarised hydride ligands. The magnetisation of the bound substrate is $c a$. 100 times larger than thermal magnetisation. As the pulse sequence employs phase cycling only signals originating from the hyperpolarised hydrides are detected. Using the sequence meant that for a whole series of exchange periods, the total experiment time was only ten minutes. In addition, the high signal-to-noise ratio obtained due to hyperpolarisation, meant that relatively dilute solutions (e.g. $250 \mu \mathrm{M}$ of pyridine) could be studied. Pyridine dissociation rates of $0.19 \mathrm{~s}^{-1}$ and $0.66 \mathrm{~s}^{-1}$ for $\left[\operatorname{Ir}(\mathrm{IMes})(\mathrm{H})_{2}(\mathrm{mtz})_{2}(\mathrm{py})\right]^{+}$and $\left[\operatorname{Ir}(\mathrm{SIMes})(\mathrm{H})_{2}(\mathrm{mtz})_{2}(\mathrm{py})\right]^{+}$respectively, which are in good agreement with reported estimates [59]. The pulse sequence can be used to measure dissociation rates between $0.1 \mathrm{~s}^{-1}$ and $3 \mathrm{~s}^{-1}$, beyond this longitudinal relaxation of the substrate proton magnetisation limits transfer magnetisation to the free substrate. For much faster dissociation rates (i.e. $<0.1 \mathrm{~s}^{-1}$ ), the efficiency of the COSY-transfer reduces, leading to a fall in experiment sensitivity and signal-tonoise gain offered by hyperpolarisation.

Strong enhancements for pyridine have been observed in ${ }^{15} \mathrm{~N}$ NMR spectrum using high-field SABRE [60]. Free pyridine was enhanced by 800 -fold whereas the equatorially bound pyridine ligands in $\left[\operatorname{lr}(\mathrm{IMes})(\mathrm{py})_{3}(\mathrm{H})_{2}\right]^{+}$were enhanced by 12000 -fold. Analogous results were obtained when Crabtree's catalyst was employed. An RF field was used to excite the frequency of the hydrides in the ${ }^{1} \mathrm{H}$ domain whereas the frequency of the ${ }^{15} \mathrm{~N}$ RF-field was varied so that the spin system passed through a LAC for coherent spin mixing. The pulse sequence is outlined in Figure 13. As the experiment uses a low RF-excitation bandwidth, polarisation cannot be transferred over a wide range of chemical shifts. However, the method does use low RF powers and so heating of the sample does not occur. 


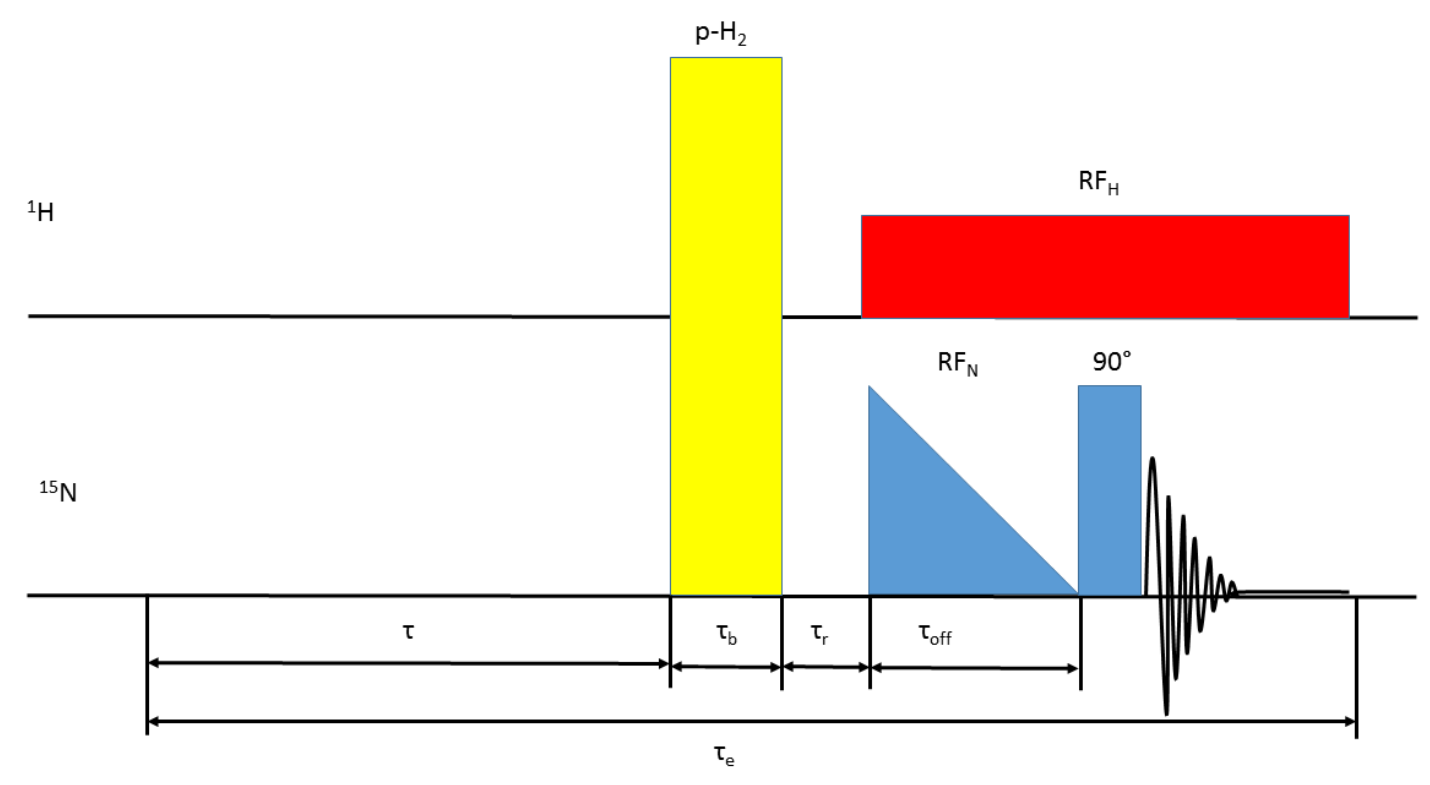

Figure 13. Transfer of polarisation to ${ }^{15} \mathrm{~N}$ at high-field developed by Ivanov and co-workers [60]. $\tau_{1}$ is the time to relax to thermal equilibrium, $\tau_{b}$ is the parahydrogen bubbling time, $\tau_{r}$ is the wait time to allow bubbles to escape from solution, $\tau_{\text {off }}$ is the time taken for the $\mathrm{RF}_{\mathrm{N}}$-field to linearly reduce to zero and $\tau_{\mathrm{e}}$ is the total experiment time.

\section{Employment of SABRE to polarise spin- $1 / 2$ nuclei}

Many spin- $1 / 2$ nuclei have been polarised by SABRE, namely ${ }^{1} \mathrm{H},{ }^{13} \mathrm{C},{ }^{15} \mathrm{~N},{ }^{19} \mathrm{~F},{ }^{31} \mathrm{P},{ }^{29} \mathrm{Si}$ and ${ }^{119} \mathrm{Sn}$. This section will look at each nucleus individually and detail the discoveries. The applications for which these nuclei are being hyperpolarised by SABRE will also be described.

\section{Polarisation transfer to ${ }^{1} \mathrm{H}$}

The polarisation of ${ }^{1} \mathrm{H}$ nuclei by SABRE has been exemplified for a number of applications. These include the hyperpolarisation of biologically relevant materials and the detection of analytes at low concentration or magnetic field, utilising 1D or 2D NMR spectroscopy.

Detection of analytes in complex mixtures or at low concentration

Tessari and co-workers have investigated the use of SABRE to hyperpolarise a complex mixture and, using standard-addition curves, quantify the original amount of analyte present [61]. The complex mixture consisted of sixteen readily polarisable analyte molecules. To exemplify their developed methodology, the original concentrations of nicotinamide, pyrazine, isoxazole and quinazoline were determined using ${ }^{1} \mathrm{H}$ NMR spectroscopy. These were determined experimentally to have reasonable agreement with the expected amount of analyte present in the original sixteen-component mixture. It must be noted that the original concentration was only an estimate based on an integral comparison between the analyte of interest and the methylene signal of ethanol, which was added as an internal reference. Thus, these data demonstrate that SABRE can be used to not only detect analytes in the micromolar regime but also to quantify them.

A further work by Tessari and co-workers has explored the use of SABRE towards nanomolar detection [59]. In order to achieve this aim, a co-substrate needs to be used based on experimental data which shows that below $25 \mu \mathrm{M}$ of pyridine, SABRE effectively ceases as all the pyridine ligands are free in solution (a $12.5: 1$ ratio of pyridine : [Ir(IMes)(COD)Cl] was used). Essentially, solvent molecules (in this instance methanol) compete with the analyte for binding sites on the catalyst, and this effect is more apparent at low concentrations of analyte. 1-methyl-1,2,3-triazole, mtz, was selected as a co-substrate as, in addition to other factors, it binds more strongly to the catalyst than 
the solvent and does not possess signals that overlap with that of the analyte pyridine. The use of a co-substrate led to the observation of two new complexes in solution $\left[\operatorname{Ir}(\operatorname{IMes})(\mathrm{mtz})_{2}(\mathrm{py})\right]^{+}$and $\left[\mathrm{Ir}(\mathrm{IMes})(\mathrm{mtz})(\mathrm{py})_{2}\right]^{+}$. A sample consisting of $2 \mu \mathrm{M}$ of pyridine, $2 \mathrm{mM}$ of $[\mathrm{Ir}(\mathrm{IMes})(\mathrm{COD}) \mathrm{Cl}]$ and $13 \mathrm{mM}$ of mtz gave a signal-to-noise ratio of $8: 1$ for pyridine after addition of parahydrogen, thus establishing the validity of using a co-substrate. A linear dependence was found to exist between SABRE linked signal intensity and substrate concentration in the low micromolar regime. It was, therefore, postulated that detection of $100 \mathrm{nM}$ of pyridine should be possible.

\section{Low-field detection using SABRE}

Using a low-field setup, pyridine has been detected down in the nanolitre regime [62]. Pyridine was detected via SABRE using a home-built NMR spectrometer $\left(3.9 \mathrm{mT}, 166 \mathrm{kHz}{ }^{1} \mathrm{H}\right.$ resonance) and $\left[\operatorname{lr}(\mathrm{COD})\left(\mathrm{PCy}_{3}\right)(\mathrm{py})\right]\left[\mathrm{PF}_{6}\right]$ as the catalyst. Comparison of hyperpolarised ${ }^{1} \mathrm{H}$ NMR spectra relative to the corresponding thermal ${ }^{1} \mathrm{H}$ NMR spectra collected following pre-polarisation at $2 \mathrm{~T}$ revealed that, through the use of SABRE, $4.9 \mathrm{~nL}$ of pyridine could be detected in a single scan. Only when the volume was increased to $4.9 \mu \mathrm{L}$ could pyridine be detected in the thermal spectrum following prepolarisation at $2 \mathrm{~T}$. As only $50 \%$ parahydrogen was used in these experiments this, therefore, indicates a route to improve the signal further, in addition to the limit of detection.

The same low-field setup has been used to detect the drug molecules harmine (harmala alkaloid, used in the treatment of patients with Parkinson's disease), nicotine and morphine in the micromolar regime [63]. For $1 \mathrm{mg}$ of morphine, the hyperpolarised signal is as large as the thermal equilibrium signal that has been pre-polarised at $2 \mathrm{~T}$. Even after dilution by a factor of two, the resulting sample can still be detected due to the hyperpolarised signal produced. Due to the lowfield nature of these measurements, it was not possible to fully discern the chemical nature of the nuclei responsible for generating the signal, although tentative assignments were possible. For example, for nicotine, an in-phase doublet was observed following polarisation transfer with a splitting of $0.95 \mathrm{~Hz}$. This equates to a chemical shift difference of $5.7 \mathrm{ppm}$. Therefore, this chemical shift difference could relate to the aromatic as well as aliphatic regions of the molecule. Similarly, the hyperpolarised spectrum of harmine possessed an anti-phase doublet with a splitting of $0.64 \mathrm{~Hz}$ (3.9 ppm). However, tentative assignments are not possible for morphine as the corresponding ${ }^{1} \mathrm{H}$ NMR spectrum possessed only a single in-phase signal.

\section{Hyperpolarisation of biologically relevant materials}

The polarisation of amino acids and some representative small peptides using SABRE has been explored by Appelt and co-workers [64]. A home-built NMR spectrometer was again used to conduct the measurements at $3.9 \mathrm{mT}$. Using Crabtree's catalyst as the polarisation transfer template, enhanced signals were obtained. In particular, an anti-phase signal was obtained which was ruled not to be due to hydride as it did not possess the ${ }^{2} \mathrm{~J}_{\mathrm{HP}}$ splitting recorded in thermal ${ }^{1} \mathrm{H}$ NMR spectra. High-field ${ }^{1} \mathrm{H}$ NMR data indicated that glycine was not chemically changed during the SABRE process and is not permanently bound to the catalytic template. Two peptides, GlyGly and ProHisLeu were also polarised by this technique, but highlighted the need for water soluble catalysts as their solubility in $d_{4}$-methanol was poor.

Building on this work, oligopeptides have also been successfully polarised by SABRE [65]. The oligopeptides were effectively SABRE-labelled with nicotinamide or isonicotinamide. The investigated models are shown in Figure 14. For all the investigated oligopeptides, no signal enhancement was observed for the peptide unit. However, the pyridyl motif did polarise with enhancements of $15-25$-fold being recorded. These decreased to about $10 \%$ of their value from moving from $d_{4}$-methanol to a $50: 50 d_{4}$-methanol : $\mathrm{D}_{2} \mathrm{O}$ mix. 
<smiles>CC(NC(=O)CNC(=O)c1ccncc1)C(=O)NCC(N)=O</smiles>

4PyGAG<smiles>CC(NC(=O)c1ccncc1)C(=O)NCC(N)=O</smiles>

4PyAAG<smiles>CC(NC(=O)CNC(=O)c1cccnc1)C(=O)NCC(N)=O</smiles>

3PyGAG<smiles>CC(NC(=O)c1cccnc1)C(=O)NC(C)C(=O)NCC(N)=O</smiles>

3PyAAG

Figure 14. Oligopeptide models investigated by Ratajczyk et al. [65].

In a further study, the hyperpolarisation of eNOS (endothelial Nitric Oxide Synthase) substrates were investigated to quantify the production of NO using ${ }^{1} \mathrm{H}$ NMR spectroscopy [66]. Two generations of eNOS substrates were synthesised; the first generation were focused on the use of a L-arginine carboxylic function to introduce a pyridyl binding group, whereas the second generation made use of $\mathrm{N}^{\omega}$-hydroxy-L-arginine (L-NOHA) to incorporate the pyridyl ring. When these substrates were hyperpolarised, it was generally found that the 4-substituted pyridines produced better enhancements in earth's magnetic field whereas the 3-substituted pyridines were enhanced better at $65 \mathrm{G}$. The addition of deuterated acetonitrile as a co-ligand, resulted in slightly improved polarisation for the sterically more encumbered substrates. The best enhancement obtained was for the derivative shown in Figure 15, which gave an enhancement of 870-fold for the four pyridyl ring protons after polarisation transfer in earth's magnetic field. This reduced to 322 -fold in the presence of $d_{3}-\mathrm{MeCN}$. However, for the dipeptide derivatives, no significant enhancement was observed, most likely due to steric hindrance around the binding site. Of the three second generation substrates produced, only the one possessing a guanidyl group showed SABRE derived enhancement and this was small ( $c a$. 50-fold following polarisation transfer in earth's magnetic field). It was hypothesised that as the other two second generation substrates possessed a hydroxyl-guanidyl group that, despite being less basic than a guanidyl group, they may bind to the metal in a stronger manner, therefore, leading to partial or full inactivation of the catalyst. All of the substrates led to comparable or higher NO production by eNOS than L-arginine. These substrates could, therefore, be potentially used to monitor NO production in in vivo. However, both the signal enhancement and the longevity of the hyperpolarised signal ( $T_{1} \mathrm{~S}$ of the pyridyl protons of the substrate in Figure 15 were only $3.2-3.3 \mathrm{~s}$ at physiological $\mathrm{pH}$ ) would need to be improved.<smiles>N=C(N)NCCC[C@H](N)C(=O)Nc1ccncc1</smiles>

Figure 15. Chemical structure of the pyridyl labelled L-arginine substrate synthesised and polarised by Zanda and coworkers [66].

The tuberculosis drugs pyrazinamide and isoniazid (Figure 16) have been polarised by SABRE in a range of solvents (methanol, $d_{4}$-methanol, ethanol and DMSO) [67]. A Polarizer as described in the section entitled "Automated delivery of SABRE hyperpolarised samples using a Polarizer" was used for these experiments. In addition to the usual setup, a home-built water bath was used to control 
the temperature of the system. The enhancement of the three ${ }^{1} \mathrm{H}$ nuclei in pyrazinamide showed a v-curve dependency with respect to the magnetic-field used for the polarisation transfer. All of these curves indicated that optimum polarisation transfer occurred at $65 \mathrm{G}$. Of the four solvents used, $d_{4^{-}}$ methanol led to the best enhancement being obtained ( $>60$-fold at room temperature). Use of DMSO only led to an enhancement of $c a$. 7-fold and hence is less suitable as a solvent in which to polarise pyrazinamide. Furthermore, polarisation transfer studies using DMSO were only conducted at high temperatures $\left(28.7^{\circ} \mathrm{C}\right.$ or above), with the maximum enhancement being achieved at $37.5^{\circ} \mathrm{C}$. A temperature of $37.5^{\circ} \mathrm{C}$ also resulted in optimal polarisation transfer for when ethanol was the solvent whereas methanol and $d_{4}$-methanol required a much higher temperature $\left(46.1^{\circ} \mathrm{C}\right)$. The latter, however, did yield an enhancement of 1400-fold for the isolated ortho-proton after polarisation transfer at $65 \mathrm{G}$. In the case of isoniazid, polarisation transfer was again optimised at a field of $65 \mathrm{G}$, where the ortho-proton nuclei were enhanced by $c a$. 60 -fold. Similar solvent dependence was observed for methanol, ethanol and DMSO as was seen for pyrazinamide. However, for all three solvents the best enhancement was observed at $46.1^{\circ} \mathrm{C}$. Use of this temperature to conduct polarisation transfer at $65 \mathrm{G}$ revealed that the ${ }^{1} \mathrm{H}$ NMR signal of the orthoprotons were enhanced by 230 -fold. Thus, given these data, pyrazinamide reflects the better spinsystem to polarise by SABRE.<smiles>NNC(=O)c1ccncc1</smiles>

Figure 16. Chemical structures of pyrazinamide (left) and isoniazid (right)

\section{D and 2D NMR investigations}

Quinoline has been the subject of a 1D and 2D NMR investigation, that employs the Polarizer to automate the collection of resulting spectra [68]. The ${ }^{1} \mathrm{H}$ NMR spectrum of quinoline following polarisation transfer in a $50 \mathrm{G}$ using $[\mathrm{Ir}(\mathrm{IMes})(\mathrm{COD}) \mathrm{Cl}]$ revealed that polarisation is transferred to the fused secondary ring, as well as the primary ring containing the ligating nitrogen atom. Perhaps more interesting is the fact that some of the ${ }^{1} \mathrm{H}$ NMR signals on the secondary ring are more enhanced than on the primary ring. The ortho-signal on the primary ring was enhanced by 60 -fold (signal-to-noise $730: 1$ ) when detecting $2 \mu \mathrm{mol}$ of quinoline. Changing the length of time that hydrogen was bubbled through the solution (from $6 \mathrm{~s}$ to $20 \mathrm{~s}$ ) increased the signal enhancement by a further 2.6. Reducing the amount of quinoline further to $0.2 \mu \mathrm{mol}$ resulted in a single-to-noise ratio of $15: 1.20 \mathrm{nmol}$ of nicotinamide could similarly be detected to give a signal-to-noise ratio of $60: 1$. A 1D NOE NMR spectrum of the $2 \mu \mathrm{mol}$ quinoline sample was collected using four polarisation transfer steps (the steps as outlined in Figure 10 was completed four times). Using a $1.5 \mathrm{~s} \mathrm{NOE}$ evolution time and exciting the $\mathrm{H}(4)$ resonance, led to a cross-peak at the resonant frequency of $\mathrm{H}(5)$ with an intensity of $0.9 \%$. Using thermal polarisation, a similar signal-to-noise was achieved after 15000 scans. Furthermore, the thermal spectrum took 20 hours to acquire whereas the polarised spectrum (which includes transfer of the hyperpolarised solution to and from the magnet to the Polarizer) took $81 \mathrm{~s}$. A hyperpolarised 2D OPSY-COSY NMR spectrum was also collected. The spectrum was collected using a parahydrogen bubbling time of $2 \mathrm{~s}$ and 64 increments, to give a total experiment time of 16 minutes. The incorporation of OPSY resulted in cross-peak encoding being optimised at the start of the COSY sequence thus maximising the observation of cross-peaks over the diagonal. Although the time of this experiment is relatively long, it was also demonstrated that a 
hyperpolarised ultrafast COSY could be collected on a $6 \mu \mathrm{mol}$ sample of quinoline in a single transient.

A further study also utilised ultrafast methods to obtain 2D spectra in one scan [69]. Initially bipyridine (bpy) was studied using pyridine as a co-substrate. The large enhancement of the orthopyridyl ${ }^{1} \mathrm{H}$ NMR signal obscured the $\beta-{ }^{1} \mathrm{H}$ of bpy, preventing its facile detection. This was circumvented by using $d_{5}$-pyridine; this led to the $\alpha$-protons of bpy increasing in signal strength from 86 -fold to 140 -fold. An ultrafast ${ }^{1} \mathrm{H}-{ }^{1} \mathrm{H}$ COSY spectrum of this solution was acquired and, due to the use of a co-substrate, enabled bpy to be detected at sub-micromolar concentrations. A mixture of five different substrates was then examined. The solution consisted of bipyridine (bpy), pyridine, nicotinamide, $\mathrm{N}, \mathrm{N}$-dimethylnicotinamide, 2,- 3,- and 4-ethylpyridine in concentrations of the order of $0.5 \mathrm{mM}$. The ultrafast single scan ${ }^{1} \mathrm{H}-{ }^{1} \mathrm{H}$ COSY spectrum obtained, following polarisation transfer is of good quality and enables all but one of the $\mathrm{N}$-heterocycles to be detected despite the convoluted nature of the corresponding $1 \mathrm{D}^{1} \mathrm{H}$ NMR spectrum. The $\mathrm{N}$-heterocycle not to be detected was 2 ethylpyridine and this was proposed to be due to steric hindrance preventing binding to the catalyst, thus preventing polarisation transfer.

Pyridazine and phthalazine are a further two $N$-heterocycles that have been polarised by SABRE [70]. Both of these substrates display an interesting exchange dynamic; as well as dissociating from the metal catalyst, they also switch ligating atoms (haptotropic shift). Using EXSY, both processes were measured for [ $\operatorname{Ir}(\mathrm{COD}$ (IMes)(pyridiazine)]Cl and $[\operatorname{Ir}(\mathrm{COD}$ (IMes)(phthalazine)]Cl. The rate of the haptotropic shift is quicker for phthalazine $\left(13.4 \mathrm{~s}^{-1}\right.$ compared to $5.8 \mathrm{~s}^{-1}$ for pyridazine at $\left.255 \mathrm{~K}\right)$. Following Eyring analysis, the enthalpy of activation for the shift was greater for [Ir(COD(IMes)(pyridiazine)]Cl by $5 \mathrm{~kJ} \mathrm{~mol}^{-1}$ compared to [Ir(COD(IMes)(phthalazine)]Cl. This represents a stronger Ir-N bond existing in the pyridazine complex. When fully activated in the presence of hydrogen, the two ligands have comparable dissociation rates from the active form of the catalyst. However, they do not possess similar enhancements; a sample consisting of [ $\mathrm{Ir}(\mathrm{IMes})(\mathrm{COD}) \mathrm{Cl}](5.2 \mathrm{mM})$ and 5 equivalents of pyridazine gave a total enhancement of 410 -fold whereas the corresponding phthalazine produced only 195-fold. Furthermore, unlike quinoline [68], the remote ring is only weakly polarised (ca. $14 \%$ relative to the primary ring). The stronger, and therefore shorter, Ir-N bond in the pyridazine system, may result in improved $\mathrm{J}$-coupling strength to propagate polarisation relative to the phthalazine system. ${ }^{1} \mathrm{H}$ MR images of pyridazine and phthalazine were also acquired. The signal-to-noise intensities in these images reflect the signal enhancements observed in the polarised ${ }^{1} \mathrm{H}$ NMR spectra.

Duckett and co-workers have reported on the synthesis of the COE (cyclooctene) derivatives of $[\operatorname{Ir}(\mathrm{IMes})(\mathrm{COD}) \mathrm{Cl}][71]$. Although it was reported that $\left[\operatorname{Ir}(\mathrm{IMes})(\mathrm{COE})_{2} \mathrm{Cl}\right]$ was unstable (despite forming $\left[\operatorname{Ir}(\mathrm{IMes})(\mathrm{H})_{2}(\mathrm{py})_{3}\right][\mathrm{Cl}]$ upon reaction with pyridine and $\left.\mathrm{H}_{2}\right)$, it was possible to treat [ $\left.\mathrm{IrCl}(\mathrm{COE})_{2}\right]_{2}$ with pyridine and $\mathrm{H}_{2}$ in $d_{8}-\mathrm{THF}$ which gave $\operatorname{IrCl}(\mathrm{H})_{2}(\mathrm{COE})(\mathrm{py})_{2}$. The chemical structure of this complex is shown in Figure 17. The pyridine dissociation rate was found to $7.8 \pm 0.1 \mathrm{~s}^{-1}$ at $298 \mathrm{~K}$; at this temperature the hydride exchange rate into $\mathrm{H}_{2}$ could not be determined. However, the two distinct hydride ligands interchanged at a rate of $3.6 \pm 0.1 \mathrm{~s}^{-1}$ whilst the $\mathrm{COE} \mathrm{CH}$ proton sites interchanged at a rate of $3.8 \pm 0.1 \mathrm{~s}^{-1}$. Changing the concentration of pyridine and $\mathrm{H}_{2}$ did not affect these ligand rates. In the SABRE enhanced ${ }^{1} \mathrm{H}$ NMR spectrum, the hydride, $\mathrm{COE}$ and pyridine ligands are all enhanced. The enhancement of pyridine was shown to be dependent on the concentration of pyridine; an 8-fold excess led to a 210-fold signal gain of the ortho-hydrogen of pyridine, whereas using a 5.6-fold excess, the enhancement increased to $>500$-fold. After a period of $24 \mathrm{hr}$, a new complex is observed to form due to the appearance of three new hydride signals. This complex 
proved to be $(\mathrm{Cl})(\mathrm{H})(\mathrm{Py}) \operatorname{Ir}(\mu-\mathrm{Cl})(\mu-\mathrm{H})\left(\mathrm{K}-\mu-\mathrm{NC}_{5} \mathrm{H}_{4}\right) \operatorname{Ir}(\mathrm{H})(\mathrm{py})_{2}$ and as such contained four distinct pyridine ligands. This complex is SABRE inactive but does catalyse $H-D$ exchange.
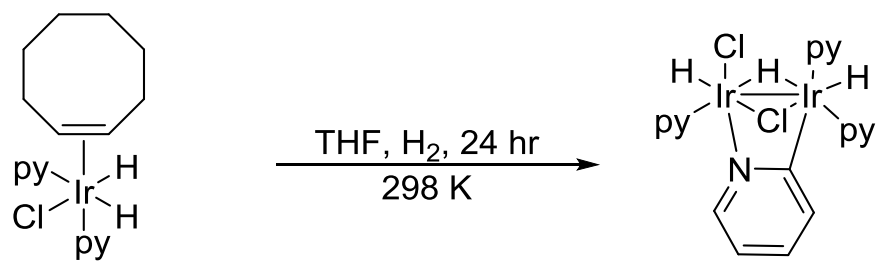

Figure 17. Reaction scheme for the formation of the SABRE-inactive binuclear complex from the mononuclear SABRE active complex prepared by Duckett and co-workers [71].

Polarisation transfer to ${ }^{13} \mathrm{C}$

Polarisation transfer to ${ }^{13} \mathrm{C}$ via SABRE was first exemplified using the $\left[\operatorname{Ir}\left(\mathrm{PC}_{3}\right)(\mathrm{COD})(\mathrm{py})\right]$ template [23]. $6 \mathrm{nmol}$ of pyridine were polarised in a $2 \times 10^{-2} \mathrm{~T}$ magnetic field to afford the ${ }^{13} \mathrm{C}\left\{{ }^{1} \mathrm{H}\right\} \mathrm{NMR}$ spectrum in a single scan. The meta-signal is the most intense, with the ortho- and para-signals being of similar intensity. In a separate study $50 \mu \mathrm{mol}$ of nicotinamide was polarised and a refocused ${ }^{13} \mathrm{C}\left\{{ }^{1} \mathrm{H}\right\}$ NMR spectrum collected. All six resonances were observed in a single transient, with the quaternary carbon of the amide being the least intense.

In order to determine a strategy to determine polarisation transfer to the two ${ }^{13} \mathrm{C}$ sites of acetonitrile, different isotopomers were polarised via SABRE and the results reported [72]. Deuterated acetonitrile resulted in no visible enhancement of either the ${ }^{13} \mathrm{C}$ site due to the absence of ${ }^{1} \mathrm{H}-{ }^{1} \mathrm{H}$ coupling between the parahydrogen derived hydrides and that of the substrate during polarisation transfer. Labelling the methyl group of acetonitrile with a ${ }^{13} \mathrm{C}$ label only resulted in a 14fold enhancement gain. The large ${ }^{1} J_{\mathrm{HC}}(\sim 145 \mathrm{~Hz})$ is not commensurate with the $J_{\mathrm{HH}}$ coupling that exists between the parahydrogen derived hydride and the proton nuclei of acetonitrile. Thus, it is hard to propagate polarisation to this site. However, ${ }^{13} \mathrm{C}$-labelling the nitrile group results in significant signal gains. Following polarisation transfer at earth's field, a single transient ${ }^{13} \mathrm{C}$ spectrum yields a signal-to-noise value of 105 for the quaternary carbon, which possesses anti-phase character. Furthermore, an antiphase signal is observed for acetonitrile ligands bound to the catalyst trans to hydride. In addition, it was shown that the ${ }^{13} \mathrm{C}$ enhancement and appearance over a range of polarisation transfer fields (earth's to $140 \mathrm{G}$ ) could be modelled theoretically and was in excellent agreement with experimental results.

The ${ }^{13} \mathrm{C}$ nuclei of nicotinamide have been the subject of a study in order to investigate ${ }^{13} \mathrm{C}$ polarisation [48]. Using the Polarizer (as detailed in the section entitled "Automated delivery of SABRE hyperpolarised samples using a Polarizer"), nicotinamide was polarised by setting the magnetic field to $70 \mathrm{G}$ and with the magnetic field switched off. Four-scan averages obtained revealed that polarisation transfer was superior in earth's magnetic field (magnetic field switched off). The signals were suitably more enhanced compared to polarisation transfer at $70 \mathrm{G}$. However, these spectra could be improved by using ${ }^{13} \mathrm{C}$ INEPTnd; in this instance polarisation transfer occurred at $70 \mathrm{G}$ to optimally polarise the ${ }^{1} \mathrm{H}$ nuclei in order to maximise the signal intensity of the ${ }^{13} \mathrm{C}$ sites following INEPT transfer. An evolution period of $12 \mathrm{~Hz}$ was used during the pulse sequence to optimise transfer further. All of the signals manifested in the ${ }^{13} \mathrm{C}$ spectrum presented as anti-phase signals.

The hyperpolarised single scan ${ }^{13} \mathrm{C}$ spectra of quinoline enables all nine of the expected signals to be observed, although the carbon located at the $C(2)$ position $(\delta 150.8)$ is significantly reduced [68]. In addition, the detected resonances appear with a degree of antiphase character. To improve the 
quality of the spectrum, and also the signal intensity of $C(2)$, INEPT was employed. A refocused single scan ${ }^{13} \mathrm{C}\left\{{ }^{1} \mathrm{H}\right\}$ INEPT NMR spectrum of $60 \mu \mathrm{mol}$ of quinoline acquired following polarisation transfer at $50 \mathrm{G}$ resulted in a signal-to-noise ratio of $40: 1 \mathrm{for} C(2)$. To achieve the same signal-to-noise ratio using thermal polarisation would take 4096 scans. Using the Polarizer, a ${ }^{13} \mathrm{C}-{ }^{1} \mathrm{H} \mathrm{HMBC}$ spectrum was collected on $2 \mu \mathrm{mol}$ of quinoline. The 32 increment spectrum was acquired using a single scan per increment, and from which, all nine of the ${ }^{13} \mathrm{C}$ signals were located. When the sample was polarised in earth's magnetic field the cross peaks derived from short range couplings, whereas when polarised at $60 \mathrm{G}$, the cross peaks derive from long-range couplings.

Polarisation of the aromatic ${ }^{13} \mathrm{C}$ sites of ${ }^{15} \mathrm{~N}$-labelled pyridine has also been probed via conventional SABRE and SABRE-SHEATH (readers are referred to the SABRE-SHEATH section for full details of the method) [73]. Conventional SABRE, following polarisation transfer at $6 \mathrm{mT}$, yields three antiphase signals. Using SABRE-SHEATH, these signals manifest as in-phase signals. However, the enhancements obtained were marginal; they were 7-fold or less. The signals obtained using conventional SABRE were visibly more enhanced. However, a later report optimised the conditions for transfer such that an enhancement of $c a .1900$-fold was obtained at $9.4 \mathrm{~T}$, which equates to $1.5 \%$ polarisation [74]. The magnitude of the enhancement was highest for the ortho-carbon site and lowest for the para-carbon site, which mirrored the size of the $J_{\mathrm{HC}}$ couplings between each site and that of the hydride. The relatively short ${ }^{13} \mathrm{C} T_{1} \mathrm{~S}$ at both earth's field and high-magnetic field (ca. 5-8 s) reduces the enhancement observed considerably. The conditions optimised included the temperature (maximum at $25^{\circ} \mathrm{C}$ ), the magnetic field in which polarisation was conducted (two maxima at $0.5 \mu \mathrm{T}$ and $-0.75 \mu \mathrm{T}$ ) and the flow rate at which the $7 \mathrm{~atm}$. of parahydrogen was delivered. The efficiency of polarisation transfer was also probed. It was found that the presence of ${ }^{14} \mathrm{~N}$ instead of ${ }^{15} \mathrm{~N}$ in the pyridine significantly reduced the efficiency of SABRE-SHEATH. As the orthocarbon signal was reduced, it was concluded that the quadrupolar ${ }^{14} \mathrm{~N}$ relaxation acts to as a sink for hyperpolarisation.

\section{Polarisation transfer to ${ }^{15} \mathrm{~N}$}

The effect on polarisation transfer using ${ }^{15} \mathrm{~N}$-labelled substrates was first exemplified using $\left[\operatorname{Ir}(\mathrm{COD})\left(\mathrm{PPh}_{3}\right)_{2}\right] \mathrm{BF}_{4}[25]$. In the presence of pyridine, $\left[\operatorname{Ir}(\mathrm{H})_{2}\left(\mathrm{PPh}_{3}\right)_{2}(\mathrm{py})_{2}\right]^{+}$and $\left[\operatorname{Ir}(\mathrm{H})_{2}\left(\mathrm{PPh}_{3}\right)(\mathrm{py})_{3}\right]^{+}$ were formed in methanol and were found to possess hydride resonances at $\delta-21.64$ and $\delta-21.80$ respectively. When ${ }^{15} \mathrm{~N}$-labelled pyridine was employed, the hydride resonances of both complexes were enhanced. Direct polarisation transfer to ${ }^{15} \mathrm{~N}$ was only reported to occur when specialised heteronuclear polarisation transfer experiments were utilised. Without them, no ${ }^{15} \mathrm{~N}$ signals of bound ${ }^{15} \mathrm{~N}$-labelled pyridine were visible after 1024 scans. The most efficient transfer of magnetisation was achieved using the PH-INEPT pulse sequence. This resulted in a signal-to-noise ratio of 27.9. The PH-INEPT pulse sequence was found to be superior to the PH-INEPT ${ }^{+}$experiment, as relaxation during the refocusing period led to only a third of the potential signal intensity surviving to the point of observation. The $\mathrm{PH}^{-I N E P T}{ }^{+}$pulse sequence yielded a signal-to-noise of 10.5 .

A further study utilised a zero-field magnetometer in which to detect the polarised signals of ${ }^{15} \mathrm{~N}$ pyridine following polarisation transfer by Crabtree's catalyst [75]. A DC magnetic-field pulse was used to convert the spin order involving heteronuclear pairs in to observable magnetisation. A 40 $\mathrm{mM}$ solution of hyperpolarised ${ }^{15} \mathrm{~N}$-pyridine possessed a signal-to-noise ratio of 300 . This contrasted with neat ${ }^{15} \mathrm{~N}$-pyridine $(14 \mathrm{M})$, which after the collection of 128 transients only produced a signal-tonoise ratio of 70 . A sensitivity gain of $\sim 1.7 \times 10^{4}$ was, therefore, obtained using SABRE. 


\section{LIGHT-SABRE}

The initial experiments to relating to the polarisation transfer to ${ }^{15} \mathrm{~N}$ have been significantly improved by employing LIGHT-SABRE (Low-Irradiation Generation of High Tesla SABRE) [76]. The coherent transfer of polarisation to the metal-bound ${ }^{15} \mathrm{~N}$-labelled pyridine was shown for the complex $\left[\operatorname{Ir}(\mathrm{IMes})(\mathrm{py})_{3}(\mathrm{H})_{2}\right]^{+}$. A continuous wave $(\mathrm{CW})$ was applied to the bound ${ }^{15} \mathrm{~N}$-labelled pyridine resonance; the power of the pulse matched the sum (or difference) of the hydride-hydride and ${ }^{15} \mathrm{~N}$ -

${ }^{15} \mathrm{~N}$ J-coupling (see Figure 18 for sequence). This lead to the transfer of polarisation of magnetisation from the parahydrogen derived hydrides to ${ }^{15} \mathrm{~N}$ that manifested itself as $\mathrm{x}$-magnetisation. However, due to exchange processes, this $x$-magnetisation would diphase immediately following dissociation from the metal centre of the catalyst. Thus, selective $90^{\circ}$ pulses were incorporated into the LIGHTSABRE pulse sequence and applied directly to the bound ${ }^{15} \mathrm{~N}$-pyridine resonance to create $\mathrm{z}$ magnetisation. The z-magnetisation accumulates in free pyridine, thus leading to a bulk reservoir of polarisation that can be read-out using a broadband pulse. The combination of CW and selective $90^{\circ}$ pulse is applied $\mathrm{n}$ times, at a repetition rate comparable to the exchange rate and for a time comparable to $T_{1}$. Optimization revealed that values of $n=15$ and $\tau_{\mathrm{cW}}=0.5 \mathrm{~s}$ should be used (total pulse length of $7.5 \mathrm{~s}$ ). When these conditions were employed, a sample consisting of $63 \mathrm{mM}$ of ${ }^{15} \mathrm{~N}$ labelled pyridine in methanol was enhanced by 150 -fold relative to a 128 -scan thermal spectrum. Reducing the concentration of ${ }^{15} \mathrm{~N}$-pyriidne to $2.5 \mathrm{mM}$ increased the enhancement further to 480 fold. In both instances, the ${ }^{15} \mathrm{~N}$-pyridine to catalyst concentration was 10:1.

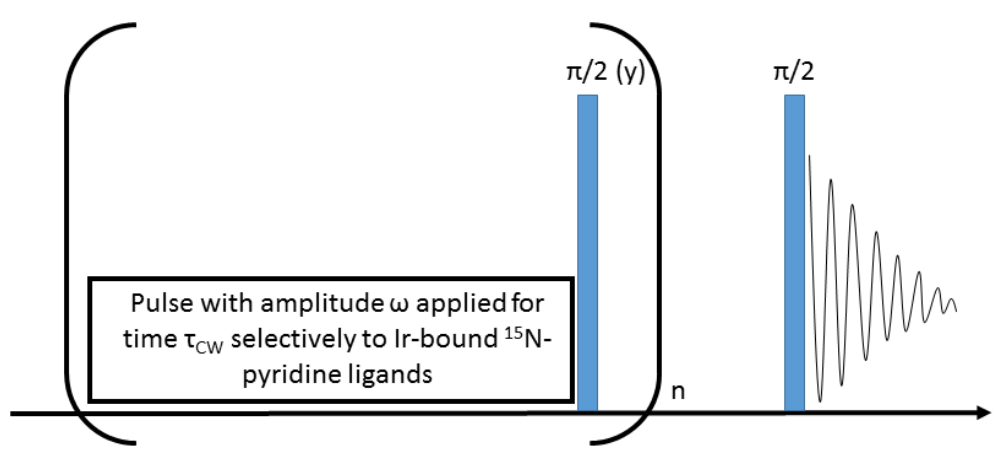

Figure 18. LIGHT-SABRE pulse sequence. The amplitude of the pulse, $\omega$, is $2 \pi\left(J_{\mathrm{HH}} \pm J_{\mathrm{NN}}\right)$ and $\tau_{\mathrm{CW}}$ is $1 / \sqrt{ } 2 \Delta J_{\mathrm{NH}}$

\section{SABRE-SHEATH}

LIGHT-SABRE enables SABRE to be conducted in the magnet and under constant bubbling of parahydrogen. This means that the method is highly reproducible, as it eliminates experimental uncertainties resulting from sample transfer and discontinued parahydrogen supply. Nonetheless, a field cycling method was found to be far superior in yielding significant polarisation values of ${ }^{15} \mathrm{~N}$. SABRE-SHEATH (SABRE in SHield Enables Alignment Transfer to Heteronuclei) [77] utilises a $\mu$-metal shield to conduct the hyperpolarisation within for approximately $30 \mathrm{~s}$. Following hyperpolarisation transfer, the sample is transferred rapidly $(\sim 4 s)$ to the NMR spectrometer for detection. At concentrations of $4 \mathrm{mM}$ of ${ }^{15} \mathrm{~N}$-labelled pyridine and $0.24 \mathrm{mM} \operatorname{Ir}(\mathrm{IMes})(\mathrm{COD}) \mathrm{Cl}$, a 30,000-fold enhancement for free ${ }^{15} \mathrm{~N}$-labelled pyridine was achieved. This equates to a polarisation value of $10 \%$. Another study that used $70 \mathrm{mM}$ of ${ }^{15} \mathrm{~N}$-labelled pyridine and $2 \mathrm{mM} \operatorname{Ir}(\mathrm{IMes})(\mathrm{COD}) \mathrm{Cl}$ yielded a 2500-fold enhancement [60]. Crucially, the signal manifests as a purely emissive in-phase triplet. This contrasts to the anti-phase signal observed in the corresponding ${ }^{15} \mathrm{~N}$ NMR spectrum when traditional SABRE is conducted in a polarisation transfer field of $\sim 6 \mathrm{mT}$ along with a lower enhancement (only 460-fold). The appearance of the signal is important from an imaging application perspective because broadened lines can lead to partial signal cancellation. Furthermore, employment of SABRE- 
SHEATH enables not just the detection of free ${ }^{15} \mathrm{~N}$-labelled pyridine, but also equatorially bound (trans to hydride) and axial (trans to IMes) ${ }^{15} \mathrm{~N}$-labelled pyridine. This is noteworthy because the latter is not observed under traditional SABRE conditions due to the anti-phase nature of the signal leading to signal cancellation. ${ }^{15} \mathrm{~N}$-labelled nicotinamide was also polarised employing SABRESHEATH; a $48 \mathrm{mM}$ solution yielded an enhancement of 20,000-fold over the thermal reference, which equates to a polarisation of $7 \%$. Compared to ${ }^{15} \mathrm{~N}$-labelled pyridine for which a higher concentration ( $63 \mathrm{mM}$ ) yielded an enhancement of only 3000 -fold, this represents a more biologically relevant concentration and as such could be used in MRI studies.

A further report on SABRE-SHEATH delved into the physical constraints that affect polarisation transfer. Parahydrogen pressure, flow rate, sample temperature, catalyst-to-substrate ratio, $T_{1}$ relaxation, and reversible oxygen quenching were all studied using a test system of ${ }^{15} \mathrm{~N}$-labelled pyridine and $\operatorname{Ir}(\mathrm{IMes})(\mathrm{COD}) \mathrm{Cl}$ ] in $d_{4}$-methanol [73]. The exposure of a sample to air was shown to have a very dramatic effect on the enhancement observed, however, this situation was recoverable upon exposure to parahydrogen for long time periods. A SABRE-SHEATH ${ }^{15} \mathrm{~N}$ NMR spectrum produced after $20 \mathrm{~min}$ of parahydrogen bubbling, (using a $20 \%$ duty cycle i.e. bubbling turned on for $30 \mathrm{~s}$ and then off for $2 \mathrm{~min}$ ) yielded an enhancement of 3600 -fold for free ${ }^{15} \mathrm{~N}$-pyridine (48 mM). Exposure to air for $\sim 5 \mathrm{~s}$ resulted in the enhancement dropping to 185 -fold. However, the 3600 -fold enhancement was fully recovered within 8 min following continuation of parahydrogen bubbling using the same duty cycle as before. The $T_{1}$ of free ${ }^{15} \mathrm{~N}$-pyridine was found to differ considerably; in the magnetic shield ${ }^{15} \mathrm{~N} T_{1}$ was $10.4 \pm 0.9 \mathrm{~s}$, at $\sim 6 \mathrm{mT} 28.4 \pm 2.6 \mathrm{~s}$ and at $9.4 \mathrm{~T} 68.6 \pm 2.4 \mathrm{~s}$. The lowest $T_{1}$ is observed in the magnetic shield, the magnetic field in which polarisation transfer occurs in SABRE-SHEATH. Thus, $T_{1}$ modulates the build-up rate and the maximum polarisation attainable. Understanding these conditions enabled the collection of a ${ }^{15} \mathrm{~N}$ image of ${ }^{15} \mathrm{~N}$-labelled pyridine $(20$ $\mathrm{mM}$ ), the first such image produced by parahydrogen-based hyperpolarisation. The image produced, which took $0.4 \mathrm{~s}$ to acquire, had a $2 \times 2 \mathrm{~mm}^{2}$ spatial resolution and the hyperpolarised liquid was visible within a $6.6 \mathrm{~mm}$ internal diameter high-pressure HPLC column.

The hyperpolarisation of neat liquids has been demonstrated using SABRE-SHEATH [78]. Using $[\operatorname{Ir}(\mathrm{IMes})(\mathrm{COD}) \mathrm{Cl}]$ as the pre-catalyst, the ${ }^{15} \mathrm{~N}$ of neat pyridine was enhanced by up to 2900 -fold. This equates to roughly $1 \%$ polarisation. Interestingly, the ortho ${ }^{1} \mathrm{H}$ signal of pyridine was only enhanced 4-fold using conventional SABRE. For these experiments, parahydrogen was bubbled into the tube containing the catalyst and neat pyridine. The ${ }^{15} \mathrm{~N}$ signal exhibited a strong dependence on the flow rate of parahydrogen over the range studies $(0-150 \mathrm{scc} / \mathrm{min})$. The signal enhancement obtained was independent of the pressure of parahydrogen supplied during polarisation transfer. The authors note that the low concentration of parahydrogen in solution relative to the catalyst, and also the significantly shorter $T_{1}$ in the micro-Tesla field in which polarisation transfer is conducted relative to the $9.4 \mathrm{~T} T_{1}\left(5.5 \pm 0.5\right.$ and $60.8 \pm 0.6 \mathrm{~s}$ respectively), results in a smaller ${ }^{15} \mathrm{~N}$ signal enhancement than what could be achieved. This was exemplified by using neat ${ }^{15} \mathrm{~N}$ labelled pyridine; the ${ }^{15} \mathrm{~N}$ signal was enhanced only 33-fold, which is two orders of magnitude different to the natural abundance sample. This is despite an increase in $T_{1}$ within the micro-Tesla field (10.2 $\left.\pm 1.1 \mathrm{~s}\right)$.

SABRE-SHEATH has been utilised to hyperpolarise a wide range of ${ }^{15} \mathrm{~N}$ containing molecules [79]. Importantly, molecules that did not contain a pyridyl motif were exemplified using this approach. A selection of the molecules that were polarised and their enhancement levels at $8.5 \mathrm{~T}$ are shown in Figure 19. These molecules suggest that $s p$ - and $s p^{2}$-hybridised ${ }^{15} \mathrm{~N}$ sites can be hyperpolarised. In addition, it is prudent to note that the ${ }^{15} \mathrm{~N}$ site of benzonitrile was polarised (21000-fold enhancement) whereas it had been previously demonstrated that the ${ }^{1} \mathrm{H}$ nuclei could not [72]. $T_{1}$ values were obtained for all the substrates; values in the order of minutes were obtained for 
acetonitrile, benzonitrile, CHCA ( $\alpha$-cyano-4-hydroxycinnamic acid), nicotinamide and a representative Schiff base. Other Schiff bases have been polarised using either the $[\operatorname{Ir}(\mathrm{IMes})(\mathrm{COD})(\mathrm{py})] \mathrm{PF}_{6}$ or $[\operatorname{Ir}(\mathrm{IMes})(\mathrm{COD}) \mathrm{Cl}]$ templates; smaller Schiff bases produced bigger enhancements when polarised by the latter, whereas vice versa is true for larger Schiff bases [80]. The ${ }^{15} \mathrm{~N} T_{1}$ times obtained in ref. [79] were strongly dependent on the magnetic field and molecular structure. The reason for this was ascribed to chemical shift anisotropy (CSA) which scales with $\mathrm{B}_{0}{ }^{2}$. As a result of this study, acetonitrile was chosen as a substrate to be optimised. The maximum enhancement was obtained using $0.25 \mathrm{mM}[\mathrm{Ir}(\mathrm{IMes})(\mathrm{COD}) \mathrm{Cl}]$ and $5 \mathrm{mM}{ }^{15} \mathrm{~N}-\mathrm{CH}_{3} \mathrm{CN}$ in the presence of $0.25 \mathrm{mM}$ pyridine as a stabilizing co-ligand. This resulted in $\mathrm{P}_{15 \mathrm{~N}}=7 \%$. The polarisation value was further optimised by increasing the flow rate of hydrogen supplied to the reaction vessel; a flow-rate of $130 \mathrm{sccm} / \mathrm{min}$ rather than $80 \mathrm{sccm} / \mathrm{min}$ increased the polarisation to $16 \%$.
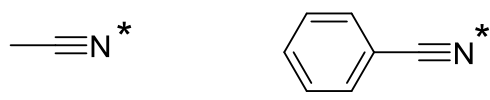

4400<smiles>CCc1cc2c(cc1N1CCC(N3CCOCC3)CC1)C(C)(C)C1Nc3cc(C#[N+])ccc3C1C2=O</smiles><smiles>[N+]#CC(Cc1ccc(O)cc1)C(=O)O</smiles>

3600<smiles>CC(=O)CC/[N+](=C\c1ccccc1)CC(C)=O</smiles>
7200
5000<smiles>[2H]C([18OH])([18OH])CC([2H])([18OH])C(=O)O</smiles>

15000<smiles>ClC1=CC=C(Cl)[N+]=[N+]1</smiles>

12000<smiles>NC(=O)c1cccnc1</smiles>

11000<smiles></smiles>

72000<smiles></smiles>

200 (average over all<smiles></smiles><smiles>CN(c1ccccc1)[N+](C)c1ccccc1</smiles>

$>40$

Figure 19. ${ }^{15} \mathrm{~N}$ containing molecules polarised by Theis et al. ${ }^{15} \mathrm{~N}$ labels are with a $*$. The ${ }^{15} \mathrm{~N}$ enhancements obtained at 8.5 $T$ relative to thermal measurements are indicated underneath each molecule.

An improved synthesis for ${ }^{15} \mathrm{~N}$-labelled nicotinamide, has been reported that makes use of the Zincke salt [81]. The nicotinamide is $98 \%$ isotopically pure with respect to the ${ }^{15} \mathrm{~N}$ label. When polarised using [ $[\mathrm{r}(\mathrm{IMes})(\mathrm{COD}) \mathrm{Cl}]$ and employing SABRE-SHEATH, an enhancement of 7,300-fold was obtained in $d_{4}$-methanol. This value is comparable to those obtained using the $66 \%$ isotopically pure ${ }^{15} \mathrm{~N}$ nicotinamide $[77,79]$. However, using the $98 \%$ isotopically pure ${ }^{15} \mathrm{~N}$-nicotinamide results in almost $50 \%$ more hyperpolarised ${ }^{15} \mathrm{~N}$ magnetisation, which is an advantage for imaging purposes.

Polarisation of metronidazole $\left({ }^{15} \mathrm{~N}\right.$ at natural abundance) via SABRE-SHEATH has yielded substantial enhancements [82]. A 72,000-fold enhancement was observed in the ${ }^{15} \mathrm{~N}$ NMR spectrum $(P=24 \%)$ for $50 \mathrm{mM}$ of metronidazole in $d_{4}$-methanol. Only $80 \%$ parahydrogen was used in the experiment, so a polarisation of $32 \%$ is feasible if $100 \%$ parahydrogen was used. It should be noted that metronidazole possesses ortho-substituents and these do not prevent successful polarisation of the molecule, unlike the picolines and lutidines noted elsewhere [78]. 
Imidazole has been polarised using SABRE-SHEATH with a view towards $\mathrm{pH}$ sensing due to the sizable chemical shift difference ( $30 \mathrm{ppm})$ that occurs upon binding to the SABRE catalyst [83]. The imidazole $(0.1 \mathrm{M}){ }^{15} \mathrm{~N}$ nuclei were polarised by ca. 2000 -fold when measured at $9.4 \mathrm{~T}$. Only $50 \%$ parahydrogen was used in this measurement and so an enhancement of 6000 -fold is theoretically possible. Of significant note, however, is the fact that a 2000 -fold enhancement was obtained in a 50:50 $d_{4}$-methanol:aqueous $(\mathrm{pH} \mathrm{12}) \mathrm{mix}$. The $\mathrm{pH}$ of the solution was varied so that it was above and below the $p \mathrm{~K}_{\mathrm{a}}\left(p \mathrm{~K}_{\mathrm{a}}\right.$ of imidazole 7.0 ) and this showed that the chemical shift of the imidazole nitrogen nuclei moved from $175 \mathrm{ppm}$ at pH 1 to $205 \mathrm{ppm}$ at pH 12. The biggest change occurred in the 6.5 to $7.5 \mathrm{pH}$ region; here a resolution of 0.1 unit of pH per $1.5 \mathrm{ppm}$ of ${ }^{15} \mathrm{~N}$ shift was observed. The presence of imidazole rings in peptides and proteins coupled with the ${ }^{15} \mathrm{~N}$ chemical shift change and associated increases in signal-to-noise afforded by SABRE-SHEATH, means that this system has potential for $\mathrm{pH}$ sensing over the physiological $\mathrm{pH}$ range.

Further research on SABRE-SHEATH has focused on utilising the technique in aqueous media [84]. The water soluble pre-catalyst, [ $\operatorname{Ir}(\mathrm{IDEG})(\mathrm{COD}) \mathrm{Cl}]$ [85], was employed to ensure compatibility with the $\mathrm{D}_{2} \mathrm{O}$ and $\mathrm{H}_{2} \mathrm{O}$ solvents used for the study. A range of substrates were again selected to probe the polarisation transfer to ${ }^{15} \mathrm{~N}$. ${ }^{15} \mathrm{~N}$-Pyridine, ${ }^{15} \mathrm{~N}$-benzonitrile, ${ }^{15} \mathrm{~N}$-CHCA, 2 -cyano-3- $\left(d_{3}\right.$-methyl- ${ }^{15} \mathrm{~N}_{2}$ diazirine)-propionic acid and ${ }^{15} \mathrm{~N}$-nicotinamide were all successfully polarised. Interestingly, the normalised hyperpolarised signals as a function evolution magnetic field strength revealed that the curve for CHCA polarised using [Ir(IDEG)(COD)Cl] showed a similar response to those obtained for acetonitrile polarised by $[\mathrm{Ir}(\mathrm{IMes})(\mathrm{COD}) \mathrm{Cl}]$.

2-cyano-3-( $\left(d_{3}\right.$-methyl- ${ }^{15} \mathrm{~N}_{2}$-diazirine)-propionic acid has been the subject of a further SABRE-SHEATH study [86]. DFT calculations revealed that the diazirine ligated through a $\eta^{1}$ arrangement through one of the nitrogen atoms, rather than a $\eta^{2}-\mathrm{N}=\mathrm{N}$ attachment. The use of $[\operatorname{Ir}(\mathrm{COD})(\mathrm{IMes})(\mathrm{py})]\left[\mathrm{PF}_{6}\right]$ instead of [Ir(IMes)(COD)Cl] resulted in a factor of 3-fold improvement in the hyperpolarisation levels. The complex $\left[\operatorname{Ir}(\mathrm{IMes})(\text { diazirine })_{2}(\mathrm{py})\right]\left[\mathrm{PF}_{6}\right]$ is formed after activation, in which the pyridine is trans to IMes and therefore avoids the pyridine competing for sites trans to hydride and thus acting as a polarisation acceptor. Following hyperpolarisation, both z-magnetisation and singlet order were produced. A 15,000 -fold enhancement ( $5 \%$ polarisation) was observed for the $z$-magnetisation produced with a $T_{1}$ of $5.8 \pm 0.3$ minutes at $12 \mathrm{mT}$, whereas the singlet order gave a 5000 -fold enhancement ( $3 \%$ polarisation) and a $T_{\mathrm{S}}$ of $23 \pm 3$ minutes at $0.3 \mathrm{mT}$. The former was produced under SABRE-SHEATH conditions, whereas the latter, which relies upon $J_{\mathrm{HH}}= \pm J_{\mathrm{NN}}$ is not dependent on magnetic field provided that the singlet state remains close to a eigenstate of the Hamiltonian. Well-suited lifetimes for the singlet state were found at fields between 0.5 and $200 \mathrm{G}$. It should be noted that the singlet readout was only $~ 60 \%$ efficient, and so the polarisation of $z$-magnetisation and singlet order are comparable, although the build-up rate for singlet order is longer than zmagnetisation ( $T_{\mathrm{b}}$ for the former is $5 \mathrm{~min}$ compared with $2 \mathrm{~min}$ for the latter). The section entitled "Generation and utilisation of long-lived states by SABRE" details further the generation and use of singlet states in conjunction with SABRE.

\section{Polarisation transfer to ${ }^{19} \mathrm{~F}$}

To date, only one analyte that contains fluorine has been polarised by SABRE; 3-fluoropyridine. This analyte is largely analogous with pyridine, and as $J_{\mathrm{HF}}$ couplings tend to be of the same order of magnitude as $J_{\mathrm{HH}}$ couplings, it is therefore not surprising that this molecule can be polarised successfully. The hyperpolarised ${ }^{19} \mathrm{~F}$ signal presents as a complicated anti-phase multiplet that is enhanced relative to the trace at thermal equilibrium [23]. $\left[\operatorname{Ir}(\mathrm{COD})\left(\mathrm{PCy}_{3}\right)(\mathrm{py})\right]$ was used as the polarisation transfer catalyst. Pentafluoropyridine has been the subject of a SABRE study but did not yield any polarisation using either $[\mathrm{Ir}(\mathrm{IMes})(\mathrm{COD}) \mathrm{Cl}]$ or Crabtree's catalyst as the polarisation transfer 
templates [87]. Investigating ${ }^{19} \mathrm{~F}$ containing substrates as analytes for SABRE should be a future focus within this research field, especially given the number of drugs that possess ${ }^{19} \mathrm{~F}$ nuclei (in 2010 it was calculated that about $20 \%$ of administered drugs contained fluorine atoms or fluoroalkyl groups [88]) and that in MRI there is no competing background signal.

\section{Polarisation transfer to ${ }^{31} \mathrm{P}$}

Phosphorous is a component of many ligands that are used in inorganic catalysis.

Triphenylphosphine, $\mathrm{PPh}_{3}$, is one such example. Zhivonitko et. al. have shown that $\mathrm{PPh}_{3}$ can be polarised using $\left[\left(\mathrm{PPh}_{3}\right)_{3} \operatorname{Ir}\left(\mathrm{H}_{2}\right) \mathrm{Cl}\right]$ [36]. The complex possesses two unique phosphorous environments, as shown in Figure 20 . Interestingly, after polarisation transfer to a heated sample $\left(60^{\circ} \mathrm{C}\right)$ inside a $\mu$ metal shield (ca. $1 \mu \mathrm{T}$ ), polarisation transfer was observed to both bound $\mathrm{PPh}_{3}$ ligands and also free $\mathrm{PPh}_{3} .{ }^{31} \mathrm{P}$ NMR signal enhancements of $c a .120$-fold were obtained in a $7 \mathrm{~T}$ measurement field. Heating the sample to $80^{\circ} \mathrm{C}$ gave higher enhancements of $c a$. 260 -fold. The reason for the increase is due to an increase in the exchange rates of both hydride and phosphine by $3-7$-fold. EXSY data showed that the phosphines trans to one another in $\left[\left(\mathrm{PPh}_{3}\right)_{3} \mathrm{Ir}\left(\mathrm{H}_{2}\right) \mathrm{Cl}\right]$ do not exchange within the relaxation time of ${ }^{31} \mathrm{P}$ magnetisation.<smiles>[PH3+][C@@H](Cl)[Pb]([PH3+])([PH3+])[PbH2]</smiles>

Figure 20. Chemical structure of $\left[\left(\mathrm{PPh}_{3}\right)_{3} \operatorname{Ir}\left(\mathrm{H}_{2}\right) \mathrm{Cl}\right]$ showing the two unique phosphorous environments (labelled a and $\mathrm{b}$ )

A mixed $\mathrm{NHC}$ and $\mathrm{PPh}_{3}$ system has also yielded polarisation transfer to ${ }^{31} \mathrm{P}$ via SABRE. The complex shown in Figure 21 yielded a 30-fold ${ }^{31} \mathrm{P}$ signal enhancement [89]. The acetonitrile ligands were also shown to polarise in the ${ }^{1} \mathrm{H}$ NMR spectrum. In the analogous complex in which one of the acetonitrile ligands is exchanged for pyridine, the methyl proton nuclei of acetonitrile were enhanced by ca. 23 -fold following polarisation transfer at $20 \mathrm{G}$. The total pyridine ${ }^{1} \mathrm{H}$ NMR enhancement was 35 -fold, but to obtain this maximum, a polarisation transfer field of $140 \mathrm{G}$ was required. The enhancement of pyridine increased further when both acetonitrile ligands were replaced by pyridine.

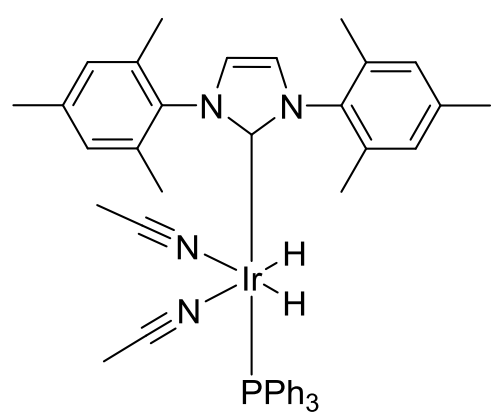

Figure 21 Chemical structure of $\left[\operatorname{Ir}(\mathrm{IMes})\left(\mathrm{PPh}_{3}\right)(\mathrm{MeCN})_{2}(\mathrm{H})_{2}\right]^{+}$utilised by Fekete et al [89]

Further work on phosphorous containing compounds, in terms of being polarised by SABRE, led to the synthesis of pyridine derived molecules possessing phosphonate groups. This work demonstrated that the ortho-site of the pyridine ring was not a suitable position for tethering groups to as it prevented polarisation transfer. This was exemplified for 2-pyridyldiethylphosphonate; no ${ }^{31} \mathrm{P}$ polarisation was observed and only a marginal enhancement of 2 -fold in the ${ }^{1} \mathrm{H}$ NMR spectrum. Similar results have been demonstrated for 2-picoline and 2,6-lutidine [78]. In contrast, substitution 
at the meta- and para-position were amenable to polarisation transfer. Total ${ }^{1} \mathrm{H}$ NMR enhancements of 1499-fold were achieved at a polarisation transfer field of $45 \mathrm{G}$ for 4-pyridyldiethylphosphonate. The ${ }^{31} \mathrm{P}$ NMR revealed a 545 -fold enhancement. It is noteworthy that the analogous phosphine, phosphine oxide and phosphine sulphide did not yield as substantial enhancements. However, tethering the diethylphosphonate to the meta-position resulted in improved polarisation transfer; the ${ }^{1} \mathrm{H}$ nuclei are enhanced to a total of 2866 -fold whereas the ${ }^{31} \mathrm{P}$ signal enhancement was enhanced by 336 -fold. The latter equates to a polarisation value of $0.44 \%$. This value was increased by further by substituting both meta-positons with diethylphosphonate groups. The ${ }^{1} \mathrm{H}$ and ${ }^{31} \mathrm{P}$ signals were enhanced by 3689 - and 860 -fold respectively. Interestingly, it was noted that a lower number of equivalents of this ligand could be used in this instance relative to the other substrates studied ( 6 equivalents instead of 7 equivalents). This is because the increased steric bulk of the dimeta-substituted diethylphosphonate results in a chloride occupying one of the coordination sites trans to hydride in the active catalyst instead of a substrate molecule. This arrangement results in improved polarisation transfer to the only di-meta-substituted diethylphosphonate ligand that is trans to hydride. Deuterating the ethyl groups of di-meta-substituted diethylphosphonate ligand further improved the ${ }^{31} \mathrm{P}$ hyperpolarised signal. Following polarisation transfer at $0.5 \mathrm{G}$ a ${ }^{31} \mathrm{P} \mathrm{NMR}$ signal gain of 3588 -fold ( $2.3 \%$ polarisation) was achieved. A diminished signal gain of 2251 -fold ( $1.4 \%$ polarisation) was obtained after polarisation transfer at $45 \mathrm{G}$, but this signal possessed significant inphase character. This observation was, therefore, prudent to conducting imaging studies which are detailed in Imaging Applications of SABRE section.

Polarisation transfer to ${ }^{29} \mathrm{Si}$ and ${ }^{119} \mathrm{Sn}$

${ }^{29} \mathrm{Si}$ and ${ }^{119} \mathrm{Sn}$ are two other nuclei that have been shown to be polarisable via SABRE [90]. The two molecules synthesised and analysed by SABRE are shown in Figure 22. A thermal spectrum of both molecules were collected; 5-(tributylstannyl)pyrimidine required 3096 averages and 5(trimethylsilyl)pyrimidine required 128 averages to give spectra with appropriate signal-to-noise. For the former, enhancements of $803 \pm 73$-fold ( $\mathrm{H}-2$ resonance) and $1486 \pm 156$-fold ( $\mathrm{H}-4$ and $\mathrm{H}-6$ resonances) were observed in the ${ }^{1} \mathrm{H}$ NMR spectrum after polarisation transfer at $70 \mathrm{G}$. $[\operatorname{Ir}(\mathrm{IMes})(\mathrm{COD}) \mathrm{Cl}]$ was employed as the SABRE pre-catalyst. To optimise transfer to ${ }^{119} \mathrm{Sn}$, the excess amount of substrate relative to SABRE catalyst was modulated in order to deliver the maximum enhancement. A 17-fold excess of substrate was required to deliver a SNR of $375: 1$ in the fully coupled ${ }^{119}$ Sn NMR spectrum and $1099: 1$ in the ${ }^{119} \mathrm{Sn}\left\{{ }^{1} \mathrm{H}\right\}$ NMR spectrum (decoupling applied only to butyl protons). This gave enhancements of 687- and 772-fold respectively. The use of [Ir(SIMes)(COD)Cl] resulted in approximately 50\% lower enhancements due to the rate of $\mathrm{H}_{2}$ loss from the active complex being $2.29 \mathrm{~s}^{-1}$ compared to $0.56 \mathrm{~s}^{-1}$ when [ $\operatorname{Ir}(\mathrm{SIMes})(\mathrm{COD}) \mathrm{Cl}$ ] is employed. Incorporation of SIMes into the catalyst structure therefore promotes more rapid ligand loss, which is detrimental in terms of polarisation transfer. Complexes formed with 5-(trimethylsilyl)pyrimidine yielded the same trend, and this was reflected in the IMes catalyst producing the largest enhancement. The hyperpolarised non-decoupled ${ }^{29} \mathrm{Si}$ NMR spectrum gave a SNR of 200. Furthermore to the hyperpolarisation study, both substrates form tri-nuclear complexes with the general formula $\left[\mathrm{Ir}(\mathrm{H})_{2} \mathrm{Cl}(\mathrm{NHC})\left(\mu-\text { pyrimidine- } \mathrm{kN}: \mathrm{KN}^{\prime}\right)\right]_{3}$. 

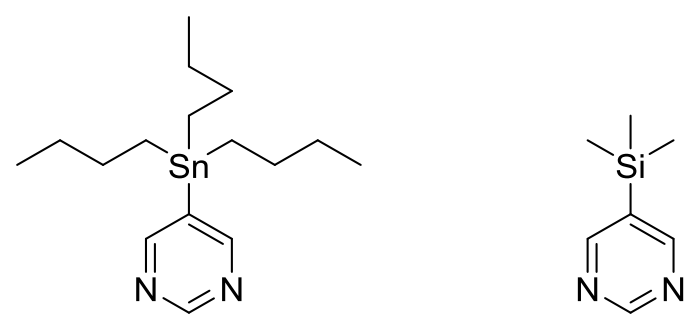

Figure 22 Chemical structures of 5-(tributylstannyl)pyrimidine and 5-(trimethylsilyl)pyrimidine

\section{Towards performing SABRE in water-based solvent systems}

It is desirable to conduct SABRE experiments in water as this enables biologically relevant molecules, such as proteins and amino acids, to be studied more readily. The production of water soluble catalysts also aids the collection of in vivo images as physiological pH can be more easily maintained. Furthermore, it avoids the use of solvents that are incompatible for in vivo use, such as methanol.

A method for achieving $1 \%$ NMR polarisation in water in less than one minute using SABRE has been reported for 3-amino-1,2,4-triazine (ATZ) [91]. A sample consisting of ATZ and [Ir(IMes)(COD)Cl] was dissolved in methanol and hydrogen bubbled through the solution for at least 2 hours. Then water was added. Following evaporation under reduced pressure for 10 minutes, the resulting molar fraction of methanol : water was $10: 90$. This solution was used for SABRE-based measurements. Following polarisation transfer at $65 \mathrm{G}$ and at $54.4^{\circ} \mathrm{C}$ for $30 \mathrm{~s}$, an enhancement of $170 \pm 45$-fold was obtained for the two protons of ATZ. The solvent signals were suppressed using excitation sculpting with gradient dephasing. Interestingly, using this methodology, no SABRE enhancement was observed for pyridine, isoniazid and pyrazinamide. This is despite the enhancement of ATZ in methanol being similar to that of the aforementioned analytes.

In a separate study, it was found that following activation of [Ir(IMes)(COD)Cl] in the presence of pyridine or nicotinamide and $\mathrm{H}_{2}$ in ethanol or methanol, the generated complex could be dried and then dissolved in pure water [51]. Using this approach, the four aromatic proton environments of nicotinamide were enhanced to give a total enhancement of 100 -fold following polarisation transfer at $6 \pm 4 \mathrm{mT}$. Although a decrease from the $c a$. 230 -fold enhancement observed in $d_{6}$-ethanol, this method again shows that SABRE can be conducted in aqueous media.

The design of new water soluble catalysts has also been the focus of some research groups. Fekete et al. modified their mixed phosphine / NHC system [89] so that the phosphine ligands possessed water solubilising sulfonated groups [92]. Complexes of the type $\left[\operatorname{Ir}(\mathrm{IMes})(\mathrm{py})(\mathrm{H})_{2}(\mathrm{MeCN})(\mathrm{L})\right] \mathrm{BF}_{4}$ were produced in the presence of $\mathrm{H}_{2}, \mathrm{MeCN}$ and pyridine, where $\mathrm{L}=\mathrm{PPh}_{3}$ or one of the phosphine ligands in Figure 23. Although these complexes are readily soluble, they failed to catalyse the SABRE of pyridine in aqueous solvent media. In an extension to this study, a series of water-soluble azolium salts were prepared. These were superior to the aforementioned mixed NHC / phosphine complexes; the pre-catalyst as seen in Figure 24 resulted in a 750 -fold enhancement of the ${ }^{1} \mathrm{H}$ nuclei of pyridine in $d_{4}$-methanol after polarisation transfer at $60 \mathrm{G}$. However, when moving towards aqueous media ( $67 \% \mathrm{D}_{2} \mathrm{O}, 3 \% \mathrm{DMSO}, 30 \%$ ethanol), only a 9.4-fold enhancement was obtained for pyridine. It is noteworthy that DMSO was included to improve the hydrogen solubility of $\mathrm{H}_{2}$ in solution and that it was not polarised in the process. Polarisation of 4-hydroxypyridine and oxazole resulted in enhancement gains of 22 - and 2.7 -fold in $70 \% \mathrm{D}_{2} \mathrm{O}: 30 \%$ ethanol respectively. 
<smiles>O=S(=O)(O)c1cccc(P(c2ccccc2)c2ccccc2)c1</smiles>

$m$ tppms<smiles>O=S(=O)(O)c1ccc(P(c2ccccc2)c2ccc(S(=O)(=O)O)cc2)cc1</smiles>

ptppds<smiles>O=S(=O)(O)c1cccc(P(c2cccc(S(=O)(=O)O)c2)c2cccc(S(=O)(=O)O)c2)c1</smiles>

$m$ tppts

Figure 23. Phosphine ligands used to create water soluble catalysts (mtppms =mono-meta-sulfonated triphenylphosphine, ptppds = di-para-sulfonated triphenylphosphine and mtppts = meta-tri-sulfonated triphenylphosphine)<smiles>Cc1cc(-n2cc(C[N+](C)(C)CCO)nn2)cc(C)c1N1CCN(c2c(C)cc(-n3cc(C[N+](C)(C)CCO)nn3)cc2C)C1[I-](Cl)(Cl)C1CC2CCC1C2</smiles>

Figure 24. Pre-catalyst synthesised by Fekete et al [92].

Spannring et al. have modified the NHC of the pre-catalyst [Ir(IMes)(COD)Cl] so that it possesses water solubilising groups [85]. Exchanging the mesityl groups for 3,4,5-tri(methoxy)benzyl groups to produce the $\mathrm{NHC}$ Itome, resulted in a catalyst that was insoluble in $\mathrm{D}_{2} \mathrm{O}$. However, exchanging the mesityl groups for 3,4,5-tri(diethyleneglycol)benzyl groups did result in a catalyst that was soluble in water and $\mathrm{D}_{2} \mathrm{O}$. The structure of this catalyst, [Ir(IDEG)(COD)Cl], is shown in Figure 25. Following polarisation transfer at $80 \mathrm{G}$, total enhancements of 64 -fold were observed for pyridine in a measurement field of $300 \mathrm{MHz}$. A 48 hour activation period was required prior to the measurement. Methyl nicotinate, $\mathrm{N}$-methyl nicotinamide and nicotinamide were also polarised yielding similar enhancements. Crucially this system does not require an organic solvent in the activation or subsequent steps. In addition, the low solubility of $\mathrm{H}_{2}$ does not preclude SABRE from occurring in pure water.<smiles></smiles>

$[\operatorname{lr}($ Itome $)(\mathrm{COD}) \mathrm{Cl}]$<smiles>[R]Oc1cc(N2C=CN(c3cc(O[R])c(O[R])c(O[R])c3)C2[I-](Cl)(Cl)C2CC3CCC2C3)cc(O[R])c1O[R]</smiles><smiles>[R][14CH2]CCOCCOC</smiles>

$[\operatorname{Ir}(\mathrm{IDEG})(\mathrm{COD}) \mathrm{Cl}]$

Figure 25. Chemical structures of the pre-catalysts $[\operatorname{Ir}(\operatorname{Itome})(\mathrm{COD}) \mathrm{Cl}]$ and $[\operatorname{Ir}(\mathrm{IDEG})(\mathrm{COD}) \mathrm{Cl}]$.

Chekmenev and co-workers have similarly modified the NHC, but in an asymmetric fashion [93]. The PEGylated iridium catalyst as shown in Figure 26 was synthesised. This catalyst proved to have excellent solubility in water. After polarisation transfer at low-field (un-optimised, $\sim 11 \pm 5 \mathrm{mT}$ ), the 
${ }^{1} \mathrm{H}$ NMR signals of pyridine gave a 16 -fold enhancement in $d_{6}$-ethanol. The addition of $\mathrm{D}_{2} \mathrm{O}$ to $d_{4^{-}}$ methanol solutions had a negative effect on the enhancement and as such had lower enhancement values than those in $d_{6}$-ethanol ( $20 \% \mathrm{D}_{2} \mathrm{O} / 80 \% d_{4}$-methanol yielded only a 6 -fold enhancement). Higher amounts of $\mathrm{D}_{2} \mathrm{O}$ led to negligible or zero enhancement being detected. Increasing the pressure of parahydrogen to 60 psi led to better polarisation efficiency as a 110-fold enhancement for pyridine was obtained. However, when a $63 \% \mathrm{D}_{2} \mathrm{O} / 37 \% d_{6}$-ethanol solution was used, no SABRE enhancement was observed. Based on this observation, a second non-PEGylated pre-catalyst was synthesised which utilised 1,2-dihydroxy-3,7-cyclooctadiene (CODDA) instead of COD to give $[\operatorname{Ir}(I \mathrm{Mes})(\mathrm{CODDA}) \mathrm{Cl}]$. Although not as soluble as the PEGylated complex, the CODDA pre-catalyst was water soluble to some extent $\left(0.3 \mathrm{mg} \mathrm{ml}^{-1}\right)$. Once activated, the catalytic form is [ $\left.\operatorname{lr}(\mathrm{IMes})(\mathrm{py})_{3}(\mathrm{H})_{2}\right]^{+}$, and under an atmosphere of parahydrogen for $30 \mathrm{~s}$ in a field of $\sim 10 \mathrm{mT}$ an enhancement of 25 -fold for the ortho ${ }^{1} \mathrm{H}$ NMR signal of pyridine. This enhancement was reproducible in subsequent repeats of the experiment. Notably, an aqueous suspension of $[\operatorname{Ir}(\mathrm{IMes})(\mathrm{COD}) \mathrm{Cl}]$ yielded no SABRE enhancement following activation. Thus, the use of CODDA pre-catalyst circumvents the need to dissolve in organic solvent, dry and then reconstitute in $\mathrm{D}_{2} \mathrm{O}[51,91]$, whilst maintaining the same level of enhancement.

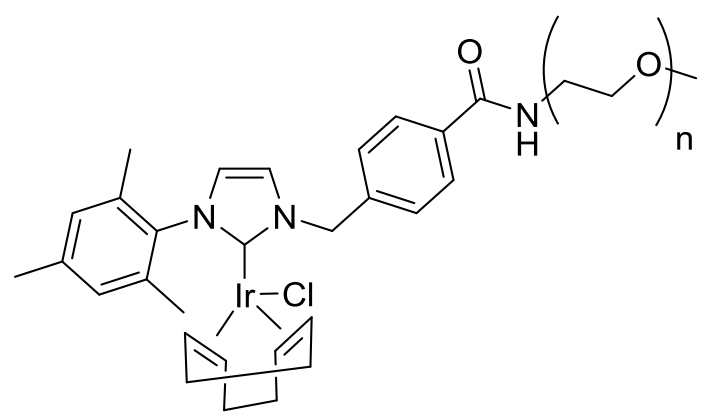

Figure 26. Pre-catalyst synthesised by Chekmenev and co-workers ( $n=12$ ) [93].

Vitamin B3 (nicotinic acid) has been polarised by SABRE and the signal enhancement of the four aromatic proton nuclei recorded as a function of $\mathrm{pH}$ [94]. In this work, nicotinic acid was polarised along with its conjugate base produced by adding increasing amounts of caesium carbonate to the solution. Compared with the uncharged form, production of the conjugate base led to the greater signal enhancement; at $\mathrm{pH} 8$ the total signal enhancement over all four proton sites was ca. 400 -fold whereas at $\mathrm{pH} 12$ the signal enhancement increased to over 800-fold. Interestingly, the $T_{1} \mathrm{~S}$ of the uncharged and conjugate base forms have similar $T_{1} \mathrm{~s}$ in the presence of transfer catalyst, aside from the $\mathrm{H}-2$ signal which is $7.3 \mathrm{~s}$ longer for the conjugate base and thus, closely mirrors that of free nicotinic acid $\left(T_{1}=18.4 \mathrm{~s}\right)$. The observation of a single hydride resonance in the ${ }^{1} \mathrm{H} N M R$ at high $\mathrm{pH}$ demonstrated that the conjugate base dominates and as such, no speciation of the catalytic species occurs.

\section{Heterogeneous SABRE}

With a future view of being able to separate the catalyst from a hyperpolarised bolus (thus maximising the longevity of the hyperpolarised state), heterogeneous catalysts for use with SABRE have been designed and synthesised. The use of heterogeneous catalysts can circumvent problems associated with the isolation of the catalyst and the production of by-products associated with catalyst activation (for example cyclooctane, the hydrogenation product of COD). Tethering of $[\operatorname{Ir}(\mathrm{IMes})(\mathrm{COD})]\left[\mathrm{PF}_{6}\right]$ on to polymer microbeads, which possess pyridyl surface groups) have been accomplished by Shi et al. [95]. Successful immobilization of the iridium complex on to the polymer microbeads was supported by AAS, IR and MS. AAS revealed that $4 \%$ of the total heterogeneous 
SABRE catalyst was iridium complex. A hyperpolarised ${ }^{1} \mathrm{H}$ NMR spectrum, following polarisation transfer at $100 \mathrm{G}$, was obtained using the heterogeneous SABRE catalyst which was qualitatively similar to that obtained using the homogeneous catalyst. Only signals for free pyridine were observed. Signals for those of the catalyst and free pyridine were not observed as the microbeads settled quickly to the bottom of the sample tube once shaking of the tube to enact polarisation transfer had ceased. The ortho-, para- and meta-proton nuclei had their respective ${ }^{1} \mathrm{H}$ NMR signals enhanced by 5.2-, 4.1- and 2.7-fold respectively. All of these signals were observed to be in emission. Under the same conditions, the homogenous catalyst produced values of $c a$. 70-fold. Isolation of the supernatant from a sample that contained the heterogeneous catalyst was evaluated for SABRE activity, primarily to see if catalyst leaching had occurred. Following polarisation transfer at $100 \mathrm{G}$, no enhancement of pyridine was observed. AAS (Atomic Absorption Spectroscopy), MS (Mass Spectrometry) and long ${ }^{1} \mathrm{H}$ NMR acquisitions correlate with this observation as the presence of leached catalyst was not detected. Thus, the heterogeneous support employed was robust and did not leach catalyst; the enhancements observed were purely associated with polarisation transfer derived from heterogeneous, rather than homogenous, catalysis. This also infers that the pyridyl linker of the microbeads is bound to the catalyst trans to IMes, and not trans to hydride, otherwise catalyst would dissociate from the support (and vice versa) during polarisation transfer.

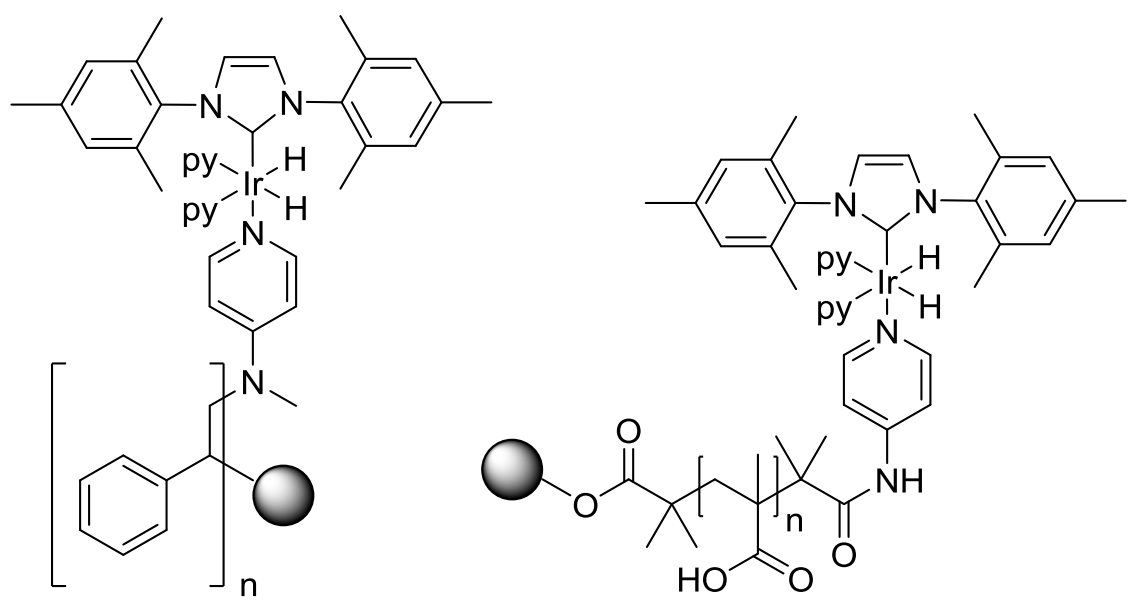

Figure 27. Heterogeneous SABRE catalysts, which have been either attached to polymer microbeads (left [95]) or $\mathrm{TiO}_{2} /$ PMAA nanoparticles (right [96]).

In a further study, the SABRE catalyst was heterogeneously supported on to a $\mathrm{TiO}_{2} / \mathrm{PMAA}$ (poly(methacrylic acid)) core / shell nanoparticle or PVP (polyvinylpyridine) "comb" polymers o produce two new heterogeneous SABRE catalysts [96]. The PMAA shell of the $\mathrm{TiO}_{2} / \mathrm{PMAA}$ nanoparticles was functionalised with 4-aminopyridine. Both catalysts were characterised by AAS, NMR and DLS (Dynamic Light Scattering). Based on AAS results, $25 \%$ of the total nano-SABRE catalyst particles by weight is the iridium complex. Analysis of filtrates by AAS isolated from the final washing step of the production of the heterogeneously supported catalyst and after catalyst activation in the presence of $\mathrm{H}_{2}$, did not detect the presence of iridium. The catalysts are again robust under the conditions in which they are employed. The PVP "comb" polymer heterogeneous SABRE catalyst enhanced the ${ }^{1} \mathrm{H}$ NMR signals of the ortho-, para- and meta-sites of pyridine by 7-, 6- and 3-fold respectively. Employment of the $\mathrm{TiO}_{2}$ / PMAA core / shell nanoparticle-based heterogeneous SABRE catalyst resulted in the pyridine ${ }^{1} \mathrm{H}$ NMR signals being enhanced by $18-, 17$ and 7-fold respectively for the ortho-, para- and meta-positions. These enhancements were improved following $300 \mathrm{~s}$ of ex situ parahydrogen bubbling; the values obtained as a result were increased to 26-, 39- and 11-fold respectively (ca. $0.13 \%{ }^{1} \mathrm{H}$ polarisation). The feasibility of recovering and recycling the supported 
catalysts was also demonstrated. The enhancements obtained were slightly reduced, but still comparable to those obtained prior to the recovery process.

Another study has looked at deactivating the SABRE catalyst, using bipyridine (bpy), in order to improve the longevity of the hyperpolarised signal [97]. In the presence of the catalyst, [Ir(IMes)(COD)Cl], the $T_{1} \mathrm{~S}$ of nicotinamide were substantially reduced compared to solely nicotinamide. These are shown in Table 3. The addition of an equimolar amount of bpy relative to nicotinamide led to the production of a new complex, $\left[\operatorname{Ir}(\mathrm{IMes})(\mathrm{bpy})(\mathrm{H})_{2} \text { (nicotinamide) }\right]^{+}$, in which bpy is trans to both hydride ligands and nicotinamide is trans to IMes. Subsequent re-polarisation of the same solution, that now contains $\left[\operatorname{Ir}(\mathrm{IMes})(\mathrm{bpy})(\mathrm{H})_{2} \text { (nicotinamide) }\right]^{+}$and [Ir(IMes) $(\mathrm{H})_{2}$ (nicotinamide $\left.)_{3}\right]^{+}$led to $T_{1} \mathrm{~S}$ of nicotinamide which were comparable to that of free nicotinamide. Notably, after $3 T_{1} \mathrm{~S}(19.5 \mathrm{~s}), \mathrm{H}-2$ of nicotinamide retains only $5 \%$ of its hyperpolarised signal, whereas after the addition of bpy, it takes $136 \mathrm{~s}$ to reach the same level. Re-polarisation of this sample resulted in a significant drop in the enhancement observed; polarisation transfer efficiency has been reduced considerably. Indeed, due to the dissociation rate of nicotinamide from $\left.\left[\operatorname{Ir}(\mathrm{IMes})(\mathrm{H})_{2} \text { (nicotinamide) }\right]_{3}\right]^{+}$being $6.7 \pm 0.1 \mathrm{~s}^{-1}$, the minimum time for $97 \%$ conversion to [Ir(IMes)(bpy)(H) $)_{2}$ (nicotinamide) $]^{+}$is ca. $1.2 \mathrm{~s}$ and so rapid quenching is achievable. Use of UV-light to remove bpy and subsequently enable the solution to be utilised for polarisation studies again, proved unsuccessful. Use of a more rigid quenching agent, 1,10-phenanthroline also resulted in elongated times that the hyperpolarised signal persisted for. Using a series of low-tip angle pulses, the ${ }^{1} \mathrm{H}$ NMR signals of nicotinamide took $c a .170 \mathrm{~s}$ to return to thermal equilibrium. When nicotinamide was exchanged for pyridine, and the catalyst quenched with 1,10-phenanthroline, the hyperpolarised signal persisted for $94 \mathrm{~s}$. Although this value is smaller than for nicotinamide, it must be noted that only 5 equivalents of pyridine relative to catalyst was used (instead of five in the case of nicotinamide) and the initial signal intensity across all the proton sites was $c a$. 300 -fold higher than that observed for nicotinamide.

Table 3. Reported $T_{1}$ data of nicotinamide in $d_{4}$-methanol under a $\mathrm{H}_{2}$ atmosphere with and without

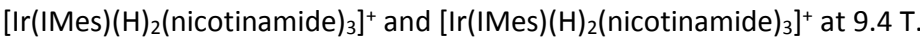

\begin{tabular}{|l|l|l|l|}
\hline Proton label & $\begin{array}{l}\mathrm{T}_{1} / \mathrm{s} \text { (free } \\
\text { form) }\end{array}$ & $\begin{array}{l}\mathrm{T}_{1} / \mathrm{s} \text { (in the presence of } \\
{\left[\operatorname{Ir}(\mathrm{IMes})(\mathrm{H})_{2}(\text { nicotinamide })_{3}\right]^{+}}\end{array}$ & $\begin{array}{l}\mathrm{T}_{1} / \mathrm{s} \text { (in the presence of } \\
\left.\left[\operatorname{Ir}(\mathrm{IMes})(\text { bpy })(\mathrm{H})_{2}(\text { nicotinamide })\right]^{+}\right)\end{array}$ \\
\hline $\mathrm{H}-2$ & 43.1 & 7.0 & 38.0 \\
\hline $\mathrm{H}-4$ & 11.3 & 6.1 & 11.5 \\
\hline $\mathrm{H}-5$ & 13.5 & 3.7 & 14.0 \\
\hline $\mathrm{H}-6$ & 6.6 & 4.3 & 6.8 \\
\hline
\end{tabular}

Deuteration of analyte molecules can improve the signal enhancement observed, provide insight in to the polarisation transfer mechanism and increase the longevity $\left(T_{1}\right)$ of the signal. This is despite the preparation of these materials sometimes being synthetically challenging. The employment of a deuteration strategy has been explored for nicotinamide and methyl nicotinate to maximise the longevity of the hyperpolarised signal [98]. For four equivalents of nicotinamide, in the presence of [Ir(IMes)(COD)Cl], the four aromatic ${ }^{1} \mathrm{H}$ sites are enhanced by $c a$. 2050 -fold over in $d_{4}$-methanol. The $T_{1} \mathrm{~s}$ range from $3.7-6.3 \mathrm{~s}$, but in ethanol they are $2.4-4.2 \mathrm{~s}$ and in $\mathrm{D}_{2} \mathrm{O}$ they are $6.5-10.7 \mathrm{~s}$, all of which are in the presence of $[\mathrm{Ir}(\mathrm{IMes})(\mathrm{COD}) \mathrm{Cl}]$ and under a hydrogen atmosphere. The longest $T_{1} \mathrm{~S}$ were obtained when either the 5,6-2,5- or the 4,6-postions were deuterated. The biggest polarisation, however, was obtained for 4,6- $d_{2}$-nicotianmide; the protons were polarised to $4.1 \%$ and the $T_{1} \mathrm{~S}$ were 26.8 and $47.9 \mathrm{~s}$ in $d_{4}$-methanol for positions 2 and 5 respectively. In ethanol the $T_{1} \mathrm{~S}$ reduced to $8.2(\mathrm{H}-2)$ and $17.5(\mathrm{H}-5)$ s whilst in $\mathrm{D}_{2} \mathrm{O}$ they were $37.1(\mathrm{H}-2)$ and $54.0(\mathrm{H}-5)$ s. Having 
established that the ${ }^{5} J_{\mathrm{HH}}$ coupling present between the two protons in 4,6- $d_{2}$-nicotianmide is sufficient for propagating polarisation (as exemplified by the polarisation levels observed on both sites), methyl nicotinate was then investigated. The methyl group of methyl nicotinate was deuterated as it was hypothesised the amide protons were aiding the relaxation process. The polarisation observed for $d_{3}$-methyl-4,6- $d_{2}$-nicotinate rose to $8.9 \%$. The $T_{1} \mathrm{~s}$ in $d_{4}$-methanol were commensurate with those of 4,6- $d_{2}$-nicotianmide, whilst the average $T_{1}$ in $\mathrm{D}_{2} \mathrm{O}$ increased. Interestingly, 4,6- $d_{2}$-nicotinate possessed better polarisation values than $d_{3}$-methyl-4,6- $d_{2}$ nicotinate, in addition to retaining similar, albeit slightly reduced $T_{1}$ values in all three solvents. This substrate was, therefore, chosen for optimisation. Increasing the parahydrogen pressure to 4.0 and 5.5 bar resulted in the polarisation of $\mathrm{H}-2$ increasing to $26.4 \%$ and $28.5 \%$ respectively. For this study, $\left[\operatorname{Ir}\left(d_{22}-\mathrm{IMes}\right)(\mathrm{COD}) \mathrm{Cl}\right]$ was used. Use of $\left[\operatorname{Ir}\left(d_{22}-\mathrm{IMes}\right)(\mathrm{COD}) \mathrm{Cl}\right]$ increased further the $T_{1} \mathrm{~s}$ of the two ${ }^{1} \mathrm{H}$ nuclei of 4,6- $d_{2}$-nicotianmide as it minimised polarisation loss due to relaxation processes. The polarisation value of $\mathrm{H}-2$ was increased to $50 \%$ ( $45 \%$ average over both sites) by employing a sacrificial co-ligand, methyl-2,4,5,6- $d_{4}$-nicotinate.

\section{Imaging Applications of SABRE}

The production of hyperpolarised molecules that possess much improved signal intensities compared to their thermal polarisations, has resulted in investigations to probe their use as contrast agents for MRI. Analytes possessing ${ }^{1} \mathrm{H},{ }^{13} \mathrm{C},{ }^{15} \mathrm{~N}$ or ${ }^{31} \mathrm{P}$ nuclei have been hyperpolarised to produce MR images using a phantom-based setup. Literature examples relating to this are presented in the following sections. At present, in vivo images have not been reported, but the following studies provide a strong foundation for this to occur in the near future.

${ }^{1} \mathrm{H}$

A field-cycling method has been detailed to obtain images at earth's magnetic field [99]. This work made use of a continuous-flow, high-throughput, high-pressure parahydrogen converter which produces a flow rate of four litres per minute of $\sim 98 \%$ para-enriched hydrogen gas [15]. Following continuous polarisation transfer, the theory of which has been described [100], in a magnetic field of $6.5 \mathrm{mT}$ for $4 \mathrm{~s}$, which took place within the MR imager, the field was then switched off to facilitate signal excitation, spatial encoding and read-out at earth's magnetic field. Imaging was limited to acquiring one line of $k$ space at a time (repetition time $8 \mathrm{~s}$ ) and thus represents an area for improvement so that images are obtained quicker. An image of a hyperpolarised solution containing $80 \mathrm{mM}$ of analyte with a field of view $64 \mathrm{~mm}^{2}$ was produced with sufficient signal-to-noise to give an interpolated resolution of $1 \mathrm{~mm}^{2}$. Total acquisition time was 4.16 minutes. An image of a solution of water $(56 \mathrm{M})$ that was pre-polarised at $20 \mathrm{mT}$ took 2.16 hours to acquire to give roughly the same signal-to-noise. Therefore, the hyperpolarised image represents a considerable time saving. With a view towards possible in vivo use, continuous hyperpolarisation of pyridine in ethanol using $[\operatorname{Ir}(\mathrm{IMes})(\mathrm{COD}) \mathrm{Cl}]$ with and without the addition of fresh human blood to the solution was probed. The polarisation values obtained are much reduced compared to a pure methanol solution and decrease further upon the addition of human blood. After obtaining one hundred scans (with a repetition time of $10 \mathrm{~s}$ ), the solution had coagulated. Although the enhancements obtained were lower than those in methanol, the use of continuous hyperpolarisation offers an attractive route to in vivo experiments.

This work was subsequently extended to an aqueous system to polarise nicotinamide continuously at low magnetic field [87]. The method developed by Truong et al. was utilised to obtain aqueous SABRE solutions [51]. At $5.6 \mathrm{mT}$, a hyperpolarised NMR signal with a signal-to-noise of 56 was detected and maintained for more than $1000 \mathrm{~s}$. The polarisation level, although only $1.6 \times 10^{-4}$, does 
benefit from the enhancement being continuously available, and therefore, adequate signal-to-noise can be easily obtained through repetitive acquisitions. A ${ }^{1} \mathrm{H} M R$ image was obtained of continuously hyperpolarised nicotinamide $(70 \mathrm{mM})$ in 5:20 minutes. This gave a signal-to-noise of 13.4 compared with water $(55 \mathrm{M})$ which had a signal-to-noise of 4.7. The relatively long time to collect the image was due to the requirement to field-cycle for hyperpolarisation $(5.9 \mathrm{mT})$ and the measurement field $(52 \mu \mathrm{T})$ for every $k$-space line. Without this requirement, it was estimated that the image could be acquired in ca. one minute.

Low-field MR images have been acquired of pyridine following polarisation under SABRE conditions [101]. Images were acquired using two different approaches; in situ and ex situ. The in situ approach utilises the same magnetic field for measurement and polarisation transfer ( $5.75 \mathrm{mT}$ or $47.5 \mathrm{mT}$ ). Ex situ utilised a magnetic field of $5.75 \mathrm{mT}$ for polarisation transfer and then a magnetic field of $47.5 \mathrm{mT}$ for detection. The high-field SABRE effect is required to generate in situ images at $47.5 \mathrm{mT}$. In situ 2D MR images acquired at $47.5 \mathrm{mT}$ possessed $0.75 \times 0.75 \mathrm{~mm}^{2}$ in-plane spatial and $4.5 \mathrm{~min}$ temporal resolution. Due to the higher polarisation yielded using the ex situ method, better in plane spatial $\left(0.125 \times 0.125 \mathrm{~mm}^{2}\right)$ and temporal resolution $(\leq 7.7 \mathrm{~s})$ were obtained. Both images have good spatial resolution, despite ex situ experiments producing signals that are two orders of magnitude larger than in situ experiments. The in situ spatial resolution is also aided by being able to use a larger excitation RF pulse tipping angle and signal averaging, due to constantly renewed polarisation that builds up quickly (time constant for build-up $=7.4 \pm 0.3 \mathrm{~s}$ ). Thus, temporal resolution can be sacrificed at the expense of improving spatial resolution greatly. Compared with a method that utilises field cycling to obtain hyperpolarised images [99], in situ detection enables a line of $k$-space to be acquired every $0.2 \mathrm{~s}$ instead of $8 \mathrm{~s}$ and gives better spatial resolution than demonstrated previously.

The effect of deuteration on the analyte on the intensity of the MR image has been demonstrated for pyridine [102]. Compared to pyridine, which gave a 169-fold contrast enhancement relative to a water internal standard, 3,4,5- $d_{3}$-pyridine produced a 807 -fold enhancement ( $\left.\mathrm{P}=2.5 \%\right)$. The decrease in the number of proton sites to accept polarisation increases the signal enhancement in the same fashion as that observed in ${ }^{1} \mathrm{H}$ NMR SABRE studies.

The effect of $\mathrm{pH}$ on the resulting signal intensity observed in MR images has been exemplified for vitamin B3 [94]. Samples consisted of $5 \mathrm{mM}$ of [ $\mathrm{Ir}(\mathrm{IMes})(\mathrm{COD}) \mathrm{Cl}]$ and 20 equivalents of vitamin B3 in $d_{4}$-methanol. An increasing amount of caesium carbonate (up to 17-fold excess) was added to the sample and MR images acquired at pHs 3.6, 4.6, 5.1, 5.7, 5.9 and 6.9 with a voxel of $3 \times 3 \times 10 \mathrm{~mm}$. Just like the ${ }^{1} \mathrm{H}$ NMR measurements, these images increase in signal intensity with increasing $\mathrm{pH}$. However, it was noted that at physiological $\mathrm{pH}$ and above, the signal-to-noise ratio plateaus before falling rapidly beyond $\mathrm{pH} 8$. This was thought to be due to the possible transverse relaxation rate effects caused by the methoxide ion. $\mathrm{A}^{13} \mathrm{C}$ image of ${ }^{13} \mathrm{C}$-labelled vitamin $\mathrm{B} 3\left({ }^{13} \mathrm{C}\right.$ located on the quaternary of the carboxylic acid) was acquired; the signal-to-noise of the uncharged vitamin B3 did not yield signals above the background noise whereas those of the conjugate base did.

${ }^{13} \mathrm{C}$

${ }^{13} \mathrm{C}$ is naturally only present at the $1 \%$ level. This makes ${ }^{13} \mathrm{C}$ labelled racers for MRI an exciting prospect. Thus far, however, there has been limited reports of ${ }^{13} \mathrm{C}$-labelled materials towards this purpose in conjunction with SABRE. The synthesis of ${ }^{13} \mathrm{C}$-labelled nicotinamide $\left({ }^{13} \mathrm{C}\right.$ located in amide) represents one example and this has enabled the collection of SABRE hyperpolarised ${ }^{13} \mathrm{C}$ images [102]. A single scan image of ${ }^{13} \mathrm{C}$-labelled nicotinamide gave a polarisation value of $0.03 \%$. Although 
this value is low, to obtain a comparative image, a total scan time of 18 hours 20 minutes was required (1100 averages).

${ }^{15} \mathrm{~N}$

The ease of obtaining a hyperpolarised ${ }^{15} \mathrm{~N}$ state using SABRE-SHEATH has motivated a ${ }^{15} \mathrm{~N}$ MRI study [73]. ${ }^{15} \mathrm{~N}$ labelled pyridine ( $\left.\sim 24 \mu \mathrm{mol}\right)$ was hyperpolarised to deliver ca. $1 \%$ polarisation following a long $30 \mathrm{~s}$ transfer from the magnetic shield in which polarisation was conducted to the $4.7 \mathrm{~T} \mathrm{MRI}$ scanner in which the measurement was performed. An axial 2D gradient echo ${ }^{15} \mathrm{~N}$ MR image with $2 \mathrm{x}$ $2 \mathrm{~mm}^{2}$ spatial resolution was acquired and this image showed hyperpolarised liquid within a $6.6 \mathrm{~mm}$ internal diameter high-pressure HPLC (High Performance Liquid Chromatography) column. This experimental setup results in the internal diameter of the column being imaged using less than four pixels. The authors note that the long-lived polarisation that is generated on the ${ }^{15} \mathrm{~N}$ nuclei could be partially transferred to ${ }^{1} \mathrm{H}$ nuclei to obtain ${ }^{1} \mathrm{H}$ MR images. The partially depleted polarised state could be utilised many times to produce subsequent ${ }^{1} \mathrm{H}$ MR images. Thus, this may offer a route to track these molecules in vivo or in metabolic processes.

${ }^{31} \mathrm{P}$

In addition to ${ }^{1} \mathrm{H},{ }^{13} \mathrm{C}$ and ${ }^{15} \mathrm{~N}$ MR images, images utilising the ${ }^{31} \mathrm{P}$ nuclei in a sample have also been acquired to demonstrate the application of SABRE. ${ }^{31} \mathrm{P}$ images of a $6 \mathrm{mM}$ solution of $\left[\left(\mathrm{PPh}_{3}\right)_{3} \mathrm{Ir}(\mathrm{H})_{2} \mathrm{Cl}\right]$ in toluene were acquired thermally and hyperpolarised at $80^{\circ} \mathrm{C}$ in a $\mu$-magnetic shield [36]. The thermal image produced does not produce a resolved image in which the cross-section of the $15 \mathrm{~mm}$ sample tube is evident. This is despite the signal being comprised of 128 transients. However, the corresponding hyperpolarised single scan ${ }^{31} \mathrm{P}$ image clearly resolves the sample tube. The hyperpolarised scan took less than one second to acquire whereas the thermal image took hours. There is quite clearly a resolution boost as well as time savings whilst employing SABRE.

The aforementioned study utilises toluene as the solvent. This is not biocompatible with a living organism. Duckett and co-workers reported RARE images of the deuterated analyte shown in Figure 28 in deuterated methanol [103]. Despite this still not being a biologically relevant medium, it does represent a move towards acquiring ${ }^{31} \mathrm{P}$ images in aqueous media. An image of the hyperpolarised sample was acquired in $500 \mathrm{~ms}$, and relative to the 2048 scan thermal image which took twelve hours of measurement time. The hyperpolarised image showed $>8$-fold improvement in signal-tonoise relative to the thermal image. The undeuterated analogue showed a $>4$-fold improvement in signal-to-noise. Conducting the experiment in a horizontal scanner led to a reduction in the SNR for the deuterated bis-3,5-substituted derivative as there was greater residual motion of the sample and a longer period of time to transfer the sample to the magnet $(c a .5 \mathrm{~s})$. As the $T_{1}$ of the ${ }^{31} \mathrm{P}$ nuclei in this substrate are only $6 \mathrm{~s}$, transfer from the polarisation transfer field to the measurement field must be as rapid as possible to ensure integrity of the polarised state. Thus, to utilise these types of ${ }^{31} \mathrm{P}$ containing substrates, the $T_{1}$ needs to be substantially longer for biomedical use.<smiles>CCOP(=O)(O[Na])c1cncc(P(=O)(O[Na])O[Na])c1</smiles>

Figure 28. Chemical structure of the deuterated analogue utilised by Burns et al. to obtain hyperpolarised ${ }^{31 P}$ images [103].

\section{Generation and utilisation of long-lived states by SABRE}

The relatively short $T_{1}$ s that some nuclei possess, such as ${ }^{1} \mathrm{H}$, limits the usefulness of the resulting hyperpolarised molecules. The section on polarisation transfer to ${ }^{15} \mathrm{~N}$ highlights this is not a problem 
for ${ }^{15} \mathrm{~N}$. To offset this shortcoming, without having to resort to deuteration strategies, utilisation of long-lived states have been investigated. 2-aminothiazole, atz, is a molecule that readily polarised by SABRE yielding enhancements of $386 \pm 20$ and $432 \pm 38$ fold for the $\mathrm{H}-4$ signal for 17 - and 2 -fold equivalents relative to $\left[\operatorname{Ir}(\mathrm{IMes})(\mathrm{atz})_{3}(\mathrm{H})_{2}\right]^{+}$(atz binds through the thiazole ring nitrogen) [104]. The respective $T_{1} \mathrm{~s}$ for $\mathrm{H}-4$ were $12.2 \pm 0.5$ and $16.2 \pm 0.6 \mathrm{~s}$ respectively at the same level of equivalence. The use of a $1 \mathrm{~s} 1 \mathrm{kHz}$ low power spin-lock, following polarisation transfer by SABRE at low-magnetic field, created a dramatic increase in the singlet magnetisation. Increasing the spin-lock time to one minute still led to the observation of significant hyperpolarised singlet derived magnetisation. The spin-lock, therefore, acts to protect the created singlet state.

This approach was extended to deuterated nicotinamide and pyrazine derivatives [105]. Singlet lifetimes for all three derivatives were in the order of $c a .40-50 \mathrm{~s}$, which were significantly longer than their corresponding $T_{1}$ values. The longest was seen for methyl-3- $d$-pyrazine-2-carboxylate, which also possessed the smallest chemical shift difference between its two proton nuclei $(34.4 \mathrm{~Hz})$. The shortest $T_{\text {LLS }}$ (LLS = long-lived singlet state) was observed for 2,4- $\mathrm{d}_{2}$-nicotinamide; the two proton nuclei are separated by a chemical shift difference of $457.0 \mathrm{~Hz}$. No significant variation in $T_{\text {LS }}$ was observed relative to substrate equivalence. This contrasts to signal enhancement which decreases with increasing substrate excess. The maximal amount of singlet order was produced following polarisation transfer that generated the largest signal SABRE derived enhancement.

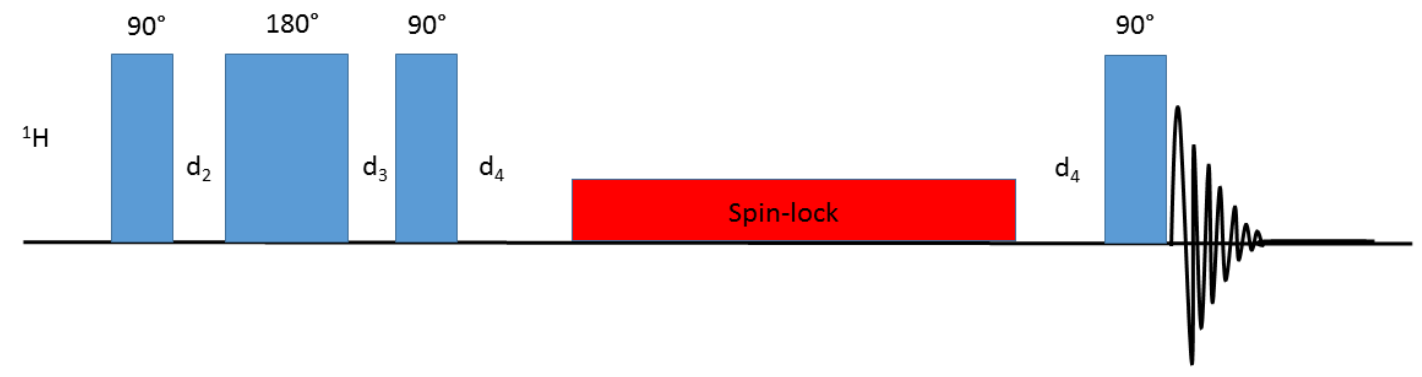

Figure 29. Pulse sequence used to create, store and read-out singlet states. $d_{2}=1 / 4 \mathrm{~J}, d_{3}=1 / 4 \mathrm{~J}+1 / 2 \Delta v$ and $d_{4}=1 / 4 \Delta v$

The importance of substrate choice in generating the longest possible $T_{\text {LS }}$ times was highlighted in a further study on pyridazine derivatives [106]. Despite the steric bulk surrounding the two nitrogen atoms of 2-methyl-6- $d_{3}$-methylpyridazine, an enhancement of 650 -fold was observed. In addition, there only exists a ${ }^{5} \mathrm{HH}_{\mathrm{HH}}$ coupling between a parahydrogen derived hydride and those of the proton nuclei of 2-methyl-6- $d_{3}$-methylpyridazine to propagate polarisation. Of the series, 2-methyl-6- $d_{3}$ methylpyridazine possessed the smallest chemical shift difference between its two proton nuclei $(0.5 \mathrm{~Hz})$. In a magnetic field of $9.4 \mathrm{~T}, T_{\text {LLS }}$ was $32 \pm 1 \mathrm{~s}$, whereas at low-field (ca. $10 \mathrm{mT}$ ), $T_{\text {LLs }}$ improved to $255 \pm 23 \mathrm{~s}$. Hyperpolarised signal was still visible 15 minutes after its creation. For $1-d_{3}$-methyl-6$d$-pyridazine, a chemical shift difference of $1 \mathrm{~Hz}$ exists between the proton nuclei. Due to the decrease in steric hindrance, the enhancement observed under SABRE increases to 2040 with TLS being $113 \pm 4 \mathrm{~s}$ at high-field with spin-locking. This material's hyperpolarised signal was still detectable 10 minutes after generation. In general, about $66 \%$ magnetisation to singlet conversion was achieved. The long periods for which the magnetisation can be stored is useful for a biological application as it allows the hyperpolarised sample to be transported to the final measurement location without any signal loss. 


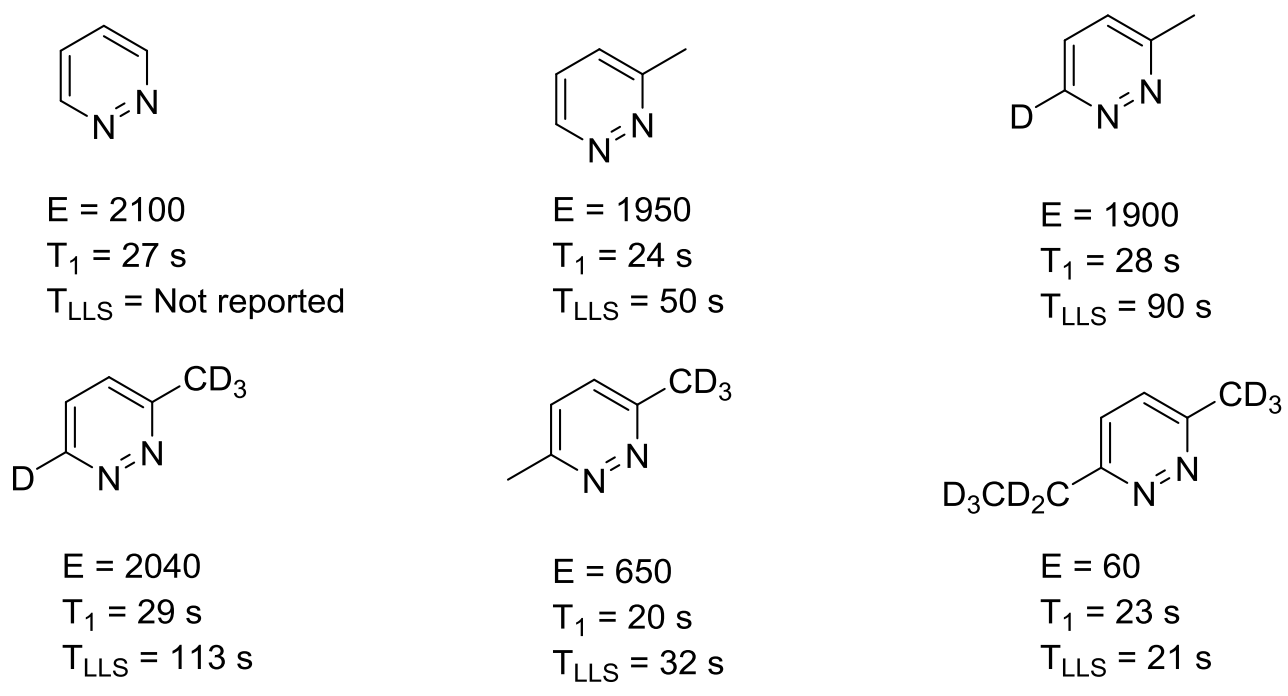

Figure 30. Pyridazine substrates and their enhancements (E), $T_{1}$ values and $T_{\text {LIS }}$ at high-field with spin-locking.

SABRE-SHEATH has also been used to create long-lived states in two pyridyl acetylene derivatives, one of which was symmetric, the other asymmetric [107]. The acetylene component was ${ }^{13} \mathrm{C}$-labelled and compared to analogous non-labelled derivatives. Employment of SABRE-SHEATH led to enhancements of 37- to 166 -fold. Derivatives that were not ${ }^{13} \mathrm{C}$-labelled, were enhanced by $2-3$ times more than ${ }^{13} \mathrm{C}$-enriched derivatives. This may be due to faster $T_{1}$ relaxation in the ${ }^{13} \mathrm{C}_{2}$ pairs as opposed to isolated ${ }^{13} \mathrm{C}$ spins. [ $\left.\operatorname{Ir}(\mathrm{IMes})(\mathrm{COD}) \mathrm{Cl}\right]$ was used as the pre-catalyst for these experiments. Interestingly, no hyperpolarisation of the ring carbons resulted and hydrogenation of the alkyne bond was observed. Both of these observations would suggest that binding was occurring predominantly through the alkyne bond rather the pyridyl motif. However, diphenyl- ${ }^{13} \mathrm{C}_{2}$-acetylene did not polarise and ${ }^{1} \mathrm{H}$ NMR spectra revealed strong SABRE enhancements for the pyridyl protons. More likely is that the $T_{1} \mathrm{~s}$ of carbon nuclei with protons directly attached are short ( $\sim 5 \mathrm{~s}$ ) and, therefore, prevent build-up and detection. Conversely, the $T_{1} \mathrm{~S}$ of the bridge and acetylene carbon nuclei are 11 and $12 \mathrm{~s}$ respectively at low-field. Magnetisation and singlet order are produced in the ${ }^{13} \mathrm{C}$-labelled derivatives. The singlet order has a lifetime of $\sim 2$ minutes. Read-out of the singlet order in the asymmetric derivative occurs readily as the singlet state is no longer an eigenstate (chemical shift difference $\left(\Delta v_{\mathrm{c}} \sim 770 \mathrm{~Hz}\right)$ is larger than the $J_{\mathrm{Cc}}$ coupling $(185 \mathrm{~Hz})$. This is not true for the symmetric derivative and as such, specialised pulse sequences would be needed to convert the singlet order in to detectable magnetisation.
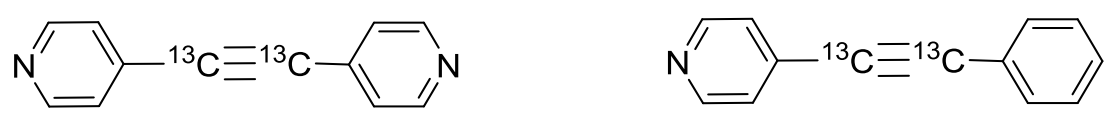

Figure 31. The symmetrical and asymmetrical acetylene derivatives that were investigated by Theis and co-workers [107].

\section{Summary}

This work has been concerned with detailing the hyperpolarisation technique SABRE and its applications in NMR and MRI. The chemical structure of the pre-catalyst was detailed and the importance of the inclusion of a carbene ligand compared to a phosphine ligand highlighted in terms of improving the enhancements obtained. The physical attributes that the catalyst needs to possess were covered and this demonstrated the complex interplay of a number of constraints such as parahydrogen pressure, solvent selection, amount of substrate, the magnetic field in which polarisation is conducted, type of substrate to be polarised and the temperature at which polarisation transfer is conducted. Analysis of parameters such as PAAP, and the use of DFT, for 
example, were detailed to explain further how insight is being gleaned about the polarisation transfer process. Exchange rates of the substrate and the hydride ligands were discussed to bring to the reader's attention the reversible nature of the process and how they can be tailored to improve polarisation efficiency. Works on the utilisation of other group 9 congeners as the central metal of SABRE catalysts and the utilisation of bi- and tri-dentate ligands in catalyst construction, were also presented.

The applications of SABRE were highlighted, using examples from the literature. These mainly focused on detecting species at low concentrations or magnetic field that would be difficult using conventional NMR. The hyperpolarisation of ${ }^{1} \mathrm{H},{ }^{13} \mathrm{C},{ }^{15} \mathrm{~N},{ }^{19} \mathrm{~F},{ }^{31} \mathrm{P},{ }^{29} \mathrm{Si}$ and ${ }^{119} \mathrm{Sn}$ nuclei were the subject of these various studies. Synthetic strategies, whereby molecules are synthesised to maximise polarisation transfer or deuterated to minimise the number of polarisation acceptors, were stressed as methods to improve signal intensities. The use of co-ligands were emphasised as a further way to increase the observable enhancement. The collection of 2D NMR spectra, such as COSY and HMBC, were discussed to demonstrate how SABRE improves the quality of these spectra, as well as reducing the time required to acquire them. Utilisation of ultra-fast techniques was another area highlighted that employed SABRE whereby 2D spectra have been acquired in a single scan.

Special emphasis was placed upon SABRE-SHEATH based experiments, as due to the wealth of research conducted recently, this is a readily apparent hot-subtopic of SABRE. The scope of the molecules polarisable by this technique were presented, and the rationale behind their relative enhancements provided. In particular, the employment of SABRE-SHEATH to polarise non- $N$ heterocycles represents an exciting breakthrough for SABRE and further diversifies what this technique can be applied to.

High-field SABRE was also presented to show that SABRE is not limited to low-field derived polarisation transfer. The improvements of this technique were detailed, by showcasing relevant pulse sequences. In addition, the employment of the technique for the collection of 1D and 2D NMR spectra of complex mixtures, and for the chemosensing of natural extracts, was exemplified.

The hyperpolarisation of biologically relevant analytes was detailed, as was the conducting of SABRE based experiments in aqueous systems. The motivation behind these studies has been mainly to demonstrate that SABRE can be translated from a NMR-based approach to MRI, as there is currently considerable interest in the production of non-gadolinium based contrast agents. Reports detailing the collection of ${ }^{1} \mathrm{H},{ }^{13} \mathrm{C},{ }^{15} \mathrm{~N}$ and ${ }^{31} \mathrm{P}$ MR images of phantoms were exemplified and the merits of the acquired images highlighted. Although a SABRE-based in vivo image is yet to be disseminated in the literature, the works detailing imaged phantoms provides a strong foundation for this to be achieved.

The work concluded with a section on long-lived states. This area presented the current research on elongating the $T_{1} \mathrm{~S}$ of substrates by accessing these substrates. As the $T_{1}$ is an effective measure of the longevity of polarisation, maximising this results in a longer time-frame to successfully deploy the hyperpolarised material prior to magnetisation read-out.

\section{Acknowledgements}

Both authors would like to acknowledge Manchester Metropolitan University for a Vice-Chancellor Scholarship for T. B. R. Robertson. 


\section{References}

[1] W. Brewer, M. Kopp, Brute-force nuclear orientation, Hyperfine Interact. 2 (1976) 299-305.

[2] M.L. Hirsch, N. Kalechofsky, A. Belzer, M. Rosay, J.G. Kempf, Brute-Force Hyperpolarization for NMR and MRI, J. Am. Chem. Soc. 137 (2015) 8428-8434.

[3] F. Jahnig, G. Kwiatkowski, M. Ernst, Conceptual and instrumental progress in dissolution DNP, J. Mag. Res. 264 (2016) 22-29.

[4] K.R. Keshari, D.M. Wilson, Chemistry and biochemistry of C-13 hyperpolarized magnetic resonance using dynamic nuclear polarization, Chem. Soc. Rev. 43 (2014) 1627-1659.

[5] Q.Z. Ni, E. Daviso, T.V. Can, E. Markhasin, S.K. Jawla, T.M. Swager, R.J. Temkin, J. Herzfeld, R.G. Griffin, High Frequency Dynamic Nuclear Polarization, Acc. Chem. Res. 46 (2013) 1933-1941.

[6] A.J. Rossini, A. Zagdoun, M. Lelli, A. Lesage, C. Coperet, L. Emsley, Dynamic Nuclear Polarization Surface Enhanced NMR Spectroscopy, Acc. Chem. Res. 46 (2013) 1942-1951.

[7] J. van Bentum, B. van Meerten, M. Sharma, A. Kentgens, Perspectives on DNP-enhanced NMR spectroscopy in solutions, J. Mag. Res. 264 (2016) 59-67.

[8] T.G. Walker, W. Happer, Spin-exchange optical pumping of noble-gas nuclei, Rev. Mod. Phys. 69 (1997) 629-642.

[9] T.C. Eisenschmid, R.U. Kirss, P.P. Deutsch, S.I. Hommeltoft, R. Eisenberg, J. Bargon, R.G. Lawler, A.L. Balch, Para hydrogen induced polarization in hydrogenation reactions, J. Am. Chem. Soc. 109 (1987) 8089-8091.

[10] D. Blazina, S.B. Duckett, J.P. Dunne, C. Godard, Applications of the parahydrogen phenomenon in inorganic chemistry, Dalton Trans. (2004) 2601-2609.

[11] S.B. Duckett, N.J. Wood, Parahydrogen-based NMR methods as a mechanistic probe in inorganic chemistry, Coord. Chem. Rev. 252 (2008) 2278-2291.

[12] R.A. Green, R.W. Adams, S.B. Duckett, R.E. Mewis, D.C. Williamson, G.G.R. Green, The theory and practice of hyperpolarization in magnetic resonance using parahydrogen, Prog. Nucl. Magn.

Reson. Spectrosc. 67 (2012) 1-48.

[13] S.B. Duckett, R.E. Mewis, Application of Parahydrogen Induced Polarization Techniques in NMR Spectroscopy and Imaging, Acc. Chem. Res. 45 (2012) 1247-1257.

[14] S. Gloggler, J. Colell, S. Appelt, Para-hydrogen perspectives in hyperpolarized NMR, J. Mag. Res. 235 (2013) 130-142.

[15] J.B. Hovener, S. Bar, J. Leupold, K. Jenne, D. Leibfritz, J. Hennig, S.B. Duckett, D. von Elverfeldt, A continuous-flow, high-throughput, high-pressure parahydrogen converter for hyperpolarization in a clinical setting, NMR Biomed. 26 (2013) 124-131.

[16] B.B. Feng, A.M. Coffey, R.D. Colon, E.Y. Chekmenev, K.W. Waddell, A pulsed injection parahydrogen generator and techniques for quantifying enrichment, J. Mag. Res. 214 (2012) 258262.

[17] A.M. Coffey, R.V. Shchepin, M.L. Truong, K. Wilkens, W. Pham, E.Y. Chekmenev, OpenSource Automated Parahydrogen Hyperpolarizer for Molecular Imaging Using C-13 Metabolic Contrast Agents, Anal. Chem. 88 (2016) 8279-8288.

[18] C.R. Bowers, D.P. Weitekamp, TRANSFORMATION OF SYMMETRIZATION ORDER TO NUCLEAR-SPIN MAGNETIZATION BY CHEMICAL-REACTION AND NUCLEAR-MAGNETIC-RESONANCE, Phys. Rev. Lett. 57 (1986) 2645-2648.

[19] C.R. Bowers, D.P. Weitekamp, PARA-HYDROGEN AND SYNTHESIS ALLOW DRAMATICALLY ENHANCED NUCLEAR ALIGNMENT, J. Am. Chem. Soc. 109 (1987) 5541-5542.

[20] S.I. Hommeltoft, D.H. Berry, R. Eisenberg, Metal-centered radical-pair mechanism for alkyne hydrogenation with a binuclear rhodium hydride complex. CIDNP without organic radicals, J. Am.

Chem. Soc. 108 (1986) 5345-5347.

[21] M.G. Pravica, D.P. Weitekamp, NET NMR ALIGNMENT BY ADIABATIC TRANSPORT OF PARAHYDROGEN ADDITION-PRODUCTS TO HIGH MAGNETIC-FIELD, Chem. Phys. Lett. 145 (1988) 255-258.

[22] R.E. Mewis, Developments and advances concerning the hyperpolarisation technique SABRE, Magn. Reson. Chem. 53 (2015) 789-800. 
[23] R.W. Adams, J.A. Aguilar, K.D. Atkinson, M.J. Cowley, P.I.P. Elliott, S.B. Duckett, G.G.R. Green, I.G. Khazal, J. Lopez-Serrano, D.C. Williamson, Reversible Interactions with para-Hydrogen Enhance NMR Sensitivity by Polarization Transfer, Science 323 (2009) 1708-1711.

[24] R.W. Adams, S.B. Duckett, R.A. Green, D.C. Williamson, G.G.R. Green, A theoretical basis for spontaneous polarization transfer in non-hydrogenative parahydrogen-induced polarization, J.

Chem. Phys. 131 (2009).

[25] K.D. Atkinson, M.J. Cowley, S.B. Duckett, P.I.P. Elliott, G.G.R. Green, J. Lopez-Serrano, I.G. Khazal, A.C. Whitwood, Para-Hydrogen Induced Polarization without Incorporation of Para-Hydrogen into the Analyte, Inorg. Chem. 48 (2009) 663-670.

[26] K.D. Atkinson, M.J. Cowley, P.I.P. Elliott, S.B. Duckett, G.G.R. Green, J. López-Serrano, A.C. Whitwood, Spontaneous Transfer of Parahydrogen Derived Spin Order to Pyridine at Low Magnetic Field, J. Am. Chem. Soc. 131 (2009) 13362-13368.

[27] M.J. Cowley, R.W. Adams, K.D. Atkinson, M.C.R. Cockett, S.B. Duckett, G.G.R. Green, J.A.B. Lohman, R. Kerssebaum, D. Kilgour, R.E. Mewis, Iridium N-Heterocyclic Carbene Complexes as Efficient Catalysts for Magnetization Transfer from para-Hydrogen, J. Am. Chem. Soc. 133 (2011) 6134-6137.

[28] B.J.A. van Weerdenburg, S. Gloggler, N. Eshuis, A.H.J. Engwerda, J.M.M. Smits, R. de Gelder, S. Appelt, S.S. Wymenga, M. Tessari, M.C. Feiters, B. Blumich, F. Rutjes, Ligand effects of NHC-iridium catalysts for signal amplification by reversible exchange (SABRE), Chem. Commun. 49 (2013) 73887390 .

[29] L.S. Lloyd, A. Asghar, M.J. Burns, A. Charlton, S. Coombes, M.J. Cowley, G.J. Dear, S.B. Duckett, G.R. Genov, G.G.R. Green, L.A.R. Highton, A.J.J. Hooper, M. Khan, I.G. Khazal, R.J. Lewis, R.E. Mewis, A.D. Roberts, A.J. Ruddlesden, Hyperpolarisation through reversible interactions with parahydrogen, Catal. Sci. Technol. 4 (2014) 3544-3554.

[30] B.J.A. van Weerdenburg, N. Eshuis, M. Tessari, F.P.J.T. Rutjes, M.C. Feiters, Application of the [small pi]-accepting ability parameter of $\mathrm{N}$-heterocyclic carbene ligands in iridium complexes for signal amplification by reversible exchange (SABRE), Dalton Trans. 44 (2015) 15387-15390.

[31] S.V.C. Vummaleti, D.J. Nelson, A. Poater, A. Gomez-Suarez, D.B. Cordes, A.M.Z. Slawin, S.P. Nolan, L. Cavallo, What can NMR spectroscopy of selenoureas and phosphinidenes teach us about the [small pi]-accepting abilities of N-heterocyclic carbenes?, Chemical Science 6 (2015) 1895-1904. [32] B.J.A. van Weerdenburg, A.H.J. Engwerda, N. Eshuis, A. Longo, D. Banerjee, M. Tessari, C.F. Guerra, F. Rutjes, F.M. Bickelhaupt, M.C. Feiters, Computational (DFT) and Experimental (EXAFS) Study of the Interaction of $\operatorname{Ir}(\mathrm{IMes})(\mathrm{H})(2)(\mathrm{L})(3)$ with Substrates and Co-substrates Relevant for SABRE in Dilute Systems, Chem. Eur. J. 21 (2015) 10482-10489.

[33] D.A. Barskiy, A.N. Pravdivtsev, K.L. Ivanov, K.V. Kovtunov, I.V. Koptyug, A simple analytical model for signal amplification by reversible exchange (SABRE) process, Phys. Chem. Chem. Phys. 18 (2016) 89-93.

[34] A.N. Pravdivtsev, A.V. Yurkovskaya, H.M. Vieth, K.L. Ivanov, R. Kaptein, Level Anti-Crossings are a Key Factor for Understanding para-Hydrogen-Induced Hyperpolarization in SABRE Experiments, Chemphyschem 14 (2013) 3327-3331.

[35] L.B. Bales, K.V. Kovtunov, D.A. Barskiy, R.V. Shchepin, A.M. Coffey, L.M. Kovtunova, A.V. Bukhtiyarov, M.A. Feldman, V.I. Bukhtiyarov, E.Y. Chekmenev, I.V. Koptyug, B.M. Goodson, Aqueous, Heterogeneous para-Hydrogen-Induced ${ }^{15}$ N Polarization, J. Phys. Chem. C 121 (2017) 15304-15309.

[36] V.V. Zhivonitko, I.V. Skovpin, I.V. Koptyug, Strong P-31 nuclear spin hyperpolarization produced via reversible chemical interaction with parahydrogen, Chem. Commun. 51 (2015) 25062509.

[37] K. Tokmic, C.R. Markus, L.Y. Zhu, A.R. Fout, Well-Defined Cobalt(I) Dihydrogen Catalyst: Experimental Evidence for a $\mathrm{Co}(\mathrm{I}) / \mathrm{Co}(\mathrm{III})$ Redox Process in Olefin Hydrogenation, J. Am. Chem. Soc. 138 (2016) 11907-11913. 
[38] J.A. Aguilar, R.W. Adams, S.B. Duckett, G.G.R. Green, R. Kandiah, Selective detection of hyperpolarized NMR signals derived from para-hydrogen using the Only Para-hydrogen SpectroscopY (OPSY) approach, J. Mag. Res. 208 (2011) 49-57.

[39] J.A. Aguilar, P.I.P. Elliott, J. Lopez-Serrano, R.W. Adams, S.B. Duckett, Only para-hydrogen spectroscopy (OPSY), a technique for the selective observation of para-hydrogen enhanced NMR signals, Chem. Commun. (2007) 1183-1185.

[40] K. Tokmic, A.R. Fout, Alkyne Semihydrogenation with a Well-Defined Nonclassical Co-H-2 Catalyst: A H-2 Spin on Isomerization and E-Selectivity, J. Am. Chem. Soc. 138 (2016) 13700-13705.

[41] A.J. Ruddlesden, R.E. Mewis, G.G.R. Green, A.C. Whitwood, S.B. Duckett, Catalytic Transfer of Magnetism Using a Neutral Iridium Phenoxide Complex, Organometallics 34 (2015) 2997-3006.

[42] A.J. Ruddlesden, S.B. Duckett, Solvent responsive catalyst improves NMR sensitivity via efficient magnetisation transfer, Chem. Commun. 52 (2016) 8467-8470.

[43] A.J. Holmes, P.J. Rayner, M.J. Cowley, G.G.R. Green, A.C. Whitwood, S.B. Duckett, The reaction of an iridium PNP complex with parahydrogen facilitates polarisation transfer without chemical change, Dalton Trans. 44 (2015) 1077-1083.

[44] E.B. Ducker, L.T. Kuhn, K. Munnemann, C. Griesinger, Similarity of SABRE field dependence in chemically different substrates, J. Mag. Res. 214 (2012) 159-165.

[45] K.X. Moreno, K. Nasr, M. Milne, A.D. Sherry, W.J. Goux, Nuclear spin hyperpolarization of the solvent using signal amplification by reversible exchange (SABRE), J. Mag. Res. 257 (2015) 15-23.

[46] A.N. Pravdivtsev, K.L. Ivanov, A.V. Yurkovskaya, P.A. Petrov, H.H. Limbach, R. Kaptein, H.M. Vieth, Spin polarization transfer mechanisms of SABRE: A magnetic field dependent study, J. Mag. Res. 261 (2015) 73-82.

[47] A.S. Kiryutin, A.N. Pravdivtsev, K.L. Ivanov, Y.A. Grishin, H.M. Vieth, A.V. Yurkovskaya, A fast field-cycling device for high-resolution NMR: Design and application to spin relaxation and hyperpolarization experiments, J. Mag. Res. 263 (2016) 79-91.

[48] R.E. Mewis, K.D. Atkinson, M.J. Cowley, S.B. Duckett, G.G.R. Green, R.A. Green, L.A.R. Highton, D. Kilgour, L.S. Lloyd, J.A.B. Lohman, D.C. Williamson, Probing signal amplification by reversible exchange using an NMR flow system, Magn. Reson. Chem. 52 (2014) 358-369.

[49] D.A. Barskiy, K.V. Kovtunov, I.V. Koptyug, P. He, K.A. Groome, Q.A. Best, F. Shi, B.M. Goodson, R.V. Shchepin, A.M. Coffey, K.W. Waddell, E.Y. Chekmenev, The Feasibility of Formation and Kinetics of NMR Signal Amplification by Reversible Exchange (SABRE) at High Magnetic Field (9.4 T), J. Am. Chem. Soc. 136 (2014) 3322-3325.

[50] A.N. Pravdivtsev, A.V. Yurkovskaya, P.A. Petrov, H.M. Vieth, K.L. Ivanov, Analysis of the SABRE (Signal Amplification by Reversible Exchange) Effect at High Magnetic Fields, Appl. Magn. Reson. 47 (2016) 711-725.

[51] M.L. Truong, F. Shi, P. He, B.X. Yuan, K.N. Plunkett, A.M. Coffey, R.V. Shchepin, D.A. Barskiy, K.V. Kovtunov, I.V. Koptyug, K.W. Waddell, B.M. Goodson, E.Y. Chekmenev, Irreversible Catalyst Activation Enables Hyperpolarization and Water Solubility for NMR Signal Amplification by Reversible Exchange, J. Phys. Chem. B 118 (2014) 13882-13889.

[52] A.N. Pravdivtsev, A.V. Yurkovskaya, H.M. Vieth, K.L. Ivanov, Spin mixing at level anticrossings in the rotating frame makes high-field SABRE feasible, Phys. Chem. Chem. Phys. 16 (2014) 24672-24675.

[53] A.N. Pravdivtsev, A.V. Yurkovskaya, H.M. Vieth, K.L. Ivanov, RF-SABRE: A Way to Continuous Spin Hyperpolarization at High Magnetic Fields, J. Phys. Chem. B 119 (2015) 13619-13629.

[54] N. Eshuis, R. Aspers, B.J.A. van Weerdenburg, M.C. Feiters, F. Rutjes, S.S. Wijmenga, M. Tessari, 2D NMR Trace Analysis by Continuous Hyperpolarization at High Magnetic Field, Angew. Chem. Int. Edit. 54 (2015) 14527-14530.

[55] N.K.J. Hermkens, N. Eshuis, B.J.A. van Weerdenburg, M.C. Feiters, F.P.J.T. Rutjes, S.S. Wijmenga, M. Tessari, NMR-Based Chemosensing via $\mathrm{p}-\mathrm{H}_{2}$ Hyperpolarization: Application to Natural Extracts, Anal. Chem. 88 (2016) 3406-3412. 
[56] A.N. Pravdivtsev, A.V. Yurkovskaya, H. Zimmermann, H.M. Vieth, K.L. Ivanov, Enhancing NMR of insensitive nuclei by transfer of SABRE spin hyperpolarization, Chem. Phys. Lett. 661 (2016) 77-82. [57] S. Knecht, A.N. Pravdivtsev, J.B. Hovener, A.V. Yurkovskaya, K.L. Ivanov, Quantitative description of the SABRE process: rigorous consideration of spin dynamics and chemical exchange, Rsc Advances 6 (2016) 24470-24477.

[58] N.K.J. Hermkens, M.C. Feiters, F.P.J.T. Rutjes, S.S. Wijmenga, M. Tessari, High field hyperpolarization-EXSY experiment for fast determination of dissociation rates in SABRE complexes, J. Mag. Res. 276 (2017) 122-127.

[59] N. Eshuis, N. Hermkens, B.J.A. van Weerdenburg, M.C. Feiters, F. Rutjes, S.S. Wijmenga, M. Tessari, Toward Nanomolar Detection by NMR Through SABRE Hyperpolarization, J. Am. Chem. Soc. 136 (2014) 2695-2698.

[60] A.N. Pravdivtsev, A.V. Yurkovskaya, H. Zimmermann, H.M. Vieth, K.L. Ivanov, Transfer of SABRE-derived hyperpolarization to spin-1/2 heteronuclei, Rsc Advances 5 (2015) 63615-63623.

[61] N. Eshuis, B.J.A. van Weerdenburg, M.C. Feiters, F. Rutjes, S.S. Wijmenga, M. Tessari, Quantitative Trace Analysis of Complex Mixtures Using SABRE Hyperpolarization, Angew. Chem. Int. Edit. 54 (2015) 1481-1484.

[62] Q. Gong, A. Gordji-Nejad, B. Blümich, S. Appelt, Trace Analysis by Low-Field NMR: Breaking the Sensitivity Limit, Anal. Chem. 82 (2010) 7078-7082.

[63] S. Gloggler, M. Emondts, J. Colell, R. Muller, B. Blumich, S. Appelt, Selective drug trace detection with low-field NMR, Analyst 136 (2011) 1566-1568.

[64] S. Gloggler, R. Muller, J. Colell, M. Emondts, M. Dabrowski, B. Blumich, S. Appelt, Parahydrogen induced polarization of amino acids, peptides and deuterium-hydrogen gas, Phys. Chem. Chem. Phys. 13 (2011) 13759-13764.

[65] T. Ratajczyk, T. Gutmann, P. Bernatowicz, G. Buntkowsky, J. Frydel, B. Fedorczyk, NMR Signal Enhancement by Effective SABRE Labeling of Oligopeptides, Chem. Eur. J. 21 (2015) 12616-12619.

[66] F.F. Diaz-Rullo, F. Zamberlan, R.E. Mewis, M. Fekete, L. Broche, L.A. Cheyne, S. Dall'Angelo, S.B. Duckett, D. Dawson, M. Zanda, Synthesis and hyperpolarisation of eNOS substrates for quantification of NO production by H-1 NMR spectroscopy, Biorg. Med. Chem. 25 (2017) 2730-2742. [67] H.F. Zeng, J.D. Xu, J. Gillen, M.T. McMahon, D. Artemov, J.M. Tyburn, J.A.B. Lohman, R.E. Mewis, K.D. Atkinson, G.G.R. Green, S.B. Duckett, P.C.M. van Zijl, Optimization of SABRE for polarization of the tuberculosis drugs pyrazinamide and isoniazid, J. Mag. Res. 237 (2013) 73-78.

[68] L.S. Lloyd, R.W. Adams, M. Bernstein, S. Coombes, S.B. Duckett, G.G.R. Green, R.J. Lewis, R.E. Mewis, C.J. Sleigh, Utilization of SABRE-Derived Hyperpolarization To Detect Low-Concentration Analytes via 1D and 2D NMR Methods, J. Am. Chem. Soc. 134 (2012) 12904-12907.

[69] V. Daniele, F.X. Legrand, P. Berthault, J.N. Dumez, G. Huber, Single-Scan Multidimensional NMR Analysis of Mixtures at Sub-Millimolar Concentrations by using SABRE Hyperpolarization, Chemphyschem 16 (2015) 3413-3417.

[70] K.M. Appleby, R.E. Mewis, A.M. Olaru, G.G.R. Green, I.J.S. Fairlamb, S.B. Duckett, Investigating pyridazine and phthalazine exchange in a series of iridium complexes in order to define their role in the catalytic transfer of magnetisation from para-hydrogen, Chemical Science 6 (2015) 3981-3993.

[71] W. Iali, G.G.R. Green, S.J. Hart, A.C. Whitwood, S.B. Duckett, Iridium Cyclooctene Complex That Forms a Hyperpolarization Transfer Catalyst before Converting to a Binuclear C-H Bond Activation Product Responsible for Hydrogen Isotope Exchange, Inorg. Chem. 55 (2016) 1163911643.

[72] R.E. Mewis, R.A. Green, M.C.R. Cockett, M.J. Cowley, S.B. Duckett, G.G.R. Green, R.O. John, P.J. Rayner, D.C. Williamson, Strategies for the Hyperpolarization of Acetonitrile and Related Ligands by SABRE, J. Phys. Chem. B 119 (2015) 1416-1424.

[73] M.L. Truong, T. Theis, A.M. Coffey, R.V. Shchepin, K.W. Waddell, F. Shi, B.M. Goodson, W.S. Warren, E.Y. Chekmenev, N-15 Hyperpolarization by Reversible Exchange Using SABRE-SHEATH, J. Phys. Chem. C. 119 (2015) 8786-8797. 
[74] D.A. Barskiy, R.V. Shchepin, C.P.N. Tanner, J.F.P. Colell, B.M. Goodson, T. Theis, W.S. Warren, E.Y. Chekmenev, The Absence of Quadrupolar Nuclei Facilitates Efficient ${ }^{13} \mathrm{C}$ Hyperpolarization via Reversible Exchange with Parahydrogen, ChemPhysChem 18 (2017) 1493-1498.

[75] T. Theis, M.P. Ledbetter, G. Kervern, J.W. Blanchard, P.J. Ganssle, M.C. Butler, H.D. Shin, D. Budker, A. Pines, Zero-Field NMR Enhanced by Parahydrogen in Reversible Exchange, J. Am. Chem. Soc. 134 (2012) 3987-3990.

[76] T. Theis, M. Truong, A.M. Coffey, E.Y. Chekmenev, W.S. Warren, LIGHT-SABRE enables efficient in-magnet catalytic hyperpolarization, J. Mag. Res. 248 (2014) 23-26.

[77] T. Theis, M.L. Truong, A.M. Coffey, R.V. Shchepin, K.W. Waddell, F. Shi, B.M. Goodson, W.S. Warren, E.Y. Chekmenev, Microtesla SABRE Enables 10\% Nitrogen-15 Nuclear Spin Polarization, J. Am. Chem. Soc. 137 (2015) 1404-1407.

[78] R.V. Shchepin, M.L. Truong, T. Theis, A.M. Coffey, F. Shi, K.W. Waddell, W.S. Warren, B.M. Goodson, E.Y. Chekmenev, Hyperpolarization of "Neat" Liquids by NMR Signal Amplification by Reversible Exchange, J. Phys. Chem. Lett. 6 (2015) 1961-1967.

[79] J.F.P. Colell, A.W.J. Logan, Z. Zhou, R.V. Shchepin, D.A. Barskiy, G.X. Ortiz, Q. Wang, S.J. Malcolmson, E.Y. Chekmenev, W.S. Warren, T. Theis, Generalizing, Extending, and Maximizing Nitrogen-15 Hyperpolarization Induced by Parahydrogen in Reversible Exchange, J. Phys. Chem. C 121 (2017) 6626-6634.

[80] A.W.J. Logan, T. Theis, J.F.P. Colell, W.S. Warren, S.J. Malcolmson, Hyperpolarization of Nitrogen-15 Schiff Bases by Reversible Exchange Catalysis with para-Hydrogen, Chem. Eur. J. 22 (2016) 10777-10781.

[81] R.V. Shchepin, D.A. Barskiy, D.M. Mikhaylov, E.Y. Chekmenev, Efficient Synthesis of Nicotinamide-1-N-15 for Ultrafast NMR Hyperpolarization Using Parahydrogen, Bioconjugate Chem. 27 (2016) 878-882.

[82] D.A. Barskiy, R.V. Shchepin, A.M. Coffey, T. Theis, W.S. Warren, B.M. Goodson, E.Y. Chekmenev, Over 20\% N-15 Hyperpolarization in Under One Minute for Metronidazole, an Antibiotic and Hypoxia Probe, J. Am. Chem. Soc. 138 (2016) 8080-8083.

[83] R.V. Shchepin, D.A. Barskiy, A.M. Coffey, T. Theis, F. Shi, W.S. Warren, B.M. Goodson, E.Y. Chekmenev, N-15 Hyperpolarization of Imidazole-N-15(2) for Magnetic Resonance pH Sensing via SABRE-SHEATH, Acs Sensors 1 (2016) 640-644.

[84] J.F.P. Colell, M. Emondts, A.W.J. Logan, K. Shen, J. Bae, R.V. Shchepin, G.X. Ortiz, P. Spannring, Q. Wang, S.J. Malcolmson, E.Y. Chekmenev, M.C. Feiters, F.P.J.T. Rutjes, B. Blümich, T. Theis, W.S. Warren, Direct Hyperpolarization of Nitrogen-15 in Aqueous Media with Parahydrogen in Reversible Exchange, J. Am. Chem. Soc. 139 (2017) 7761-7767.

[85] P. Spannring, I. Reile, M. Emondts, P.P.M. Schleker, N.K.J. Hermkens, N.G.J. van der Zwaluw, B.J.A. van Weerdenburg, P. Tinnemans, M. Tessari, B. Blumich, F. Rutjes, M.C. Feiters, A New Ir-NHC Catalyst for Signal Amplification by Reversible Exchange in $D_{2} O$, Chem. Eur. J. 22 (2016) 9277-9282.

[86] T. Theis, G.X. Ortiz, A.W.J. Logan, K.E. Claytor, Y. Feng, W.P. Huhn, V. Blum, S.J. Malcolmson, E.Y. Chekmenev, Q. Wang, W.S. Warren, Direct and cost-efficient hyperpolarization of long-lived nuclear spin states on universal N-15(2)-diazirine molecular tags, Sci. Adv. 2 (2016).

[87] P. Rovedo, S. Knecht, T. Baumlisberger, A.L. Cremer, S.B. Duckett, R.E. Mewis, G.G.R. Green, M. Burns, P.J. Rayner, D. Leibfritz, J.G. Korvink, J. Hennig, G. Putz, D. von Elverfeldt, J.B. Hovener, Molecular MRI in the Earth's Magnetic Field Using Continuous Hyperpolarization of a Biomolecule in Water, J. Phys. Chem. B 120 (2016) 5670-5677.

[88] Y. Zhou, J. Wang, Z. Gu, S. Wang, W. Zhu, J.L. Aceña, V.A. Soloshonok, K. Izawa, H. Liu, Next Generation of Fluorine-Containing Pharmaceuticals, Compounds Currently in Phase II-III Clinical Trials of Major Pharmaceutical Companies: New Structural Trends and Therapeutic Areas, Chem. Rev. 116 (2016) 422-518.

[89] M. Fekete, O. Bayfield, S.B. Duckett, S. Hart, R.E. Mewis, N. Pridmore, P.J. Rayner, A. Whitwood, Iridium(III) Hydrido N-Heterocyclic Carbene-Phosphine Complexes as Catalysts in Magnetization Transfer Reactions, Inorg. Chem. 52 (2013) 13453-13461. 
[90] A.M. Olaru, A. Burt, P.J. Rayner, S.J. Hart, A.C. Whitwood, G.G.R. Green, S.B. Duckett, Using signal amplification by reversible exchange (SABRE) to hyperpolarise 119Sn and 29Si NMR nuclei, Chem. Commun. 52 (2016) 14482-14485.

[91] H.F. Zeng, J.D. Xu, M.T. McMahon, J.A.B. Lohman, P.C.M. van Zijl, Achieving 1\% NMR polarization in water in less than 1 min using SABRE, J. Mag. Res. 246 (2014) 119-121.

[92] M. Fekete, C. Gibard, G.J. Dear, G.G.R. Green, A.J.J. Hooper, A.D. Roberts, F. Cisnetti, S.B. Duckett, Utilisation of water soluble iridium catalysts for signal amplification by reversible exchange, Dalton Trans. 44 (2015) 7870-7880.

[93] F. Shi, P. He, Q.A. Best, K. Groome, M.L. Truong, A.M. Coffey, G. Zimay, R.V. Shchepin, K.W. Waddell, E.Y. Chekmenev, B.M. Goodson, Aqueous NMR Signal Enhancement by Reversible Exchange in a Single Step Using Water-Soluble Catalysts, J. Phys. Chem. C. 120 (2016) 12149-12156.

[94] A.M. Olaru, M.J. Burns, G.G.R. Green, S.B. Duckett, SABRE hyperpolarisation of vitamin B3 as a function of $\mathrm{pH}$, Chemical Science 8 (2017) 2257-2266.

[95] F. Shi, A.M. Coffey, K.W. Waddell, E.Y. Chekmenev, B.M. Goodson, Heterogeneous Solution NMR Signal Amplification by Reversible Exchange, Angew. Chem. Int. Edit. 53 (2014) 7495-7498.

[96] F. Shi, A.M. Coffey, K.W. Waddell, E.Y. Chekmenev, B.M. Goodson, Nanoscale Catalysts for NMR Signal Enhancement by Reversible Exchange, J. Phys. Chem. C. 119 (2015) 7525-7533.

[97] R.E. Mewis, M. Fekete, G.G.R. Green, A.C. Whitwood, S.B. Duckett, Deactivation of signal amplification by reversible exchange catalysis, progress towards in vivo application, Chem. Commun. 51 (2015) 9857-9859.

[98] P.J. Rayner, M.J. Burns, A.M. Olaru, P. Norcott, M. Fekete, G.G.R. Green, L.A.R. Highton, R.E. Mewis, S.B. Duckett, Delivering strong H-1 nuclear hyperpolarization levels and long magnetic lifetimes through signal amplification by reversible exchange, Proceedings of the National Academy of Sciences of the United States of America 114 (2017) E3188-E3194.

[99] J.B. Hovener, N. Schwaderlapp, T. Lickert, S.B. Duckett, R.E. Mewis, L.A.R. Highton, S.M. Kenny, G.G.R. Green, D. Leibfritz, J.G. Korvink, J. Hennig, D. von Elverfeldt, A hyperpolarized equilibrium for magnetic resonance, Nat. Commun. 4 (2013).

[100] J.B. Hovener, S. Knecht, N. Schwaderlapp, J. Hennig, D. von Elverfeldt, Continuous Rehyperpolarization of Nuclear Spins Using Parahydrogen: Theory and Experiment, Chemphyschem 15 (2014) 2451-2457.

[101] D.A. Barskiy, K.V. Kovtunov, I.V. Koptyug, P. He, K.A. Groome, Q.A. Best, F. Shi, B.M. Goodson, R.V. Shchepin, M.L. Truong, A.M. Coffey, K.W. Waddell, E.Y. Chekmenev, In Situ and Ex Situ Low-Field NMR Spectroscopy and MRI Endowed by SABRE Hyperpolarization, Chemphyschem 15 (2014) 4100-4107.

[102] J.B. Hovener, N. Schwaderlapp, R. Borowiak, T. Lickert, S.B. Duckett, R.E. Mewis, R.W. Adams, M.J. Burns, L.A.R. Highton, G.G.R. Green, A. Olaru, J. Hennig, D. von Elverfeldtt, Toward Biocompatible Nuclear Hyperpolarization Using Signal Amplification by Reversible Exchange: Quantitative in Situ Spectroscopy and High-Field Imaging, Anal. Chem. 86 (2014) 1767-1774.

[103] M.J. Burns, P.J. Rayner, G.G.R. Green, L.A.R. Highton, R.E. Mewis, S.B. Duckett, Improving the Hyperpolarization of P-31 Nuclei by Synthetic Design, J. Phys. Chem. B 119 (2015) 5020-5027.

[104] A.M. Olaru, S.S. Roy, L.S. Lloyd, S. Coombes, G.G.R. Green, S.B. Duckett, Creating a hyperpolarised pseudo singlet state through polarisation transfer from parahydrogen under SABRE, Chem. Commun. 52 (2016) 7842-7845.

[105] S.S. Roy, P.J. Rayner, P. Norcott, G.G.R. Green, S.B. Duckett, Long-lived states to sustain SABRE hyperpolarised magnetisation, Phys. Chem. Chem. Phys. 18 (2016) 24905-24911.

[106] S.S. Roy, P. Norcott, P.J. Rayner, G.G.R. Green, S.B. Duckett, A Hyperpolarizable H-1 Magnetic Resonance Probe for Signal Detection 15 Minutes after Spin Polarization Storage, Angew. Chem. Int. Edit. 55 (2016) 15642-15645.

[107] Z. Zhou, J. Yu, J.F.P. Colell, R. Laasner, A. Logan, D.A. Barskiy, R.V. Shchepin, E.Y. Chekmenev, V. Blum, W.S. Warren, T. Theis, Long-Lived ${ }^{13} \mathrm{C}_{2}$ Nuclear Spin States Hyperpolarized by Parahydrogen in Reversible Exchange at Microtesla Fields, J. Phys. Chem. Lett. 8 (2017) 3008-3014. 
